ISSN $2686-9012(O N L I N E)$

Oonomic

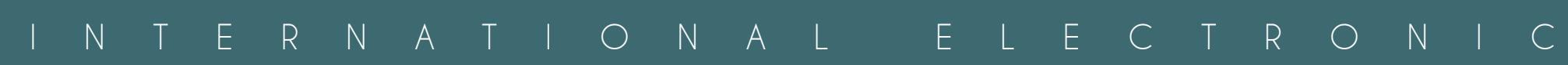

$2020 \vee \bigcirc L .30 . N O .2$

$S C|E N T| F \mid C$ A N D P R A C T I C A L J O UR N A L 


\section{INTERNATIONAL ELECTRONIC SCIENTIFIC \& PRACTICAL JOURNAL "ECONOMIC CONSULTANT"}

(Previous title - Gosudarstvennyj sovetnik | State counsellor | ISSN 2308-9369) Publication Frequency Quarterly

\section{statecounsellor.wordpress.com}

The journal has ISSN Pendind and presented in:

| Ulrich's Periodicals Directory | RePEc | Elibrary.ru (RSCI) | Cenamics JournalSeek | | EBSCO Publishing | ResearchBib | Integrum | CyberLeninka |

Included in the list of the Higher Attestation Commission, by order of the Ministry of Education and Science of Russia dated February 12, 2019 No 21 -p. Scientific specialties: 08.00.05 - Economy and management of a national economy

Journal DOI: https://doi.org/10.46224/ecoc

CHIEF EDITOR:

Ph.D. Roman I. Ostapenko

EDITORIAL BOARD:

Prof., Dr. of Econ. Sciences Victor Ya. Tsvetkov (Russia)

$\mathrm{PhD}$ in Economics Alexandru Trifu (Romania)

Dr. of Philos. Sciences Victor V. Zinchenko (Ukraine)

Prof., Dr. of Soc. Sciences Tamara K. Rostovskaya (Russia)

Prof., Dr. Phys. \& Mat. Sciences Eduard A. Sosnin (Russia)

PhD Santosh Kumar Behera (India)

Prof., Dr. of Econ. Sciences Yuri I. Treshchevsky (Russia)

Prof., Dr. of Econ. Sciences Andrey B. Kondrashihin (Ukraine)

$\varepsilon$

Prof., Dr. of Econ. Sciences Boris. B. Leont'ev | Prof., Dr. of Econ. Sciences Lyudmila lu. Filobokova | Prof., Dr. of Econ. Sciences Sergey A. Vladimirov| Prof., Dr. of Econ. Sciences Andrey V. Belousov | Prof., Dr. of Econ. Sciences Igor E. Risin | Dr. of Econ. Sciences Ekaterina A. Efimova | Prof., Dr. of Legal Sciences Valeriy P. Beliaev |

Prof., Dr. Phys. Mat. Sciences Vyacheslav M. Zelenev | Prof., Dr. of Tech. Sciences Vladimir P. Kulagin

FOUNDER ADDRESS:

Russian Federation, 394051, Voronezh, st. Geroev Sibirjakov, 29/65. Founder: LLC "Ecological help"

PUBLISHER ADDRESS:

Russian Federation, 394049, Voronezh, st. Fedora Tyutcheva, 95M/195.

Publisher: LLC "Scientific and Educational Initiative". Phone: +7(951)878-21-20

All questions and accepting articles at: economic-consultant@mail.ru 


\section{CONTENTS}

\section{ECONOMICS, ORGANIZATION AND MANAGEMENT OF ENTERPRISES, INDUSTRIES, COMPLEXES}

A. V. Kuchumov, E. V. Pecheritsa, A. M. Vorontsova

Risks of managerial control at service enterprises 4

\section{REGIONAL ECONOMY}

\section{S. V. Konovalenkov}

Digital transformation of obtaining data for an express

assessment of regional sustainable development

V. S. Vasilyeva

Structural and spatial priorities of socio-economic development and their implementation in the territory of the Rostov region (Russian Federation) 25

\section{MANAGEMENT IN EDUCATION}

D. G. Sandler, D. A. Gladyrev

Factors influencing on extra budgetary income

of leading Russian universities: econometric analysis

N. B. Kirillova, O. N. Tomyuk, M. A. Dyachkova

Educational segment of modern media market: features and trends in digitalization

L. A. Kravchenko, N. R. Pashuk, A. A. Vertinova, I. A. Bedrachuk

Trends and priority areas of state policy development in higher education for the period of 2000-2020

\section{$\underline{L A B O R}$ ECONOMICS}

V. K. Egorov

Human capital and effective development. 


\section{A. V. Kuchumov, E. V. Pecheritsa, A. M. Vorontsova \\ Risks of managerial control at service enterprises}

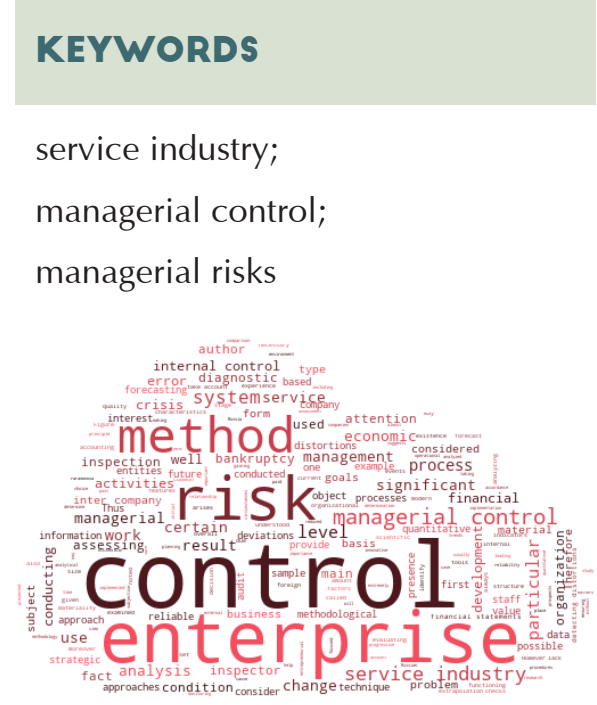

Word Cloud Generated by:

https://wordscloud.pythonanywhere.com/
|FOR CITATION

\section{ABSTRACT}

With the increase in the number of enterprises in the nongovernmental sector of the economy, a characteristic feature of which is the expansion of the boundaries of financial independence and their simultaneous and full responsibility for the results of economic activity, special importance is given to the methods of managerial control in the organization. Competitiveness and financial performance of an enterprise depend on the effective managerial control. At present, when one economic crisis replaces another, questions of the correctness of managerial decisions and the formation of financial indicators of an economic entity are aggravated.

To analyze the essence of managerial control along with the search for information on managerial control at service enterprises, the authors used the method of analysis of scientific and educational literature of Russian and foreign authors who consider managerial control from the point of view of systematic and process approaches, as well as methods of systematization and processing of the obtained information.

The result of the study is the conclusion that the incompetence in making managerial decisions in times of crisis in various sectors of the economy leads to the difficult financial situation of the organization, especially for service enterprises, the activity of which directly depends on the state of the basic sectors of the economy, as well as incomes of the population.

It is proposed to take into account the industry-specific features of the service sector for the competent and efficient management of the enterprise, aimed at achieving high financial results, given that any form of control poses risks that can be represented in three components, containing: inter-company risk, risk during control and risk of not detecting distortion. Each component of the risk has its own significance, while particular attention as part of the overall control risk should be paid to such a component as the risk of not detecting distortions

Kuchumov, A. V., Pecheritsa, E. V., \& Vorontsova, A. M. (2020). Risks of managerial control at service enterprises. Economic consultant, 30 (2), 4-12. doi: 10.46224/ecoc.2020.2.1 


\section{INTRODUCTION}

A nalyzing the approaches to interpreting the essence of managerial control, it should be noted that it is a conceptual system that provides the processes of planning, analysis, control and managerial decision-making with information-analytical and methodological approaches for the competent implementation of the enterprise's goals, implemented in a strategic and operational format.

Managerial control should be considered as a certain form of the forecast system for the future of an enterprise with a set of managerial tools that change in accordance with the size of the enterprise and the characteristics of its strategic prospects.

In the current economic environment for entities operating in Russia with a view to efficient functioning and sustainable development, it is extremely important to skillfully use and apply advanced theories, methods and tools of management, as well as to use the progressive experience of leading world companies in the field of managerial control.

\section{MATERIALS AND METHODS}

For a more detailed consideration of the essence of managerial control, the method of analysis of scientific and educational literature on the examined topic was used, in particular the works of Russian and foreign scientists.

The study guides by Kobyak M.V. and Skobkin S.S. [3], Gerasimov B.I., Sizikin A.Yu. and Gerasimova E.B. [6], Zaitsev L.G. and Sokolova M.I. [11] were analyzed, in which the authors consider managerial control in terms of the systematic approach. The theoretical and methodological basis of this study was composed of scientific papers in which managerial control is considered from the point of view of the process approach of such Russian researchers as Paramonova L. [1], Makrinova E.I., Vasilev A.G., Vasileva A.S. [2], Zhukov B.M., Lyausheva S.A. [3], Groshev I.V. [7], Klyuchko V.I., Shumkov E.A., Vlasenko A.V., Karnizyan R.O. [8], Kovalchuk A.P. [9], Deinekin T.V. [10], Plugar E.V., Stakhno N.D. [12], and Moryakova A.V. [15].

The work by Hahn D. was of particular interest [5], in which the author draws attention to national features in ensuring managerial control. The works of foreign authors are also of interest, as in the works [16 and 18] the issues of changes in the structure of managerial control related to the development of a common service center are considered. The work [19] is devoted to the determination of six main goals of managerial decisions in the matters of cloud computing confidentiality. In [20], the author concludes that the competencies and processes of PM (process manager) in managerial control provide a favorable basis for the deployment of any project without compromising its initial characteristics.

The authors used the method of analyzing the main problems that companies interested in servitization strategies should overcome, with special emphasis on the development of managerial control systems, presented in the book by Pistoni A. and Songini L. [17]. 


\section{RESULTS}

Managerial control should be considered as a certain form of the forecast system for the future of an enterprise with a set of managerial tools that change in accordance with the size of an enterprise and the characteristics of its strategic prospects.

For the purposes of managerial control in the service industry, economic and managerial diagnostics are used, diagnostics of the enterprise's development crisis, business diagnostics, diagnostics of the economic system, as well as diagnostics of the problem.

The diagnostic process has the following features:

1) the identification of the causes that affect the problem, faced by the enterprise, for which formalized subjective methods of obtaining data are usually used, such as observation, survey, tests, and interviews;

2) analysis and assessment of the quality of managerial control is not always possible to carry out with the help of quantitative methods, due to the lack of criteria and a basis for comparison;

3) modern economic and mathematical methods are rarely used to build a causal relationship when a problem arises [6, p. 68].

Under such circumstances, it is possible to resolve the question in various ways. In particular, to control deviations at the enterprise, an approach based on leading control can be introduced. It is assumed that the owner of the enterprise seeks to establish the difference between the expected results, which were calculated on the basis of extrapolation, and the actually obtained results of the enterprise's activities [12]. However, for the organization of a certain type of control, corresponding to the principle of enterprise management, there is a need to obtain a significant amount of new information; in the development of innovative methods of measurement and the construction of graphs and procedures for evaluating, processing data; as well as in the active participation and support of all levels of management and control. Particular attention is paid to the long-term planning and forecasting of future events of a service enterprise, the main principle of which is the quantitative determination of the set goals. The most common way of conducting this kind of research can be considered to be an extrapolation of past events, in which changes will be implemented, albeit sequentially, but in an accelerated way [3, p. 51]. And this suggests that a progressive reaction to such changes, given the experience, is excluded.

It should be noted that the most common method for evaluating the managerial control of service enterprises is to diagnose precisely the financial condition. Thus, L. Paramonova [1], evaluating the control of business entities, considers it necessary to determine the level of crisis phenomena occurring in the organization, focusing on the fact that bankruptcy and crisis are synonyms only in case of the financial crisis. In other circumstances, the enterprise's control system may be in economic, innovative, financial, managerial and other crises, while bankruptcy is only the final stage of the financial crisis. However, each crisis phenomenon can 
cause the "death" of the enterprise, which simultaneously indicates its possible bankruptcy, and therefore crisis forecasting techniques can be arbitrarily called bankruptcy forecasting techniques. Moreover, studies of domestic [12] and foreign authors [13; 17] confirm the reliability of the fact that almost all methods of forecasting bankruptcy of enterprises that lack internal managerial control are reduced to diagnosing the financial condition of functioning entities. At the same time, the results of monitoring the activities of enterprises in the service industry are reflected in the economic indicators in the form of a quantitative and qualitative assessment of the examined processes.

Recently, taking into account the integration processes that are directly taking place in Russia, the control of enterprises on the basis of entrepreneurial managerial control has been gaining popularity [14].

The essence of this approach is that extrapolation of the current state is complemented by a forecast of positive and negative opportunities with the calculation of a thorough and comprehensive analysis of trends in the external and internal environment. Attention is focused on reformatting the objectives of the studied object, while changing the previous priorities of the company and adding social goals. The uniqueness of this methodology lies in the fact that certain flexibility in control appears exactly for enterprises in the service industry. The control of the entrepreneurial type is based on the fact that future events have no connection with the past of the organization, and given this, methodological approaches to inter-company control are the prevention of undesirable deviations, including the choice of strategic management, accounting for conflicts of interest, the relationship of control with staff motivation, etc. [11, p. 78].

Given the current trends in the development and functioning of service enterprises [20], the use of more modern models of managerial control in an organization is gaining importance. And this, in turn, suggests that at a certain stage in the development cycle of the company, management should select appropriate control measures [19]. Thus, the "unconventional" methodology for monitoring the activities of the enterprise becomes relevant, which does not take into account the experience of the enterprise, but is based on three components of control, in particular: the object of control, the subject of control and control actions [21]. Decisions as a result of control are made by the head of the subject of control or the subject in whose interests this control was conducted. That is, the application of this control technique consists in the fact that the control subject checks how the control object fulfills its orders. However, at this stage, control should not provide only for the implementation of the chain of command, but, first of all, it should be conducted as a process ensuring the achievement of the goals of the enterprise, motivating not only the top management, but also the entire staff of the company.

\section{DISCUSSION OF THE RESULTS}

When regulatory authorities inspect the enterprises in the service industry, there is a change in the level of materiality, which can always have a multidirectional effect on the risk of 
rejecting the reliability of the financial statements or recognizing such statements, vice versa, as a reliable one, which, in turn, contains significant distortions. Thus, the risk of control is appropriately understood as the risk of recognition of reliable financial statements with significant distortions. Moreover, it is advisable to call such a risk a priority risk of control, since in practice there are less important risks, for example, when reliable reports are rejected in all material respects. Therefore, in conditions of an extremely low level of the materiality of distortions, the inspection body almost always considers the financial statements of the service industry company to be unreliable, indicating a very small risk of control.

It should be noted that the risk arises while implementing any form of control, in particular during the audit, desk or thematic tax audit. Considering that the authorities, when conducting control of enterprises in the service industry, use mainly probabilistic statistical methods, the so-called occupational risk arises, on the level of which not only the material responsibility but also the moral responsibility of the inspector depends. Therefore, if while conducting control, the inspector did not reveal any material distortions in the financial statements, although there were mismanagement, loss and irrational use of material, labor and financial resources at the enterprise, then he or she can be blamed for both unskilled work and incompetence in these matters. Therefore, it is necessary to change approaches to assessing the performance of service enterprises when conducting a certain type of control, and, first of all, it is advisable to determine the materiality threshold.

A number of factors may influence the level of overall control risk, such as those presented in Figure 1.

the volume of financial and economic activity of the enterprise of the service industry;

professional training of specialists;

general conceptual approach to controlling;

changes in the legal and regulatory system of the country;

degree of accounting's computerization;

reliability of the internal control system of a service industry enterprise;

frequency of leadership changes and personal characteristics of managers;

number of non-standard operations for a particular enterprise

Figure 1 Factors affecting the level of overall control risk at enterprises of the service industry 
Thus, it can be stated that the control risk can be represented in the form of three components containing:

- inter-company risk;

- risk while conducting control;

- risk of not detecting distortions.

Inter-company risk should be understood as the probability of the existence of an error exceeding the permissible value before checking the system of inter-company control.

Moreover, while assessing the internal risk, the inspection body should consider and analyze:

1) the conditions and methods of conducting business activities of a hotel enterprise, in particular the conditions of competition, changes in tax legislation;

2) the location of the examined enterprise, its transportation problems, the volume of sales of services due to the unstable economic situation;

3) staff and organization of activities, for example, managerial reevaluation of the effectiveness of internal control;

4) revenues and operational plans, in particular a decrease in the quantity or quality of the services, as well as significant deviations from the results of the inventory;

5) property, including a significant reduction in its value, maybe one of the signs of the bankruptcy of a service industry enterprise;

6) liquidity and financing, and first of all, this concerns the lack of working capital and unpredictable losses.

When calculating inter-company risk, as a rule, PEST analysis and SWOT analysis are commonly performed.

As for the risk during the control process, while assessing it, the scope of work performed by the inspector and the quality of the audit conducted by the internal control system, as well as the timing of the audit, should be taken into account. The costs of internal control should not be higher than the amount of estimated losses for the same period, which could have been present if internal control had not been conducted.

When assessing this type of risk, one should take into account the main factors influencing it, such as: leadership style; organizational structure of a service industry enterprise; staff policy; correct accounting and financial reporting; timely provision of information to management about the presence of errors and abuses; the existence of procedures for protection against unauthorized access to documents, records, property, as well as the existence of an internal control system.

\section{CONCLUSIONS}

It is necessary to pay attention to the fact that the internal control system of service enterprises is analyzed in order to take into account its organizational and managerial structure, to prepare a plan and an inspection program to identify the so-called "bottlenecks", subject to enhanced control. 
Particular attention in the overall control risk should be paid to the risk of not detecting distortions, which is understood as a subjective certain probability that the methods used in the inspection process are not able to identify real violations that have a significant impact both individually and together. The degree of this type of risk is usually affected by the presence of repeated checks, for example, if the inspector checks the activities of the enterprise not for the first time, then he or she already knows the organizational, technological features, as well as the "bottlenecks" at the enterprise. In the case of the initial inspection of the enterprise, the risk of detecting distortions is significantly increased.

The risks of not detecting distortions are divided into two main blocks:

1) analytical risks, that is, the risks of the danger of making errors in the process of applying the methodological techniques of analysis or the use of inaccurate or insufficiently reliable information by the inspector; possible comparison of data without regard to their inconsistency for different reporting periods; the presence of errors in the process of calculating relative values and coefficients, based on which certain conclusions can be drawn; the presence of significant deviations in the values of accounting figures; the degree of misunderstanding of the purpose of the analysis and the capabilities of the selected methods; insufficiency of professional skills of the inspector;

2) statistical risks, that is, risks of the likelihood of detecting significant errors in the process of conducting random inspections, which should certainly reveal:

a. choice of erroneous methods of sample preparation, for example, instead of selecting objects for sampling according to quantitative indicators, they are selected according to qualitative indicators;

b. errors in determining the size of the sample and its formation;

c. the use of inconsistent data in the electoral aggregate;

d. groundless application of the sample method instead of the continuous one;

e. discrepancy between the actual amount of the error made in the sample.

In modern business conditions, scientific research regarding methods for assessing the level of control over the activities of service industry enterprises does not have a unique algorithm that would professionally substantiate the level of the control system that takes place in a particular organization. The main attention is focused on the primary link of management - the enterprise, and with the strengthening of the market economy, the role of external control, due to the spread of economic freedom of business entities, is reduced, which provides an impetus to the growth of the importance of internal control in service industry enterprises. Therefore, the combined use of the above-mentioned methods for assessing the level of control at service industry enterprises will help to identify objective results of analyzing the work of a service industry enterprise. 


\section{REFERENCES}

1. Paramonova, L. (2012). Typology and organization models of internal control of an economic entity. Resources. Information. Provision. Competition, 2, 362-365.

2. Makrinova, E.I., Vasilev A.G., \& Vasileva, A.S. (2013). Staff management in hotel management: a study guide. Saint-Petersburg: Troitskii most, pp. 173-176.

3. Kobyak, M.V., \& Skobkin, S.S. (2012). Quality management in a hotel: a study guide. Moscow: Magistr, Scientific and research center INFRA-M.

4. Zhukov, B.M., \& Lyausheva, S.A. (2012). Modernization of hotel industry enterprises based on flexible management. Bulletin of the Adyghe State University. Series 5: Economics, 1, 245-250.

5. Hahn, D. (1997). Planning and control: the concept of controlling: translated from German. In A.A. Turchak, L.G. Golovach, M.L. Lukashevich (Eds.). Moscow: Finansy i statistika, 1997.

6. Gerasimov, B.I., Sizikin, A.Yu., \& Gerasimova E.B. (2013). Quality management: design: a study guide. Moscow: Forum, Scientific and research center INFRA-M.

7. Groshev, I.V., \& Krasnoslobodtsev, A.A. (2012). The emotional forces of the motive of brand selection in the prism of consumer behavior. Marketing in Russia and Abroad, 4, 13-28.

8. Klyuchko, V.I., Shumkov, E.A., Vlasenko, A.V., \& Karnizyan, R.O. (2013). Modeling the work of a hotel. Polythematic Online Scientific Journal of Kuban State Agrarian University, 91, 742-751.

9. Kovalchuk, A.P. (2012). Analysis of the directions of development of hotel enterprises in modern conditions in Russia. Economics, Entrepreneurship and Law, 4(15), 53-62.

10. Deinekin, T.V. (2012). Online forums as a marketing tool. Marketing in Russia and Abroad, 1, 73-79

11.Zaitsev, L.G., \& Sokolova, M.I. (2012). Strategic management: a study guide. Moscow: Yurist.

12.Plugar, E.V., \& Stakhno, N.D. (2019). Risk-oriented control of the main hotel processes. Service in Russia and Abroad, Vol. 13, 2(84), 213-222.

13. Saouma, R. (2011). Risk Management in the Swedish Hotel Industry - Managing Safety \& Security Infra Hospitium. School of Business Studies. Retrieved May 10, 2020, from http://www.diva-portal.org/smash/get/ diva2:431731/FULLTEXT01.pdf

14. Filatov, A., Egorova, E., et al. (2015). Risk management, audit and internal control. Moscow: Izdatelskie resheniya.

15. Moryakova, A.V. (2014). Managerial errors: causes, solutions. Economics and Management: New Challenges and Perspectives, 6, 156-158.

16. Minnaar, R., \& Vosselman, E. (2013). Shared service centers and management control structure change: Exploring the scope and limitations of a transaction cost economics approach. Journal of Accounting \& Organizational Change, 1(9), 74-98.

17.Pistoni, A., \& Songini, L. (2017). Strategic Managerial Control for the Servitization 
Strategy. In A. Pistoni, and L. Songini (Eds.), Servitization Strategy and Managerial Control (Studies in Managerial and Financial Accounting, Vol. 32), Emerald Publishing Limited, pp. 111-224.

18. Minnaar, R. (2014). Governance and Control of Shared Service Centers. Some parts of this chapter are derived from the paper of Minnaar and Vosselman (2013) and of the PhD thesis of Minnaar (2014), Shared Services as a New Organizational Form (Advanced Series in Management, Vol. 13), Emerald Group Publishing Limited, pp. 85-103.

19. Coss, D., \& Dhillon, G. (2019). Cloud privacy objectives a value based approach. Information and Computer Security, 2(27), 189-220.

20.Su, C., \& Chen, P. (2016). Applying project management for new service development. International Journal of Innovation Science, 3(8), 185-198.

21.Sofiah, ?., Auzair, ?., Aman, A., Maelah, R., Amiruddin, R., \& Hamzah, N. (2013). Management control in accounting outsourcing services. Business Strategy Series, 2/3(14), 43-49.

\section{INFORMATION ABOUT THE AUTHORS}

1. Arthur V. Kuchumov (Russia, St. Petersburg) - Associate Professor, PhD in Economic Sciences, Associate Professor of the Department of Economics and management in services. St. Petersburg state University of Economics. E-mail:arturspb1@ya.ru

2. Elena V. Pecheritsa (Russia, St. Petersburg) - Associate Professor, PhD in Sociological Sciences, Associate Professor of the Department of Economic Security. St. Petersburg State University of Economics. E-mail: helene8@yandex.ru

3. Aleksandra M. Vorontsova (Russia, St. Petersburg) - Associate Professor, PhD in Economic Sciences, Associate Professor of the Department of Commercial Activities. St. Petersburg State University of Civil Aviation. E-mail:arturspb1@ya.ru 


\section{S. V. Konovalenkov}

\section{Digital transformation of obtaining data for an express assessment of regional sustainable development}

\section{KEYWORDS}

region;

sustainable development;

express assessment;

managerial decisions;

regional legislative and executive authorities;

digital transformation of data acquisition;

interdepartmental electronic exchange

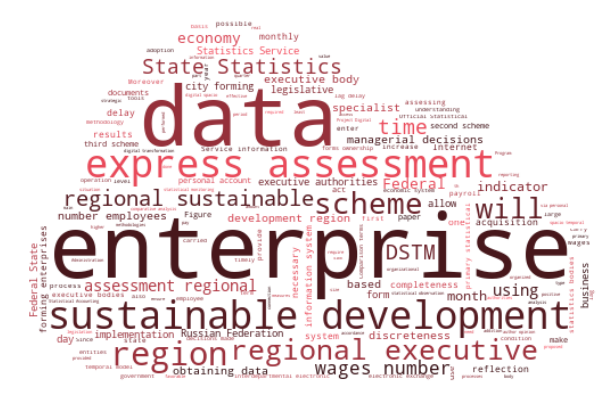

Word Cloud Generated by:

https://wordscloud.pythonanywhere.com/

\section{ABSTRACT}

Sustainable development of the Russian Federation is impossible without the sustainable development of its regions. To make managerial decisions aimed at sustainable development of the regions, it is necessary to carry out appropriate monitoring. It is proposed to use the methodology and tools of an express assessment, which are based on the dynamics of wages at the enterprises of the region, as operational control over the processes taking place in the economy of the regions. This is due to the fact that in a market economy there is a clear direct relationship between the timeliness and size of wages paid to employees and the state of corporate businesses.

The aim of this study is to select the optimal data acquisition scheme for an express assessment of the sustainable development of the regions. For this purpose, a comparative analysis of three schemes for obtaining paper-based data was applied, using personal accounts on the Internet and the information system of the Federal State Statistics Service using the system of interdepartmental electronic exchange in terms of the following indicators: completeness, delay and discreteness of the wages reflection and the number of enterprises in the region in the digital spatio-temporal model and complexity of organizational measures.

It has been established that in the near future, it will the most effective to use the scheme for obtaining data from the Internet, which provides high completeness of reflection of the source data and minimizes the delay time of an express assessment relative to the real state of the regional economy. This creates objective conditions for the rapid identification of trends in the regional economy and contributes to the timely formation of legislative initiatives and the adoption of managerial decisions by the regional legislative and executive authorities to improve the legal framework conducive to business development in the region.

The data collected by state statistics bodies as per the form No. P-4 "Information on the wages and number of employees" can also serve as a source for an express assessment. However, the federal law currently prohibits state statistics from providing access to this information to regional executive bodies.

Konovalenkov, S. V. (2020). Digital transformation of obtaining data for an express assessment of regional sustainable development. Economic consultant, 30 (2), 13-24. doi: 10.46224/ecoc.2020.2.2 


\section{INTRODUCTION}

$\mathrm{R}$ esponsible government officials and the public against the background of the rapidly developing global economy and environmental degradation formulated the concept of "sustainable development" [1] and continue to improve the international regulatory framework $[2 ; 3]$. The President, the Government, and the leading national economists pay much attention to the sustainable development of the Russian Federation $[4 ; 5]$. In a market economy, an important factor affecting sustainable development is strategic planning [6; 7] and control over its implementation. Since the national economy is a combination of regional economies, there is a need to assess their sustainable development.

Currently, domestic scientists are offering various methodologies for assessing the sustainable development of regions [8-10] and tools for that [11]. Foreign scientists pay attention to the problem of improving the methodology for assessing the sustainable development of regions $[12 ; 13]$. In addition, there is a tendency to develop a methodology for assessing the sustainable development of large cities [14-16] and metropolitan areas [17], as well as the corresponding tools [18]. However, it should be noted that all the proposed methods and tools have two main disadvantages.

First, in these methodologies, the economy of the regions is considered as a holistic object, although in reality, it is a comprehensive hierarchical system consisting of municipal entities in which enterprises of various sizes and forms of ownership are operating. This approach does not allow one to identify which enterprises make a positive contribution to the sustainable development of the region and which ones make somewhat negative. It also does not allow assessing the effectiveness of managerial decisions of the regional legislative and executive authorities and, accordingly, building a focused, reasoned dialogue between the state and the business.

Second, these methodologies are based on a large number of indicators, the initial data for which are the statistics characterizing the regional economy as a whole over long periods. Collecting a large number of indicators takes a long time. This causes the fact that by the time an assessment of sustainable development is completed, the economic system of the region will necessarily move to a different state and it is highly likely that the managerial decisions made on the basis of this assessment will be ineffective.

In order to overcome the above disadvantages in assessing regional sustainable development, it is proposed to use an express assessment methodology [19] and appropriate tools [20]. This methodology is based on the understanding that in a market economy there is a clear direct relationship between the timeliness and size of wages paid to employees of enterprises and the state of the business at these enterprises. Since, if enterprises pay wages in a timely manner and their growth compensates for inflation processes or is even higher, this indicates that the business of these enterprises is developing successfully. Meantime, the financial situation of enterprises here allows the timely purchase of necessary stock and components, maintenance 
of equipment, timely payment for the electricity and other energy resources consumed, timely and full payment of taxes and fees, as well as dividends in an amount that satisfies the founders and shareholders. Also, this suggests that managerial decisions made by enterprise management, regional executive authorities, and local governments are generally effective and positively affect business development. Moreover, it is natural that such enterprises make a positive contribution to the sustainable development of not only the municipality but also the entire region. Otherwise, if wages at enterprises are not paid on time and at the same time either decrease or remain at the same level and do not compensate for the inflationary processes, then a detailed analysis is required in connection with the reasons for the lack of business development, both on the part of the management and owners of enterprises and the regional executive authorities and local self-government in which territory these enterprises carry out their production operations.

Taking into account that an express assessment of regional sustainable development is based on the data contained in the digital spatio-temporal model (DSTM) [21], the reliability of this assessment directly depends on the quality of reflection of the real state of the payroll and the number of regional enterprises by this model.

The objective of this paper is to select the most optimal data acquisition scheme for an express assessment of regional sustainable development and to identify the set of organizational and technical measures necessary for its implementation. For this, a comparative analysis of three possible data acquisition schemes has been performed.

\section{MATERIALS AND METHODS}

In the medium term, the acquisition of data by a regional executive body for an express assessment of regional sustainable development can be organized using the following schemes.

I. Obtaining paper-based data from city-forming enterprises.

In the author's opinion, a representative sample for conducting an express assessment of regional sustainable development is the data on the payroll and the size of the aggregate of city-forming enterprises. In a number of the federal laws [22], enterprises are recognized as city-forming, if the total number of their employees is at least $25 \%$ of the working population in the municipality. After getting the documents from the city-forming enterprises, a specialist of the regional executive body will be required to enter the data on the payroll and the number of employees using the Program for Express Assessment of Sustainable Development of Regions (Figure 1).

I. Obtaining data from regional enterprises on the Internet.

This scheme for obtaining data for an express assessment assumes that authorized specialists of all enterprises in the region independently enter data on the payroll and employee number in the DSTM via personal accounts on the Internet. Personal accounts of enterprises can be organized using the Program for Express Assessment of Sustainable Development of Regions (Figure 2). 


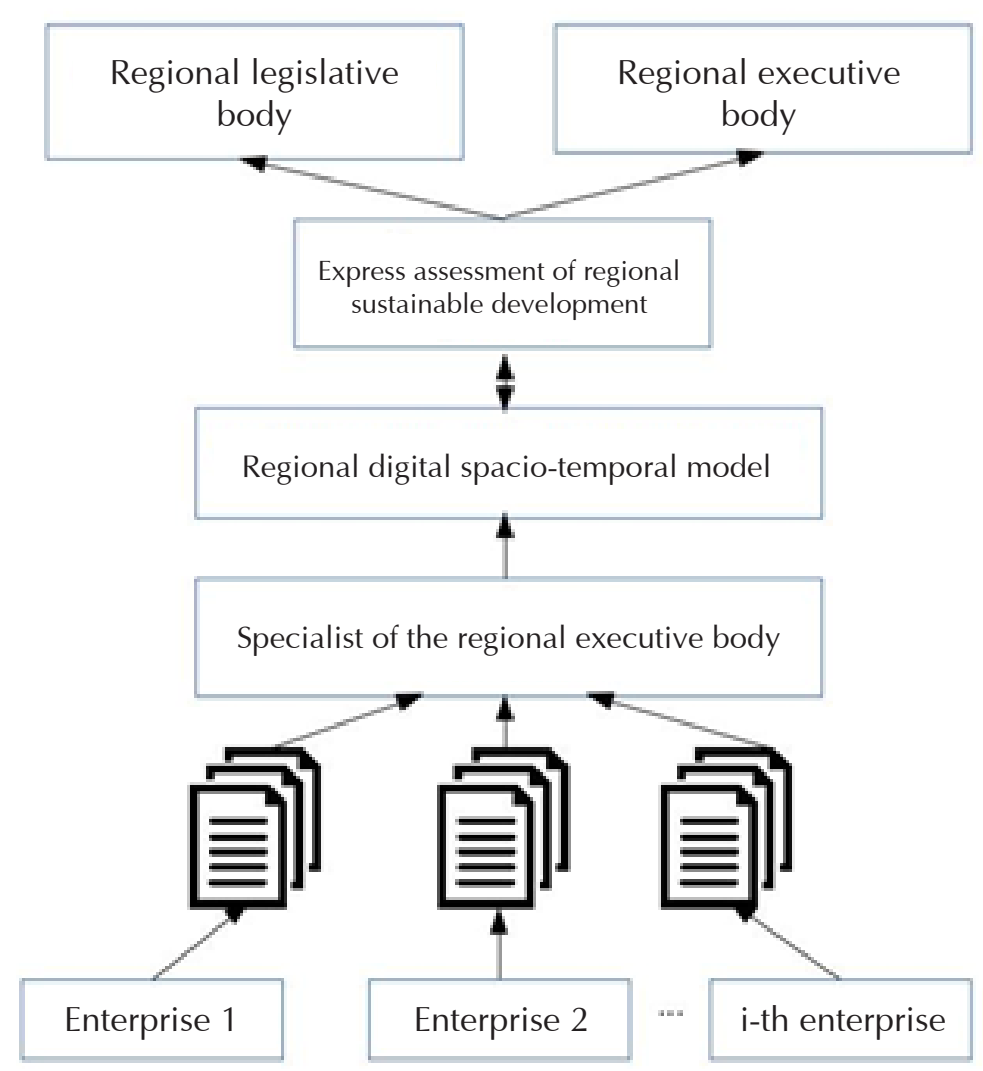

Figure 1 Scheme for obtaining paper-based data from city-forming enterprises

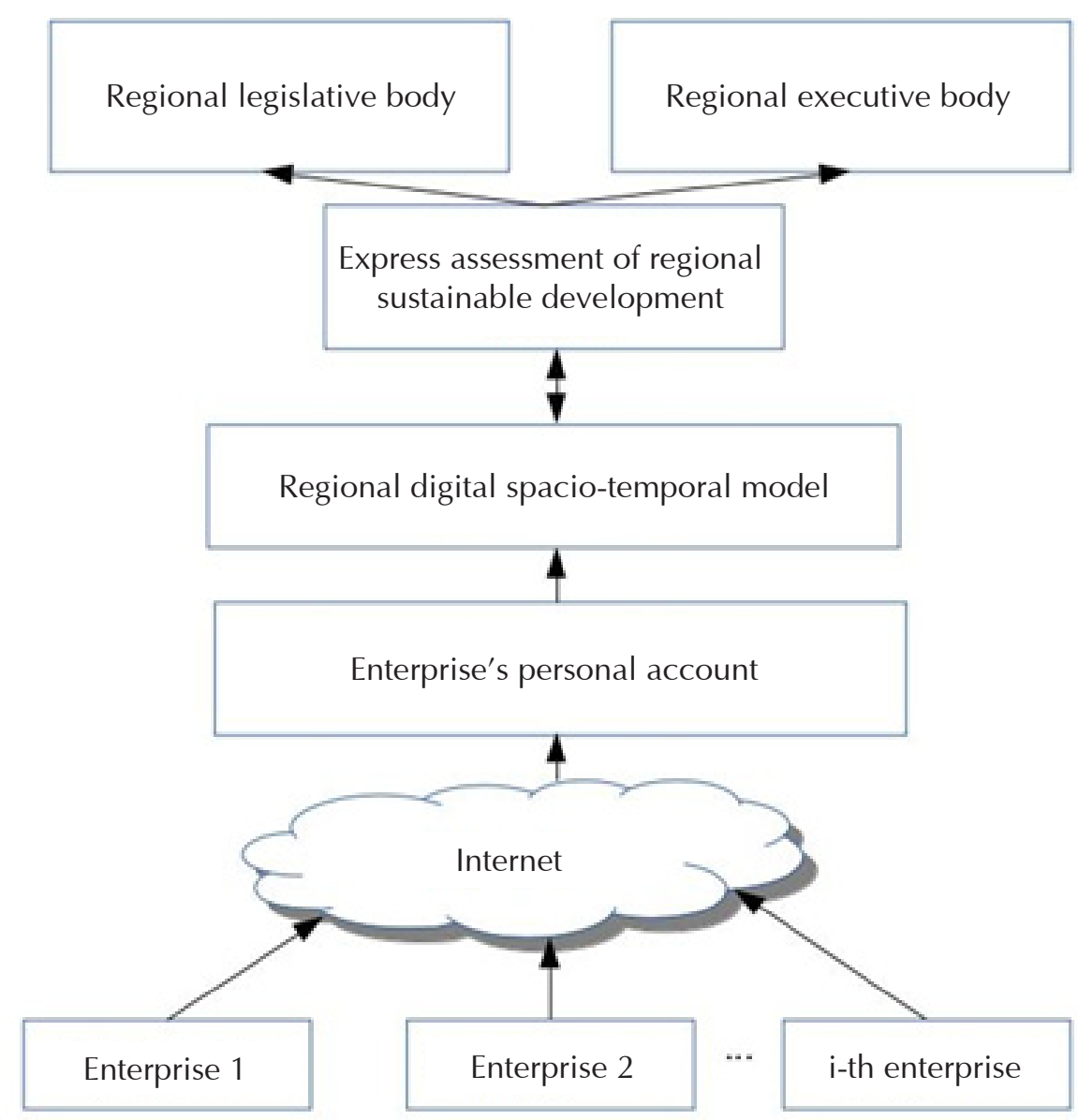

Figure 2 Scheme for obtaining data from enterprises using the Internet 
III. Obtaining data from the Federal State Statistics Service information system using the system of interdepartmental electronic exchange (SIEE).

In the context of the development of a digital economy, the big data collected by the state statistics bodies, in the author's opinion, should become a source of data for the regional executive bodies to conduct an express assessment of the sustainable development of the regional economy and make managerial decisions aimed at creating favorable conditions for business development in the region. It is proposed, when implementing the Federal Project "Digital State Administration" [23], to digitally transform the acquisition of data for an express assessment by organizing the interaction of regional executive authorities with the state statistics bodies using the SIEE (Figure 3).

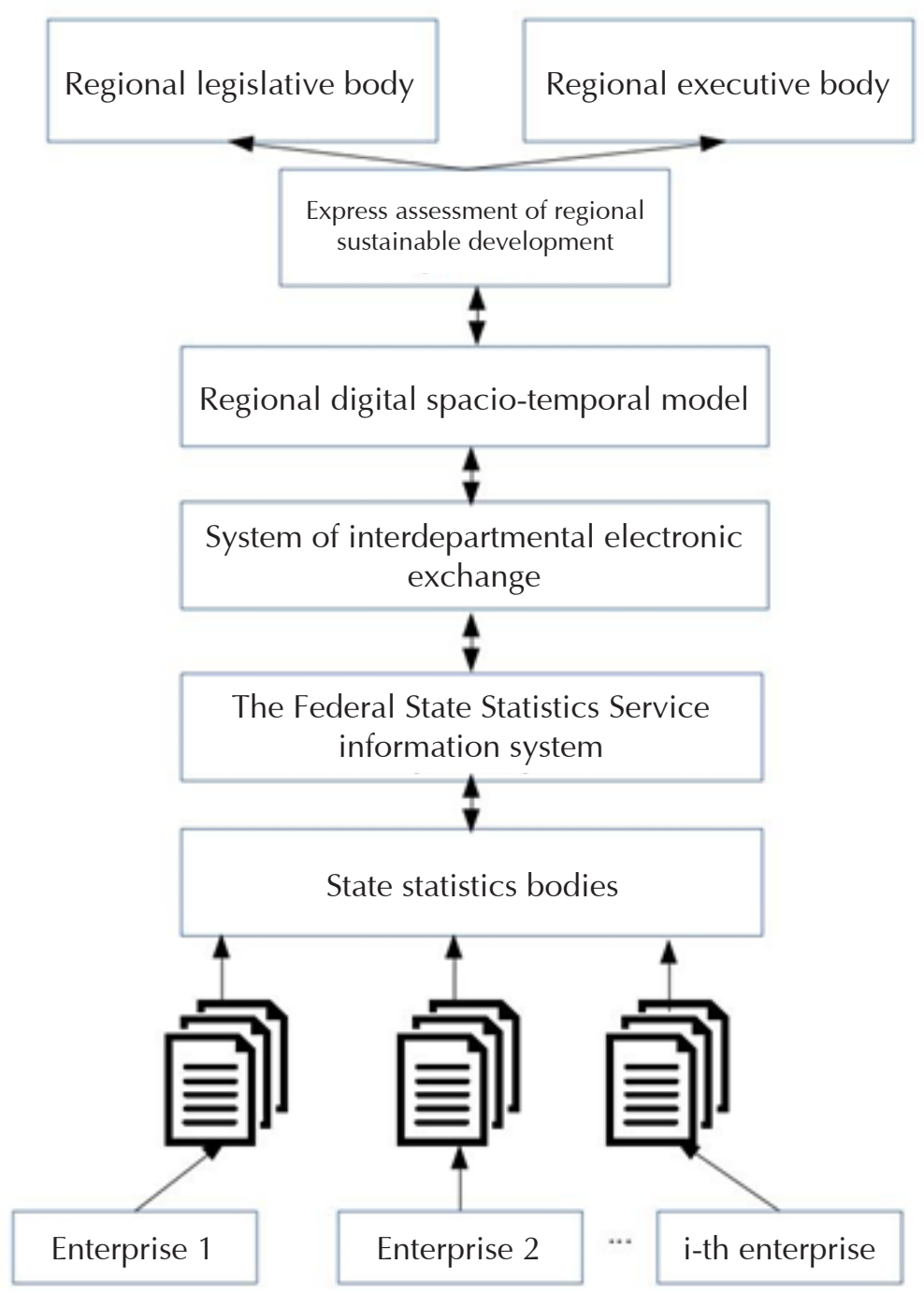

Figure 3 Scheme for receiving data from the Federal State Statistics Service information system using SIEE

A comparative analysis of the possible schemes for obtaining data for an express assessment of regional sustainable development will be performed in terms of indicators of completeness, delay, discreteness, and complexity of organization [24].

\section{Comparison in terms of "completeness"}

This indicator characterizes the share of enterprises for which the data on the wages and 
the number of employees have been entered in the DSTM of the total number of enterprises operating in the region.

The first scheme can ensure the completeness of the data no higher than the value of 0.25 , since the data will be provided only by city-forming enterprises. The second scheme can ensure the completeness of the data equal to 1.0, since it is assumed that the information will be provided by all enterprises in the region. The third scheme can provide the completeness of the data in the range from 0.7 to 0.8 , depending on the structure of the region's business, i.e. shares of small businesses with less than 15 employees.

Thus, for this indicator, the second scheme is preferred.

\section{Comparison in terms of "delay"}

This indicator characterizes the lag of a delay in the reflection in the DSTM of the wages and the number of enterprises in the region. Meantime, it should be noted that an increase in a delay in the reflection in the DSTM of the wages and the number of enterprises in the region increases the likelihood that, at the time of an express assessment, the economic system of the region will switch to a different state than that in which it was in the assessment period. On the contrary, the smaller the lag of a delay, the higher the likelihood that the region's economic system at the time of making managerial decisions based on the results of an express assessment is in a state close to that in which it was at the time of assessment. In this case, an analysis of the state of the region's economic system based on an express assessment will be more objective, and managerial decisions made on this basis will be more effective.

The DSTM readiness lag of delay in an express assessment in the first scheme is determined by the time of entering a large amount of wages data at the number of city-forming enterprises. Moreover, if the data entry into the DSTM from paper documents provided by enterprises for the previous month is not completed, and new documents have been sent to the regional executive body that evidence the wages and the number of employees for the next month, then to eliminate the "snowball" effect, it is required to either increase the number of specialists who carry out the process of inputting the data from paper documents into the DSTM, or increase the time interval between filing documents. The most rational, in the author's opinion, is a compromise solution with a simultaneous increase in the number of specialists who carry out data transfer and in the time interval for the filing of documents. Apparently, with such a scheme for obtaining data, the lag delay in the range of 30-45 days seems optimal. This is necessary so that the executive authority can make an express assessment, analyze the results, and make appropriate managerial decisions. Moreover, it is advisable to choose the last months of the quarter, i.e. March, June, September, and December, as reporting months.

Using the second scheme will allow entering into the DSTM the data on the wages and the number of enterprises on the day after the payroll calculation, which is made at the beginning of each month following the reporting one. Moreover, the delay lag is 1-2 days, i.e. data entry into the DSTM can be done in near real time.

When using the third scheme, the delay lag will be determined by the amount of the time for transferring the statistical form No. P-4 to the state statistics bodies from the end of the 
reporting period (today it is 15 days) and the time the data were entered by state statistics specialists into the Federal State Statistics Service information system. Currently, the lag of delayed publication of the information on the wages and the number of employees in the bulletins of the Federal State Statistics Service is 60 to 63 days.

Thus, for this indicator, the second scheme is preferred.

\section{Comparison in terms of "discreteness"}

This indicator determines the discreteness of reflection in the DSTM of the wages and the number of enterprises in the region, which determines the frequency of express assessments of regional sustainable development. For example, if the DSTM contains a reflection of the wages and the number of employees with a discreteness of one year, then an express assessment can be done only once a year. If the DSTM contains an above reflection with a discreteness of a quarter, then an express assessment can be carried out quarterly. The reflection in the DSTM of the wages and the number of enterprises with a one-month discreteness is of the greatest interest. This allows specialists of the region's executive authorities to conduct an express assessment on a monthly basis, which creates an opportunity to accurately correlate managerial decisions of the legislative and executive authorities of the region with their positive or negative impact on the sustainable development of the economy of enterprises, municipalities and the region as a whole.

The use of the first scheme may allow an express assessment to be performed with the discreteness once a quarter. The second and third schemes will allow for an express assessment on a monthly basis.

\section{Comparison in terms of "complexity of organizational measures"}

To implement the first scheme, it is enough to adopt a regional act so that city-forming enterprises of all municipalities send information on the wages and the number of employees on paper to the regional executive body that carries out strategic planning for the sustainable development of the region and monitors its implementation. Obtaining data according to this scheme can be organized within 1-2 months, after the adoption of the relevant regional act.

The second scheme can be implemented after the adoption of a regional act that all enterprises of the region of all forms of ownership monthly enter into the DSTM of the region the data on the wages and the number of employees via personal accounts created on the Internet using the Program for Express Assessment of Sustainable Development of Regions. For this, it is also necessary to authorize the specialists of enterprises who will enter the data on the wages and the number of enterprises into the DSTM. This can be done within 1-2 months.

When using the third scheme, the source of data for an express assessment of regional sustainable development may be the form of statistical observation No. P-4 "Information on the wages and number of employees", which is monthly filled up by legal entities of all types of economic activities and forms of ownership, the average staff of which, based on the operational performance for the previous year, exceeds 15 persons. However, in accordance with the provisions of Article 9 of the Federal Act "On Official Statistical Accounting and the System of State Statistics in the Russian Federation" dated November 29, 2007, No. 282-FZ 
[25], the primary statistical data contained in the forms of federal statistical monitoring are classified as limited access information and the subjects of official statistical accounting are not entitled to provide them to the state authorities of the constituent entities of the Russian Federation. In addition, in accordance with paragraph 3 of Article 9 of this Federal Act, state authorities of the constituent entities of the Russian Federation are not entitled to require the provision of primary statistics, as being limited access information, from the subjects of official statistical accounting.

Therefore, the most important condition for the implementation of the third scheme is the need to amend the Federal Act No. 282-FZ "On Official Statistical Accounting and the System of State Statistics in the Russian Federation" in terms of providing the regional executive authorities with access to primary statistics. In addition, the roadmap for the implementation of the Federal Project "Digital State Administration" must include the creation of the data type "Number and wages of corporate employees" as part of the information system of the Federal State Statistics Service and its input in the productive zone of the interdepartmental electronic exchange system. This type of information should have two main operations. One operation should, at the request of the executive branch of the region, provide an up-to-date list of enterprises filling in the statistical observation form No. P-4 "Information on the wages and number of employees". Another operation should provide the data on the wages and the number of enterprises at the requested date. These legislative and technical processes, even with an optimistic forecast of developments, will take at least 2-3 years.

\section{RESULTS}

The values of the indicators characterizing each of the possible schemes for obtaining data for an express assessment of regional sustainable development are presented in Table 1.

Table 1

The results of a comparative analysis of data acquisition schemes for an express assessment of regional sustainable development

\begin{tabular}{|c|l|c|c|c|}
\hline \multirow{2}{*}{\multicolumn{2}{|c|}{ Indicator }} & \multicolumn{2}{c|}{ Values of indicators and organizational measures } \\
\cline { 3 - 5 } & & Scheme 1 & Scheme 2 & Scheme 3 \\
\hline 1. & Completeness & 0.25 & 1.0 & $0.7-0.8$ \\
\hline 2. & Delay & $30-45$ days & $1-2$ days & $60-63$ days \\
\hline 3. & Discreteness & quarterly & monthly & monthly \\
\hline 4. & Implementation time & $1-2$ months & $1-2$ months & $2-3$ years \\
\hline
\end{tabular}

During this study, it has been found that in the near future, the digital transformation of data acquisition for an express assessment of regional sustainable development can be carried out using the second scheme, the implementation of which has a short time, and can be carried out 
in accordance with the decisions made at the regional level. Moreover, this scheme provides the highest completeness, minimum delay lag, and the discreteness equal to one month.

Digital transformation of data acquisition using the third scheme is possible only in the medium term, as it requires amendments to the federal legislation, which is usually a fairly lengthy process.

\section{DISCUSSION}

At present, it is becoming apparent that for the successful solution of strategic tasks for the sustainable development of the economy of the Russian Federation, it is necessary for leaders at all levels, federal, regional and municipal, to form an understanding that their main task is not to allocate budget funds, but to create favorable working conditions at enterprises of all forms of ownership, the combination of which represents the economic potential of the country, and the results of their activities are the taxable base to budgets of all levels. The process of creating favorable conditions for business in the region requires a constant understanding by regional executive bodies of the impact of their managerial decisions. This understanding can be achieved through a monthly express assessment of regional sustainable development, for which it is necessary to organize the receipt of data on the wages and the number of enterprises in the region.

In the course of the study, it has turned out that at present there is a situation in the Russian Federation in which big data of primary statistical observation are collected exclusively for processing by state statistics authorities and their interpretation in departmental bulletins in a generalized form. At the same time, regional executive bodies are legally deprived of the opportunity to use these data for an express assessment of the sustainable development of regions and making informed managerial decisions.

The author believes that during the implementation of the Federal Project "Digital State Administration", it is necessary to eliminate the legislative restrictions on the use of primary statistical monitoring data by regional executive bodies in connection with the form No. P-4 and to digitally transform the data received for an express assessment of regional sustainable development from the information system of the Federal State Statistics Service. In this case, there will be no need to enter data into the DSTM of the region by specialists of enterprises via personal accounts on the Internet.

\section{CONCLUSION}

A digital transformation of obtaining data for an express assessment of regional sustainable development until the federal legislation is amended to allow regional executive bodies to use the data of primary statistical monitoring can be carried out using personal accounts of 
enterprises on the Internet. An analysis of the results obtained in the process of an express assessment will ensure the rapid identification of trends in the development of the regional economy and the adoption of effective managerial decisions, as they will be based on knowledge of the real situation in the economy of the region's enterprises. At the same time, the monopoly of the state statistics bodies in connection with the right to collect, process and interpret primary data on the wages and the number of employees at the enterprises in the region will be destroyed.

If there is a legislative initiative on the part of the regions of the Russian Federation to amend the federal legislation to remove the restriction on the use by regional executive authorities of primary statistical monitoring data in general, or at least, as an exception, those from the No. P-4 form and after the adoption of these changes by the State Duma and the Council of Federation it will be possible to carry out a digital transformation of obtaining data for an express assessment of regional sustainable development from the Federal State Statistics Service information system using the system of interdepartmental electronic exchange.

\section{REFERENCES}

1. Rio Declaration on Environment and Development. (1992, June 3-14). Adopted at the 1992 United Nations "Conference on Environment and Development".

2. Stiglitz, J., Sen, A., \& Fitoussi, J.-P. (2016). Mis-Measuring Our Lives. Why GDP Doesn't Add up? Report by the Commission on the Measurement of Economic Performance and Social Progress. (I. Kushnareva, Trans., T. Drobyshevskaya, Ed.). Moscow: Publishing House of The Gaidar Institute. (p. 216).

3. The 2030 Agenda for Sustainable Development. (2015, September 25). Adopted by the United Nations General Assembly.

4. Mau, V.A. (2012). From Perestroika to Radical Reforms: To the Twentieth Anniversary of the Beginning of Post-Communist Transformations. Economic Policy, 1, 5-20.

5. Bobylev, S.N., \& Grigoriev, L.M. (Eds.). (2016). The Report on Human Development in the Russian Federation "Development Goals of the UN and Russia". Moscow: Publishing House of the Analytical Center under the Government of the Russian Federation.

6. The Federal Act No. 172-FZ "On Strategic Planning in the Russian Federation". (2014, June 28).

7. Forecast of the Socio-Economic Development of the Russian Federation for the Period until 2030. (2013). Moscow: Ministry of Economic Development.

8. Golovanov, E.B. (2015). A Methodological Approach to Assessing the Sustainable Development of the Regional Economy. Modern Management Technologies, 3(51). Article number: 5104. Retrieved May 10, 2020, from https://sovman.ru/article/5104/

9. Tretyakova, E.A., \& Osipova, M.Yu. (2015). Methodological Foundations of Sustainable Development of Regional Socio-Economic Systems. In Proceedings of the Conference at the Perm National Research Polytechnic University (pp. 223-228). 
10. Feraru, G.S., \& Orlova, A.V. (2014). A Methodology for Assessing the Level of Sustainable Socio-Economic Development of Regions. Modern Problems of Science and Education, 1. Retrieved March 10, 2018, from http://science-education.ru/en/article/view? id=12151

11. Ferova, I.S., Lobkova, E.V., Tanenkova, E.N., \& Kozlova, S.A. (2019). Tools for Assessing the Sustainable Development of Territories Taking into Account Cluster Effects. Bulletin of the Siberian Federal University. Humanities and Social Sciences, 4, 600-626.

12. Bolcarova, P., \& Kolosta, S. (2015). Assessment of the Sustainable Development in the EU 27 Using Aggregated SD Index. Ecological Indicators, 48, 699-705.

13. Grzebyk, M., \& Stec, M. (2015). Sustainable Development in EU Countries: Concept and Rating of Levels of the Development. Sustainable Development, 23, 110-123.

14. Yin, K., Wang, R., An, Q., Yao, L., \& Liang, J. (2014). Using Eco-Efficiency as an Indicator for the Sustainable Urban Development: A Case-Study of Chinese Provincial Capital Cities. Ecological Indicators, 36, 665-671.

15. Musakwa, W., \& Van Niekerk, A. (2014). Monitoring of the Sustainable Urban Development Using Built-Up Area Indicators: Case-Study of Stellenbosch, South Africa. Environment Development and Sustainability, 17(3), 1-20.

16. Shen, L., Zhou, J., Skitmore, M., \& Xia, B. (2015). Application of a Hybrid Entropy McKinsey Matrix Method in Evaluating Sustainable Urbanization: A China Case-Study. Cities, 42, 186-194.

17.Xu, C.A., Wang, S., Zhou, Y., Wang, L., \& Liu, W. (2016). Comprehensive Quantitative Evaluation of New Sustainable Urbanization Level in 20 Chinese Urban Agglomerations. Sustainability, 8(2).

18. Ding, X., Zhong, W., Shearmur, R.G., Zhang, X., \& Huisingh, D. (2015). An Inclusive Model for Assessing the Sustainability of Cities in Developing countries: Trinity of Cities' Sustainability from Spatial, Logical and Time Dimensions (TCS-SLTD). Journal of Cleaner Production, 109, 62-75.

19. Tyaglov, S.G., \& Konovalenkov, S.V. (2019). The Concept of an Express Assessment of the Regional Sustainable Development. Bulletin of the Rostov State Economic University (RSEU), 2(66), 147-153.

20. Konovalenkov, S.V., \& Komarov, V.A. (2019, October 30). The Computer Software "Express Assessment of the Regional Sustainable Development". State Registration Certificate No. 20169664114.

21. Konovalenkov, S.V. (2019). Digital Model and Algorithm for an Express Assessment of the Regional Sustainable Development. In Innovative Research in the Modern World: Theory, Methodology, Practice. Collection of Papers on the Proceedings of the 1st International Scientific and Practical Conference (May 6, 2019, Ufa). In 4 Volumes (Vol. 2, pp, 133-142). Ufa: NITS Bulletin of Science.

22. Federal Act No. 127-FZ "On Insolvency (Bankruptcy)". (2002, October 26).

23. National Program "Digital Economy of the Russian Federation". (2018, December 24). Approved by the Presidium of the Council under the President of the Russian Federation 
for Strategic Development and National Projects, Protocol No. 16.

24. Konovalenkov, S.V. (2019). Factors Affecting the Quality of Assessment of the Regional Sustainable Development. Actual Problems of Economics, Sociology and Law, 4(2), 6065.

25. Federal Act No. 282-FZ "On Official Statistical Accounting and the System of State Statistics in the Russian Federation". (2007, November 29).

\section{INFORMATION ABOUT THE AUTHOR}

Stanislav V. Konovalenkov (Russia, Rostov-on-Don) - 2nd year graduate student. Rostov State University of Economics. E-mail: stvik4308@gmail.com 
V. S. Vasilyeva

\section{Structural and spatial priorities of socio-economic development and their implementation in the territory of the Rostov region (Russian Federation)}

\section{KEYWORDS}

agro-industrial parks;

public-private partnership;

poles of growth;

priorities of socio-economic development;

Rostov Region;

strategic project initiatives;

structural and spatial priorities

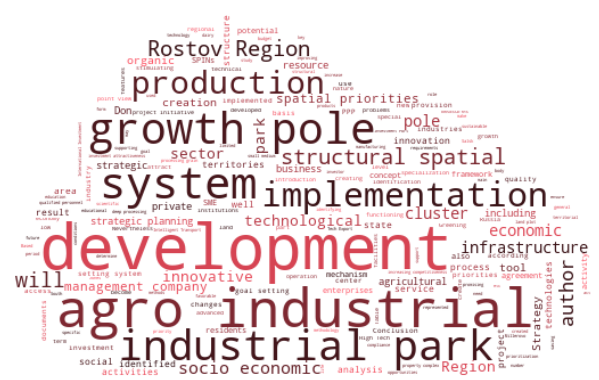

Word Cloud Generated by:

https://wordscloud.pythonanywhere.com/

\section{ABSTRACT}

Proper strategic management of regional socio-economic development is impossible without strategic planning that provides a full analysis of the current development of the system and the formation of a desired image of its future development and the mechanisms for its implementation. An element of the goal-setting system in the process of strategic planning is the identification of priorities for socio-economic development that allow for more efficient use of limited budget resources. It has been offered to focus on structural-spatial type priorities, providing for the interconnection of structural and spatial changes in the system and an opportunity to solve restructuring problems by stimulating territorial development and, conversely, developing territories through support for specific sectors of the economy.

The methods of logical, comparative and economic analysis, tabular and graphical data visualization have been used. The structural and spatial priorities of the socio-economic development of the Rostov Region have been highlighted and the growth poles and strategic design initiatives of a structural-spatial nature defined in the Strategy for the Socio-Economic Development of the Rostov Region for the period up to 2030 have been systematized from the point of view of implementing the identified priorities. This, in turn, made it possible to consider the opportunity of realizing structural and spatial priorities within the framework of measures enshrined in the strategic planning documents of the Rostov Region using the example of agroindustrial growth poles, to propose an additional set of measures to implement the spatial development tool - to prepare and create agroindustrial parks in agro-industrial growth poles of the Rostov Region using the mechanism of public-private partnership.

Vasilyeva, V. S. (2020). Structural and spatial priorities of socioeconomic development and their implementation in the territory of the Rostov region (Russian Federation). Economic consultant, 30 (2), 25-35. doi: 10.46224/ecoc.2020.2.3 


\section{INTRODUCTION}

$\ln$ theory and practice, strategic planning is an integral part of the strategic management process. It includes an analysis of the system, its weaknesses and promising areas of development, identification of images of the desired future in the form of a goal-setting system, the selection of alternative development options, and the choice of a mechanism for achieving the desired image of the system's future. Along with the mission, goals, and objectives identified during goal setting, the system's development priorities play an important role. There are different approaches to prioritization in the academic literature: as the most urgent problems, or as the most promising areas of development of the system. The author proposes to address priority from a pragmatic point of view in its role in the system of strategic planning considering such factors as the accepted concept of development that determines the generally accepted belief system, and the technological system that determines the prospects of the technological development system: the priority of socioeconomic development is the direction of development, defined in the course of strategic planning as significant in accordance with the adopted concept of development and the features of the current technological paradigm, for the implementation of which some activities will be worked out and fixed in strategic planning documents, budget resources will be allocated, and tools for attracting private investment for its implementation will be developed to solve the most acute problems of the socio-economic system, which will ultimately improve the quality of people's living standards. Within the framework of strategic planning of regional development, the importance of prioritization is determined by the special limited budget resources for the implementation of planned activities, which increases the need to specify the most significant areas of development and related activities of medium-term state programs [1].

A special role belongs to strategic priorities of a structural and spatial nature, reflecting the interdependence of the process of economic restructuring and spatial changes: the development rate of a particular industry may depend on the development of a specific territory (for example, differentiation and linking the level of agricultural development to the quality of rural territories), while the restructuring process may have influence on the development of a territory (cases of depression of single-industry towns). Nevertheless, prioritization is recommended [18], but is not always implemented in practice in strategic documents, while the topic of structural and spatial priorities remains poorly developed.

The aim of this work is to highlight the system of structural and spatial priorities of the socio-economic development of the Rostov Region, as well as discuss mechanisms for their implementation. 


\section{MATERIALS AND METHODS}

The methods of logical, comparative and economic analysis, tabular and graphical data visualization were used. The study is based on the provisions of the concept of strategic planning [10], the theory of regional economics [11], and the concept of growth poles [9].

The statistical collections of Rosstat [15] and Rostovstat [16], as well as the analysis results reflected in the Strategy for the Socio-Economic Development of the Rostov Region for the period up to 2030 (hereinafter referred to as "Strategy-2030") [4], were used as an empirical and factual base.

\section{RESULTS}

The author offers a general methodology for identifying the structural and spatial priorities of a region (Figure 1), including an analysis of the region's socio-economic system using various methods [3], the need for coordination with the federal goal-setting system, development concept, and technological paradigm. They become the basis for identifying the system of goals and objectives of Strategy-2030 and the identification of strategic priorities. An analysis of the region's spatial structure and the point of contact of the expected structural changes in the economy and the features, problems and development potential of the territories allows highlighting the structural and spatial development priorities. The formed goal-setting system becomes the basis for the development of specific activities and tools for its implementation. The whole process is carried out in accordance with the principles highlighted in [17, p. 20].

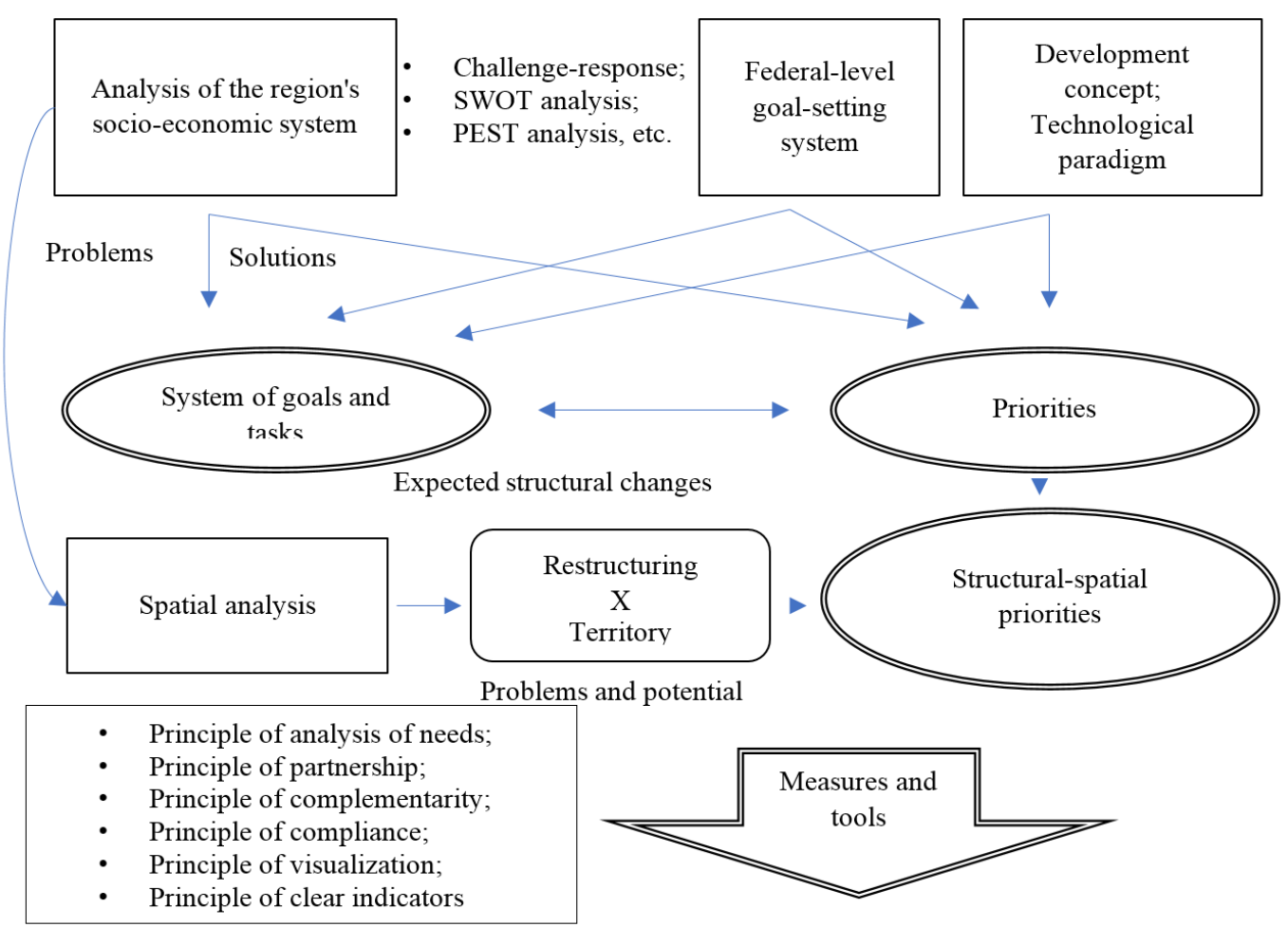

Figure 1 General methodology for identifying structural and spatial priorities [Compiled by the author] 
Also, to identify the structural and spatial priorities, the author's matrix methodological approach was used, implying an analysis of the region's socio-economic development, the global sustainable development goals defined by the UN, and the goal-setting system of Strategy-2030 [21]. According to the described methodology, on the basis of official statistics and the provisions of Strategy-2030, the author identified the key development problems of the Rostov Region related to the deterioration of the material and technical base, low availability of demanded qualified personnel, differentiation of spatial development, inconsistency of the sectoral investment structure with the industrial needs and with the structure of gross added value, low incomes of some categories of citizens, low socio-economic activity of some population groups, insufficient interaction of business, science and education, etc., as well as features of the spatial structure, including a support frame in the form of a system of growth poles and the presence of a system of clusters, opportunities and prospects for regional development.

Based on them and taking into account the principles of sustainable development as the stated conceptual approach of strategic planning for the current planning period, the following structural and spatial priorities were identified:

1. Greening and digitalization of the manufacturing sector and increasing the competitiveness of regional industries, considering spatial tools as advanced institutions for the development of technology. Moreover, greening has two key areas: resource-saving technologies and adoptions that reduce the negative impact on the environment. As a result - increasing competitiveness via saving resources and using a green brand; reduction of anthropogenic impact on the environment.

2. Equalizing the center and the periphery in access to social services by enhancing their provision and accessibility at the growth poles.

3. Territorial implementation of the growth poles as a supporting framework of the region's spatial tools to increase the investment attractiveness of the poles, attract resources, stimulate innovative and economic, and as a result, social development.

4. Stimulating the innovative activity of organizations and enterprises, the interaction of business, educational and scientific institutions in terms of training demanded qualified personnel, development and implementation of innovative technologies, a platform for which can be created through the implementation of spatial policy instruments. As a result - increasing the efficiency of business functioning, its competitiveness in the interregional and world arena.

The implementation of the identified structural and spatial priorities is considered from the point of view of the strategic project initiatives identified in Strategy-2030, as well as the system of growth poles as a supporting territorial framework for the socio-economic development of the region.

Strategic project initiatives (hereinafter referred to as SPINs) are the main tool for structural changes in the region's socio-economic system in Strategy-2030. The author selected SPINs of a structural and spatial nature, that is, their implementation affects changes in the structure of the economy and territorial development and can be associated with the implementation of spatial development tools (the implementation of a system of growth poles, the creation and 
functioning of clusters, industrial parks, special economic zones, territories of advanced socioeconomic development): in the agricultural sector - "Rostov Region - Agro-Industrial Pole of Russia"; in industry - "New Industrialization of the Don"; in small and medium business - "Cluster of Industrial SMEs"; in investment - "International Investment Port"; in innovation "The Don Valley of Innovation Development"; in export - "The South Pole of High-Tech Export Growth"; in tourism - "The Hospitable Don"; in transport - "Intelligent Transport System of the Rostov Region"; in the resettlement system - "The System of Growth Poles of the Rostov Region".

The author has proposed a table reflecting the correspondence of structural-spatial SPINs to structural-spatial priorities and key growth poles in which they will be implemented (Table 1).

Table 1

Growth poles of the Rostov Region and strategic project initiatives of a structural and spatial nature implemented in their territories [Compiled by the author]

\begin{tabular}{|c|c|c|c|c|c|c|c|c|}
\hline \multirow{3}{*}{$\begin{array}{c}\text { Structural-spatial } \\
\text { priorities }\end{array}$} & \multirow{3}{*}{$\begin{array}{c}\text { Structural-spatial } \\
\text { SPINs }\end{array}$} & \multicolumn{7}{|c|}{ Growth poles } \\
\hline & & \multirow{2}{*}{$\begin{array}{c}\begin{array}{c}\text { Innovative } \\
\text { and } \\
\text { technological }\end{array} \\
\begin{array}{c}\text { Rostov } \\
\text { aglomeration }\end{array}\end{array}$} & \multicolumn{3}{|c|}{ Industrial } & \multicolumn{3}{|c|}{ Agro-industrial } \\
\hline & & & $\begin{array}{l}\text { Volga- } \\
\text { Don }\end{array}$ & $\begin{array}{c}\text { East- } \\
\text { Donbass }\end{array}$ & Taganrog & Millerovo & Morozovsk & Salsk \\
\hline \multirow{2}{*}{$\begin{array}{l}\text { Greening and } \\
\text { increasing the } \\
\text { competitiveness of } \\
\text { manufacturing }\end{array}$} & $\begin{array}{c}\text { New } \\
\text { Industrialization } \\
\text { of the Don }\end{array}$ & + & + & + & + & & & \\
\hline & $\begin{array}{l}\text { Rostov Region - } \\
\text { Agro-Industrial } \\
\text { Pole of Russia }\end{array}$ & & & & & + & + & + \\
\hline \multirow{2}{*}{$\begin{array}{l}\text { Equalizing the } \\
\text { center and the } \\
\text { periphery in access } \\
\text { to social services }\end{array}$} & $\begin{array}{c}\text { The Hospitable } \\
\text { Don }\end{array}$ & + & & + & + & & & \\
\hline & $\begin{array}{c}\text { Intelligent } \\
\text { Transport System } \\
\text { of the Rostov } \\
\text { Region }\end{array}$ & + & + & + & + & + & + & + \\
\hline \multirow{3}{*}{$\begin{array}{l}\text { Implementation of } \\
\text { spatial development } \\
\text { tools to attract } \\
\text { investment }\end{array}$} & $\begin{array}{c}\text { Cluster of } \\
\text { Industrial SMEs }\end{array}$ & + & + & + & + & + & + & + \\
\hline & $\begin{array}{c}\text { International } \\
\text { investment port }\end{array}$ & + & + & + & + & + & + & + \\
\hline & $\begin{array}{l}\text { The System of } \\
\text { Growth Poles of } \\
\text { the Rostov Region }\end{array}$ & + & + & + & + & + & + & + \\
\hline \multirow{2}{*}{$\begin{array}{l}\text { Cooperation of } \\
\text { business, education } \\
\text { and science }\end{array}$} & $\begin{array}{l}\text { The Don Valley } \\
\text { of Innovation } \\
\text { Development }\end{array}$ & + & & & & & & \\
\hline & $\begin{array}{l}\text { The South Pole of } \\
\text { High-Tech Export } \\
\text { Growth }\end{array}$ & + & + & + & + & + & + & + \\
\hline
\end{tabular}

The specialization of growth poles was identified on the basis of the structure of their economy, as well as on the basis of infrastructure development. So, in the Rostov agglomeration, an innovative technological infrastructure is developed, and high-tech industries and the service sector are actively developing. The infrastructure of industrial and agro-industrial poles is 
aimed at ensuring industrial and agro-industrial activity, respectively, and is not so innovative in nature (in agro-industrial poles, innovation is represented only by business incubators, and in the Morozovsky District there are no higher education institutions at all). Nevertheless, the potential of the growth poles is sufficient to act as centers in the zones of its influence and advanced territories for the development of the respective industries in the region.

\section{RESULTS AND DISCUSSION}

The author offers to focus on agro-industrial growth poles as first-level poles for the development of a life quality infrastructure. Each of them has its own characteristics, which can become priorities for their development. In addition, the agro-industrial growth poles have agro-industrial specialization, which is one of the priority areas for the development of the "granary of Russia".

The Millerovo agro-industrial growth pole is the center of the cluster for the deep processing of grain, and its enterprises are also part of the Don dairy products cluster. It has the most favorable position in terms of being on federal highways and railways [6].

The Morozovsk growth pole is characterized by the prevalence of the sector of small and medium-sized enterprises, which almost forced out large players. In the agricultural sector, 2/3 of the output is crop production, while livestock production, represented mainly by peasant (household) farms and private subsidiary farms, has limited sales opportunities, still its potential has not yet been exhausted [7]. It is worth noting that according to Orekhova and Kislitsyn, small business does not always act as a driver of structural changes in the economy [13]. Nevertheless, in Strategy-2030 a bet was placed on the SME sector, as evidenced by, among other things, the strategic project initiative "Cluster of Industrial SMEs".

The Salsk growth pole can be called the most developed agro-industrial growth pole, which has the most extensive social infrastructure (however, with some uncovered areas), characterized by the implementation of a number of investment projects in deep processing of grain and meat and dairy farming, in other industries with export potential. Innovation activity mainly falls on small and medium-sized businesses [8].

According to Table 1, the following structural-spatial SPINs are implemented in agroindustrial growth poles: "Rostov Region - Agro-Industrial Pole of Russia", "Intelligent Transport System of the Rostov Region", "Cluster of Industrial SMEs", "International Investment Port", "The South Pole of High-Tech Export Growth", "The System of Growth Poles of the Rostov Region". In general, the measures of the Action Plan for the implementation of Strategy-2030 [5] and existing state programs [14] ensure the implementation of the opportunities and parameters set by the SPINs.

The main spatial tools indicated in the actions are clusters and agro-industrial parks. The author believes that among spatial development tools, they are the least costly from the point of view of the state budget: special economic zones and territories of advanced socio-economic 
development provide their residents with benefits and preferences, while clusters involve the investment costs of private individuals, and agro-industrial parks suggest the possibility of applying the mechanism of public-private partnership (municipal-private partnership) with minimization of costs of the state via the form of land provision. Land development, creation of a property complex, providing access to engineering networks in this case can be realized by private investors. Unfortunately, the agro-industrial sector does not have such an investment attractiveness as the manufacturing sector, the service sector and the digital technologies. Nevertheless, the creation of primary facilities and support from the park management company reduce the risks of the first stages of operation for new industries and allows focusing directly on the production process, including by stimulating innovative activity, the level of which is relatively low in the agro-industrial sector [12]. Therefore, it is advisable to apply the PPP mechanism with sharing risks and realizing the advantages of both parties to attract private investment resources.

Measures to create agro-industrial parks in strategic planning documents are limited to assessing the financial and economic model for creating agro-industrial parks with preferences for residents, creating economic and organizational conditions for the leading universities of the region to implement the functions of the anchor structure of technology parks (provided that at least one of the created agro-industrial parks is technological by type). The author proposes to add a number of specific measures preceding the period of the park's full operation, taking into account the use of the PPP mechanism as a way of stimulating the introduction of modern technologies in the production process [20, p. 21]:

- Identification of a management company (it may be represented by an investor - a private partner of a PPP). It can participate in all activities of the preparatory phase.

- Monitoring the interest of economic entities in the creation of an agro-industrial park. They can be both direct producers and scientific and educational institutions and other enterprises that make up the innovative infrastructure of the park, as well as service entities that ensure the use of innovative technologies in agro-industrial production. An analysis of the existing system of industrial parks, the socio-economic and spatial system of the region, the study of all aspects of the functioning and potential of the agroindustrial park project.

- Improving the regulatory framework governing the activities of agro-industrial parks in the Rostov Region.

- Based on the monitoring results, identification of the necessary technical characteristics of the agro-industrial park, creation of a full-fledged project.

- Selection of a land plot owned by the state (a municipality), corresponding to the requirements for the parks.

- Conducting a tender and drawing up an agreement on PPP to create a property complex on the land plot to ensure the functioning of an agro-industrial park on it.

- Submission of the application to the responsible body of the Rostov Region by the initiator (state/municipal body, initiative group, including management company) for 
the creation of an agro-industrial park with the submission of the feasibility study of the project and a package of supporting documents. Upon approval, the documentation is handed over to the Government of the Rostov Region to make a decision on the creation of the park to be confirmed by a normative legal act.

- Conclusion of an agreement on the implementation of the project to create and develop a park between the management company and the responsible body of the Rostov Region. Further, it will coordinate the development and operation of the agro-industrial park.

- Concluding agreements and carrying out the technological connection to utility networks, providing access to industrial and technological infrastructure. Construction and preparation of premises for production activities by future residents. Carrying out the necessary work to bring the permitted uses of the land into compliance with its intended use within the framework of the agro-industrial park (but agricultural land for use in agricultural production cannot exceed $25 \%$ of the area of an agro-industrial park).

- Conclusion of preliminary agreements between the management company of the industrial park and its potential residents.

- Conclusion of an agreement and transfer of rights to operate a land plot and property complex of the management company.

- The management company submits an application and a package of documents to confirm the compliance of the agro-industrial park and the management company with the requirements for the industrial park and the management company of an industrial park in order to apply incentive measures in the industry. Compliance must be verified every 5 years.

- Conclusion of agreements between the management company and residents and the beginning of the direct operation of the park.

It is worth noting that, according to the law, the PPP mechanism can be implemented in the social sphere, in the provision of ICT services, infrastructure, etc., as well as objects and property complexes in the industry [2], thereby limiting the specialization of the planned agroindustrial park to the processing of agricultural raw stock. The features of agro-industrial growth poles determine that in the Morozovsky District, the main residents of the park will be SMEs; in Millerovo and Salsk - enterprises for the deep processing of grain and for the processing of meat and dairy products, including those that are part of the clusters. The opportunity of organizing a technology park with the involvement of leading agricultural and technical research and educational centers in the innovation infrastructure - DonSAU, DSTU, etc. should also be noted.

Also, according to the author, when creating projects for agro-industrial parks, an alternative to a specialization in organic production should be worked out. This direction is considered promising from the point of view of the concept of sustainable development, but organic production is inferior to traditional in a number of ways, including in terms of economic profitability. In addition, obstacles limiting the green modernization of production facilities (including the political, economic, informational factors, the level of business activity, the appropriate regulatory framework, the institutional support for innovative enterprises, the 
availability of financial, scientific, technical, technological and other resources, the government interest in modernization [19]) should be assessed and overcome. Creating favorable conditions for the development of organic production, certification and branding of organic products by the state, improving and making organic production commercially profitable through the development and implementation of organic innovations can make it more attractive for investors. Organic food production will meet the demand for organic agricultural raw stock, thus stimulating its production. The introduction of environmentally friendly and resourcesaving technologies into production will have a beneficial effect on the environmental processes. This also refers to the creation of the infrastructure of an industrial park as a whole: all environmental safety requirements must be met. Ultimately, the consumption of organic food has a beneficial effect on public health and quality of life.

\section{CONCLUSION}

The creation of agro-industrial parks at agro-industrial growth poles will facilitate the implementation of all the structural and spatial priorities identified by the author: production sites will be created for new facilities, which will provide favorable conditions for the implementation of investment projects and the introduction of modern technologies, including as part of the greening process. The development of production facilities in the growth poles will not only increase investment attractiveness but also create new jobs and help attract and retain qualified personnel. Population growth, in turn, will become an incentive for the development of social services and improving the quality of life. The peculiarity of the agroindustrial poles is that their development will spread to a greater extent to the surrounding rural territories, increasing their access to social infrastructure and other benefits.

\section{REFERENCES}

1. Federal Act No. 172-FZ dated (as amended on July 18, 2019) "On Strategic Planning in the Russian Federation". (2014, June 28). Retrieved January 23, 2020, from http://www. consultant.ru/cons/cgi/online.cgi? req $=$ doc \&base $=\mathrm{LAW} \& \mathrm{n}=329362 \& \mathrm{fld}=134 \& \mathrm{dst}=100$ 009,0\&rnd=0.9612583527063561\#07252657297050626

2. Federal Act of the Russian Federation No. 224-FZ "On Public-Private Partnerships, Municipal-Private Partnerships in the Russian Federation and Amending Particular Legislative Acts of the Russian Federation". (2015, July 13). Retrieved March 18, 2020, from http://www.consultant.ru/cons/cgi/online.cgi? req=doc\&base=LAW\&n=330160\&fl $\mathrm{d}=134 \& \mathrm{dst}=100009,0 \& \mathrm{rnd}=0.4203955017914949 \# 075376046416113$

3. Order of the Ministry of Economic Development of Russia No. 132 (as amended on September 7, 2018) "On Approval of the Methodological Recommendations for the 
Development and Adjustment of the Socio-Economic Development Strategy of a Region of the Russian Federation and the Action Plan for Its Implementation". (2017, March 23). Retrieved March 23, 2020, from http://www.consultant.ru/document/cons_doc_ LAW_214725/e2a7dc65b5742f224b8aa5ca26a813ee33bd1b5b/

4. Decree of the Government of Rostov Region No. 864 "On Approval of the Strategy for the Socio-Economic Development of the Rostov Region for the Period up to 2030". (2018, December 26). Retrieved October 23, 2019, from http://old.donland.ru/documents/Obutverzhdenii-Strategii-socialno-ehkonomicheskogo-razvitiya-Rostovskojj-oblasti-naperiod-do-2030-goda?pageid=128483\&mid=134977\&itemld=28439

5. Decree of the Government of Rostov Region No. 885 "On the Approval of the Action Plan for the Implementation of the Strategy for the Socio-Economic Development of the Rostov Region for the Period up to 2030". (2018, December 29). Retrieved March 21, 2020, from https://www.donland.ru/documents/10047/

6. Decision of the Meeting of Deputies of the Millerovsky District No. 383 "On approval of the Strategy for the socio-economic development of the Millerovsky District of the Rostov Region until 2030". (2018, December 27). Retrieved March 10, 2020, from http:// millerovoland.ru/index.php?option=com_content \&view=article\&id=8534:strategiyasotsialno-ekonomicheskogo-razvitiya-millerovskogo-rajona\&catid=339:materialy-2019

7. Decision of the Meeting of Deputies of the Morozovsky District No. 376 "On Approval of the Strategy for the Socio-Economic Development of the Morozovsky District until 2030". (2018, September 18). Retrieved March 14, 2020, from https://morozovsky. donland.ru/documents/active/2022/

8. Decision of the Meeting of Deputies of the Salsky District dated December 25, 2018 No. 253 "On the Strategy for the Socio-Economic Development of the Salsky District of the Rostov Region until 2030". (2018, December 25). Retrieved March 14, 2020, from http://www.salsk.org/index.php?option=com_content\&view=article\&id=2946:strategi ya-razvitiya-2030\&catid=92:tselevye-programmy

9. Abdullaev, R.A., \& Mishchenko, K.N. (2017). A Study of the Theoretical and Methodological Foundations of the Concept of Territorial Development of a Region and the Formation of a System of Growth Poles of the Rostov Region. Regional Economy: Theory and Practice, 15(5(440)), 802-813.

10. Kareva, A.V. (2014). The Strategic Planning System as the Basis for Sustainable Regional Development Management. University Herald, 16, 120-125.

11.Lapaev, S.P., \& Zatsarinina, Yu.V. (2017). Theoretical Foundations of the Balanced Development of Regional Economies. Intelligence. Innovation. Investments, 9, 31-34.

12. Neganova, V.P., \& Dudnik, A.V. (2019). Readiness to Innovations in a Regional AgroIndustrial Sector as a Subjective Factor of Innovative Activity. Economy of the Region, 15(3), 880-892.

13. Orekhova, S.V., \& Kislitsyn, E.V. (2019). Small Business and Structural Changes in Industry. Terra economicus, 17(4), 129-147. 
14.Programs. (n.d.). Official portal of the Government of Rostov Region. Retrieved March 29, 2020, from https://www.donland.ru/activity/14/

15. Regions of Russia. Socio-Economic Indicators - 2019. (2019). Retrieved February 10, 2020, from https://gks.ru/bgd/regl/b19_14p/Main.htm

16. Rostovstat. (2019). Rostov Region - Movement towards the Goals of Sustainable Development. Information and Analytical Materials. Rostov-on-Don. (p. 202).

17. Ostropilova, V.V. (Ed.). (2009). Strategic Priorities of Regional Development: From Theory to the Principles of a Single Socio-Economic Space. St. Petersburg: Nauka. (p. 448).

18. Shekhovtsov, R.V., Abdullaev, R.A., \& Astakhova, O.Yu. (2015). Organizational and Methodological Strategic Planning Decisions in the Regional Economy (Case Study of the Rostov Region. In Logistics in the Resource Portfolio of Import-Substituting Industrialization: Anti-Crisis Growth and Development Strategies under Conditions of Sanctions: Materials of the International Scientific and Practical XI South Russian Logistics Forum (pp. 513-521).

19. Shkarupa, E.V. (2015). Management of Environmental Modernization of the SocioEconomic Development of the Region. Economic Journal-XXI, 7-8-2, 57-60.

20. Tikhonova, A., Melnikova, N., \& Vishnevskaya, N. (2018). Readiness of Russian Regions to Digitize the Economy. Economic Journal-XXI, 11-12(174), 16-21.

21. Vasilyeva, V.S. (2020). Assessment of the Degree of Accounting for Global Sustainable Development Goals in the Strategy for Socio-Economic Development of the Rostov Region (the Russian Federation) until 2030. Economic Consultant, 29(1), 21-38. Retrieved April 3, 2020, from https://statecounsellor.wordpress.com/012020-2/

\section{INFORMATION ABOUT THE AUTHOR}

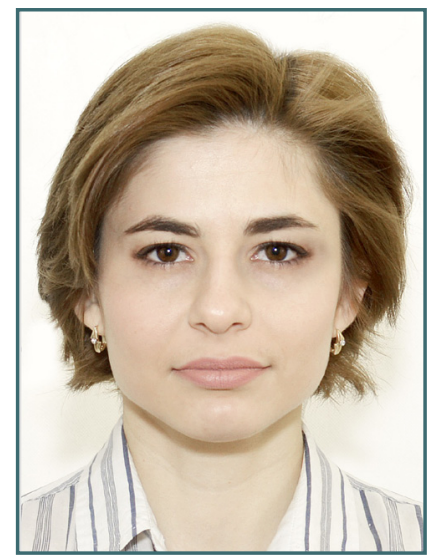

Valentina S. Vasilyeva (Russia, Rostov region) - Postgraduate student. Department of Economics of the Region, Industries and Enterprises. Rostov State Economic University. E-mail: avakyanvs@gmail.com 


\author{
D. G. Sandler, D. A. Gladyrev
}

\title{
Factors influencing on extra budgetary income of leading Russian universities: econometric analysis
}

\section{KEYWORDS}

university economics;

higher education management;

university strategy;

university competitiveness;

entrepreneurial universities;

extrabudgetary revenues;

scientometrics

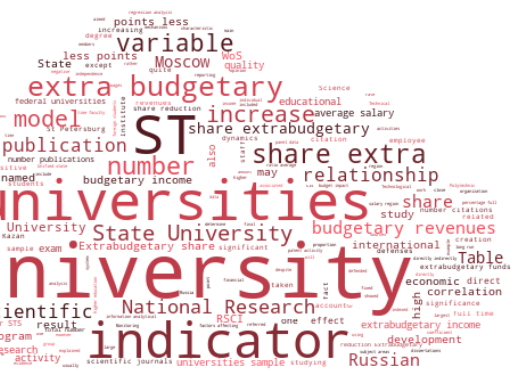

Word Cloud Generated by:

https://wordscloud.pythonanywhere.com/

FOR CITATION

\section{ABSTRACT}

This study is aimed to study the mechanisms that contribute to increasing the economic independence of universities, which in conditions of high dependence on-budget funding is exceptionally relevant in Russia. Even though the share of extra-budgetary revenues is growing at most Russian universities, this growth is heterogeneous and partly due to the "low base effect".

To determine the factors of economic independence of universities, we used data on the 49 largest universities in Russia over four years, taken from monitoring the effectiveness of higher educational institutions. The primary research method is regression analysis using panel data models.

The analysis reveals that the share of extra-budgetary funds of the university is positively influenced by factors such as the number and quality of publications, the number of journals published by the university, and the ratio of employees to the regional average. These dependencies are important in the long-term comprehensive planning of university activities.

Sandler, D. G., \& Gladyrev, D. A. (2020). Factors influencing on extra budgetary income of leading Russian universities: econometric analysis. Economic consultant, 30 (2), 36-47. doi: 10.46224/ ecoc.2020.2.4 


\section{INTRODUCTION}

$\mathrm{T}$ he development of the higher education system in Russia is one of the priority areas of state policy, as evidenced by such initiatives as the creation and development of federal universities, research university programs (hereinafter NII), the program for increasing international competitiveness "5-100", universities as centres for the creation of innovations, programs of supporting universities. The targets for these programs contain both scientific and economic variables. Although the role of the latter is somewhat underestimated, it is proved that the achievement of scientific indicators ultimately has a positive effect on economic indicators [9].

There are quite a few works dealing with factors affecting individual sources of extra-budgetary income of a university, for example, the number of patents and startups. In particular, the influence of the average age of employees (inverse relationship), the size of the university, and the characteristics of the country or region where the university is located were proved [8]. In some works, a connection was noted between the university's business indicators and the quantity and quality of its publications. It was found that patent and publication activity, despite the rather popular opinion of poor compatibility with each other [13], is in fact, directly related [1, 4, 11]. The high patent activity of individual researchers is usually associated with the high quality of previous publications and a large number of subsequent publications [3]. At the same time, the most prominent scientists usually do not have high patent activity [7]. Also, a positive relationship was found between the university's publication activity and other indicators of entrepreneurial activity, such as the amount of R\&D and the number of spin-offs [14]. All these results can be explained by the fact that the listed variables are united by one common characteristic, which can be called "research efforts and competencies" [2]. Also among the factors affecting the entrepreneurial activity of the university, the quality of education [10], the university's connection with the industry $[5,12]$ and the employee compensation system $[6,15]$ are noted.

At the same time, existing studies practically do not consider the economic independence of universities, especially relevant in Russia, given the significant state funding of universities. Although government initiatives involve a large amount of budget funding, they also aim to increase the economic independence of universities, especially in the long run. This study is aimed at studying the factors affecting the share of extrabudgetary revenues of Russian universities. These factors must be taken into account when forming comprehensive university development plans.

\section{DATA AND METHODS}

The study is based on the application of economic, structural and scientometric data on the 49 largest universities in Russia over four years (2015-2018). It is noteworthy that most 
of the external "shocks" (for example, the creation of federal universities, the start of the "5100 " program) are outside the period under review, and this allows focusing on studying the relationship between the university's intnal indicators rather than modelling these "shocks".

The sample included universities participating in the 5-100 project, federal universities (except Krymsky University due to the recent date of its formation), NRU (except Nanotechnology Research and Education Centre of the Russian Academy of Sciences named after Zh. I. Alferov), as well as Russian universities to international QS or THE ratings (as of March 2020).

Table 1

List of Universities included in the sample

\begin{tabular}{|c|c|c|c|c|}
\hline No & University & $5-100$ & $\begin{array}{c}\text { Federal } \\
\text { Universities }\end{array}$ & NRU \\
\hline 1 & Immanuel Kant Baltic Federal University & + & + & \\
\hline 2 & Belgorod State National Research University & & & + \\
\hline 3 & Voronezh State University & & & \\
\hline 4 & Higher School of Economics & + & & + \\
\hline 5 & Far Eastern Federal University & + & + & \\
\hline 6 & Irkutsk National Research Technical University & & & + \\
\hline 7 & Kazan (Volga region) Federal University & + & + & \\
\hline 8 & Kazan National Research Technical University & & & + \\
\hline 9 & Kazan National Research Technological University & & & + \\
\hline 10 & Mordovian State University named after N. P. Ogaryov & & & + \\
\hline 11 & Moscow Aviation Institute & & & + \\
\hline 12 & Moscow State Institute of International Relations (MGIMO) & & & \\
\hline 13 & Moscow State University of Civil Engineering & & & + \\
\hline 14 & Moscow State Technical University named after N. E. Bauman & & & + \\
\hline 15 & Moscow State University & & & \\
\hline 16 & Moscow Institute of Physics and Technology & + & & + \\
\hline 17 & Moscow Power Engineering Institute & & & + \\
\hline 18 & National Research Technological University "MISiS" & + & & + \\
\hline 19 & $\begin{array}{l}\text { National Research University "Moscow Institute of Electronic } \\
\text { Technology" }\end{array}$ & & & + \\
\hline 20 & ITMO National Research University & + & & + \\
\hline 21 & National Research Nuclear University MEPhI & + & & + \\
\hline 22 & Nizhny Novgorod State University named after N. I. Lobachevsky & + & & + \\
\hline 23 & Novosibirsk State Technical University & & & \\
\hline 24 & Novosibirsk State University & + & & + \\
\hline 25 & Perm State University & & & + \\
\hline 26 & Perm National Research Polytechnic University & & & + \\
\hline 27 & Russian State University of Oil and Gas named after I. M. Gubkin & & & + \\
\hline 28 & Russian Academy of National Economy and Public Administration & & & \\
\hline 29 & Russian National Research Medical University named after N. I. Pirogov & & & + \\
\hline 30 & Peoples' Friendship University of Russia & + & & \\
\hline 31 & Russian University of Economics named after G. V. Plekhanov & & & \\
\hline
\end{tabular}




\begin{tabular}{|c|l|c|c|c|}
\hline 32 & $\begin{array}{l}\text { Samara National Research University named after Academician } \\
\text { S. P. Korolyov }\end{array}$ & + & & + \\
\hline 33 & St. Petersburg Mining University & & \\
\hline 34 & St. Petersburg State University & + & & + \\
\hline 35 & St. Petersburg State Electrotechnical University "LETI" & + & & \\
\hline 36 & St. Petersburg Polytechnic University of Peter the Great & & \\
\hline 37 & Saratov State University named after N. G. Chernyshevsky & & + \\
\hline 38 & Northern (Arctic) Federal University & & + \\
\hline 39 & Northeastern Federal University & + & \\
\hline 40 & North Caucasus Federal University & + & & + \\
\hline 41 & Sechenovskiy University & + & & + \\
\hline 42 & Siberian Federal University & + & \\
\hline 43 & Tomsk State University & + & & + \\
\hline 44 & Tomsk Polytechnic University & + & + \\
\hline 45 & Tyumen State University & & + \\
\hline 46 & Ural Federal University & + & + \\
\hline 47 & Financial University under the Government of the Russian Federation & + & + \\
\hline 48 & South Ural State University & + & + \\
\hline 49 & Southern Federal University & + \\
\hline
\end{tabular}

Data on universities are taken from Information and analytical materials based on the results of monitoring the effectiveness of the activities of educational institutions of higher education. Monitoring is carried out according to 63 variables, divided into seven categories: educational, research, international, financial, and economic activities, infrastructure, graduate employment, staffing.

The primary research method is regression analysis using panel data models. Despite the potential promise of using lag variables, the effect of using many mechanisms may be delayed. Therefore, in this study, lag variables are not considered because of the small number of years available for analysis.

\section{RESULTS}

The dynamics of the share of extra-budgetary income by universities in the sample (Fig. 1) demonstrates the increase in the share of extra-budgetary income for all groups of universities in the sample. However, despite the similar dynamics, the average values for individual groups differ significantly: in particular, federal universities have a lower share of extra-budgetary income, and metropolitan universities, by contrast, a higher share of extrabudgetary income.

A detailed analysis of this dynamics (Table 2) leads to the conclusion that an increase in the share of extra-budgetary revenues from 2015 to 2018 was demonstrated by 42 of the 49 sample universities. All Federal Universities and all Moscow Universities from the sample showed an increase in the share of extra-budgetary revenues, except one (NRU MGSU). 


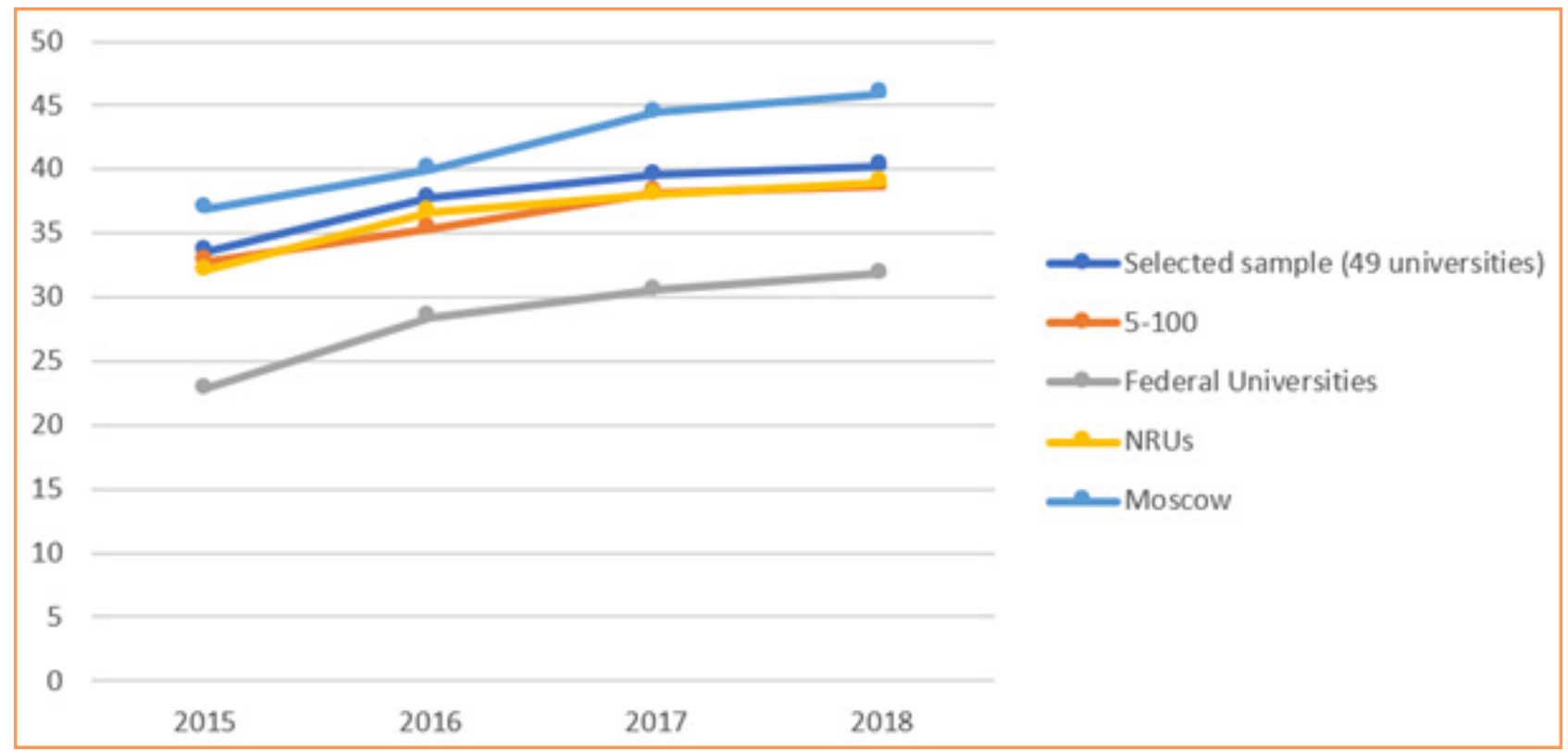

Figure 1 The share of extrabudgetary funds by a group of Universities (2015-2018)

Table 2

Number of universities in the sample, according to their share change extrabudgetary funds from 2015 to 2018

\begin{tabular}{|c|c|c|c|}
\hline \multicolumn{4}{|c|}{ Whole sample -49 universities } \\
\hline \multicolumn{2}{|c|}{ Extrabudgetary share reduction } & \multicolumn{2}{|c|}{ Extrabudgetary share increase } \\
\hline \multicolumn{2}{|c|}{$7(14,3 \%)$} & \multicolumn{2}{|c|}{$42(85,7 \%)$} \\
\hline more than 10 points & less than 10 points & less than 10 points & more than 10 points \\
\hline $2(4,1 \%)$ & $5(10,2 \%)$ & $29(59,2 \%)$ & $13(26,5 \%)$ \\
\hline \multicolumn{4}{|c|}{$« 5-100 »-21$ universities } \\
\hline \multicolumn{2}{|c|}{ Extrabudgetary share reduction } & \multicolumn{2}{|c|}{ Extrabudgetary share increase } \\
\hline \multicolumn{2}{|c|}{$3(14,3 \%)$} & \multicolumn{2}{|c|}{$18(85,7 \%)$} \\
\hline more than 10 points & less than 10 points & less than 10 points & more than 10 points \\
\hline $1(4,8 \%)$ & $2(9,5 \%)$ & $11(52,4 \%)$ & $7(33,3 \%)$ \\
\hline \multicolumn{4}{|c|}{ Federal universities - sample of 9} \\
\hline \multicolumn{2}{|c|}{ Extrabudgetary share reduction } & \multicolumn{2}{|c|}{ Extrabudgetary share increase } \\
\hline \multicolumn{2}{|c|}{$0(0 \%)$} & \multicolumn{2}{|c|}{$9(100 \%)$} \\
\hline more than 10 points & less than 10 points & less than 10 points & more than 10 points \\
\hline $0(0 \%)$ & $0(0 \%)$ & $5(55,6 \%)$ & $4(44,4 \%)$ \\
\hline \multicolumn{4}{|c|}{ NRU - sample of 28 universities } \\
\hline \multicolumn{2}{|c|}{ Extrabudgetary share reduction } & \multicolumn{2}{|c|}{ Extrabudgetary share increase } \\
\hline \multicolumn{2}{|c|}{$4(14,3 \%)$} & \multicolumn{2}{|c|}{$24(85,7 \%)$} \\
\hline more than 10 points & less than 10 points & less than 10 points & more than 10 points \\
\hline $1(3,6 \%)$ & $3(10,7 \%)$ & $17(60,7 \%)$ & $7(25 \%)$ \\
\hline \multicolumn{4}{|c|}{ Moscow universities - sample of 17 universities } \\
\hline \multicolumn{2}{|c|}{ Extrabudgetary share reduction } & \multicolumn{2}{|c|}{ Extrabudgetary share increase } \\
\hline \multicolumn{2}{|c|}{$1(5,9 \%)$} & \multicolumn{2}{|c|}{$16(94,1 \%)$} \\
\hline more than 10 points & less than 10 points & less than 10 points & more than 10 points \\
\hline $0(0 \%)$ & $1(5,9 \%)$ & $11(64,7 \%)$ & $5(29,4 \%)$ \\
\hline
\end{tabular}


Table 3 shows the leaders in reducing and increasing the share of extrabudgetary revenues from 2015 to 2018. It is noteworthy that the main reason for the increase in the share of extrabudgetary income among the leaders was the direct increase in extrabudgetary incomes, while the leaders in reducing the share of extrabudgetary incomes were diverse: they may be hidden both in a decrease in extra-budgetary revenues, and in an increase in the share of budget financing, or a combination of these reasons.

Table 3

Universities with the largest change in the share of extra-budgetary revenues from 2015 to 2018

\begin{tabular}{|l|c|l|l|}
\hline \multicolumn{2}{|c|}{$\begin{array}{c}\text { Top-5 universities samples to reduce the share of } \\
\text { extra-budgetary revenues }\end{array}$} & $\begin{array}{c}\text { Top-5 universities samples to increase the share of } \\
\text { extra-budgetary revenues }\end{array}$ \\
\hline $\begin{array}{l}\text { Kazan National Research } \\
\text { Technological University }\end{array}$ & $49,5 \%->38,3 \%$ & Moscow Energy Institute & $6,5 \%->42,1 \%$ \\
\hline $\begin{array}{l}\text { St. Petersburg State } \\
\text { Electrotechnical University "LETI" }\end{array}$ & $44,4 \%->34,3 \%$ & Saratov State University & $3,6 \%->29,6 \%$ \\
\hline $\begin{array}{l}\text { ITMO National Research } \\
\text { University }\end{array}$ & $35,3 \%->29,4 \%$ & Kazan Federal University & $29,7 \%->52,1 \%$ \\
\hline $\begin{array}{l}\text { Perm National Research } \\
\text { Polytechnic University }\end{array}$ & $55,6 \%->50,2 \%$ & North Caucasus Federal University & $19,5 \%->35,2 \%$ \\
\hline Tyumen State University & $64 \%->59,1 \%$ & Sechenov University & $35,2 \%->50,7 \%$ \\
\hline
\end{tabular}

For determining the factors affecting the share of extrabudgetary revenues, a regression analysis was performed using panel data models. The share of extra-budgetary income of the university was taken as the studied variable. For the creation of a model, it is necessary to determine the variables with which the indicator understudy will be explained.

Since the purpose of the study is to determine the mechanisms and competencies, the use of which allows directly or indirectly increasing the share of extra-budgetary funds of the university, the model does not include variables that are a direct measure of those or other components of extra-budgetary income: income from research and development work (hereinafter - R\&D), the amount of paid admission, the number of grants won and the number of startups.

At the same time, the model includes indicators from Monitoring the performance of educational institutions of higher education. These indicators, on the one hand, quite fundamentally determine what a university is. On the other hand, all these indicators can be targeted in university development programs and improve as a result of the implementation of specific strategies. These are indicators of the quality of admission, the quality and number of publications, the current dynamics of defenses, the number of scientific journals, the share of international students and Scientific and teaching staff (after this referred to as the STS), the indicator of salary, the share of STS with a scientific degree and the share of full-time teaching staff. All selected indicators are described in Table 4.

The study originally planned to use the number of publications indexed in the Web of Science database (after this referred to as WoS) per 100 STS. However, a preliminary analysis of 
the data showed an extremely high (0.8) correlation with the citation rate of WoS publications per 100 STS, which makes it impossible to use of both indicators in the model simultaneously. It was decided to include an indicator of the number of citations in the final model. However, the fact of such a close relationship between the number and quality of publications deserves special mention as evidence that the dilemma of choosing between the number and quality of publications is exaggerated, and these indicators usually have common dynamics.

Table 4

Variables selected for inclusion in the model

\begin{tabular}{|l|l|}
\hline \multicolumn{1}{|c|}{ Variable } & \multicolumn{1}{|c|}{ Description } \\
\hline Exam point, Unified state exam & $\begin{array}{l}\text { Averaged by the implemented areas (specialities) the minimum score of the } \\
\text { exam for students accepted by the results of the exam for full-time study at } \\
\text { the undergraduate and speciality programs }\end{array}$ \\
\hline $\begin{array}{l}\text { WoS Citation Count per 100 } \\
\text { STS }\end{array}$ & $\begin{array}{l}\text { The number of citations of publications published over the past five years, } \\
\text { indexed in the information-analytical system of scientific citation WoS per } \\
\text { 100 STS }\end{array}$ \\
\hline RSCI publications at 100 STS & $\begin{array}{l}\text { The number of publications of the organization indexed in the information- } \\
\text { analytical system of scientific citation of RSCI, per 100 STS }\end{array}$ \\
\hline $\begin{array}{l}\text { The share of defended STS for } \\
\text { the reporting year }\end{array}$ & $\begin{array}{l}\text { The proportion of scientific and pedagogical workers who defended their } \\
\text { candidate and doctoral dissertations for the reporting period in the total } \\
\text { number of STS }\end{array}$ \\
\hline Number of scientific journals & $\begin{array}{l}\text { The number of scientific journals, including electronic, published by an } \\
\text { educational organization }\end{array}$ \\
\hline $\begin{array}{l}\text { Share of foreign students } \\
\text { (except CIS) }\end{array}$ & $\begin{array}{l}\text { Percentage of international students (except for countries of the } \\
\text { Commonwealth of Independent States (after this referred to as the CIS)) } \\
\text { studying undergraduate, speciality, and master's programs in the total } \\
\text { number of students (reduced contingent) }\end{array}$ \\
\hline Share of foreign STS & $\begin{array}{l}\text { The proportion of the number of foreign citizens from STS in the total } \\
\text { number of STS }\end{array}$ \\
\hline $\begin{array}{l}\text { The ratio of the average salary } \\
\text { of the STS to the average salary } \\
\text { of the region }\end{array}$ & $\begin{array}{l}\text { The ratio of the average STS salary in an educational organization (from all } \\
\text { sources) to the average salary in the region's economy }\end{array}$ \\
\hline Graduated STS & $\begin{array}{l}\text { The proportion of STSs with a PhD and Doctor of Science degree in the } \\
\text { total number of STS educational organizations (without part-time workers } \\
\text { and working under civil law contracts) }\end{array}$ \\
\hline $\begin{array}{l}\text { The percentage of full-time } \\
\text { faculty }\end{array}$ & The percentage of full-time faculty in the total number of faculty \\
\hline
\end{tabular}

The correlation matrix (Table 5) demonstrates that the relationship between the other indicators is quite moderate, so their simultaneous use in the model will not lead to the creation of a multicollinearity problem.

As a result of econometric modelling, taking into account the panel data structure, a through model, a model with fixed and random effects, was compiled. The application of Wald and Hausman tests showed that the model with fixed effects describes the specifics of the interconnections between the indicators of Russian universities most optimally - it was she who was chosen as the final one. 
Table 5

The correlation matrix of the variables in question

\begin{tabular}{|c|c|c|c|c|c|c|c|c|c|c|c|}
\hline & 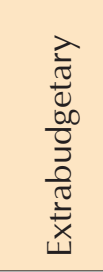 & 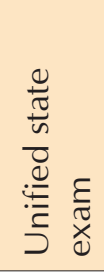 & $\tilde{n}$ & $\begin{array}{l}\bar{\bigcup} \\
\stackrel{2}{n}\end{array}$ & 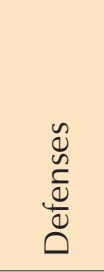 & 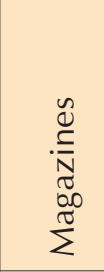 & 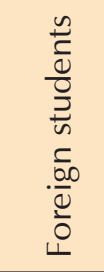 & 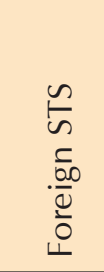 & 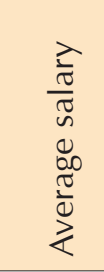 & $\begin{array}{l}\frac{0}{0} \\
\frac{0}{00} \\
\frac{0}{0} \\
\frac{5}{5} \\
3\end{array}$ & 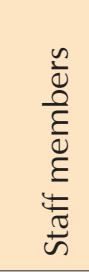 \\
\hline Extrabudgetary & 1,00 & & & & & & & & & & \\
\hline Unified state exam & $-0,01$ & 1,00 & & & & & & & & & \\
\hline WoS & $-0,14$ & 0,48 & 1,00 & & & & & & & & \\
\hline $\mathrm{RSCl}$ & 0,22 & 0,03 & 0,07 & 1,00 & & & & & & & \\
\hline Defenses & 0,04 & 0,18 & 0,07 & $-0,11$ & 1,00 & & & & & & \\
\hline Magazines & 0,14 & 0,12 & 0,05 & 0,14 & $-0,10$ & 1,00 & & & & & \\
\hline Foreign students & 0,40 & 0,19 & 0,17 & 0,09 & 0,22 & 0,10 & 1,00 & & & & \\
\hline Foreign STS & $-0,05$ & 0,45 & 0,49 & 0,17 & 0,17 & 0,12 & 0,21 & 1,00 & & & \\
\hline Average salary & 0,03 & 0,17 & 0,22 & 0,11 & 0,08 & 0,13 & $-0,06$ & 0,36 & 1,00 & & \\
\hline With degree & 0,00 & $-0,09$ & $-0,11$ & 0,21 & 0,20 & $-0,03$ & 0,17 & $-0,04$ & $-0,17$ & 1,00 & \\
\hline Staff members & 0,14 & $-0,35$ & $-0,58$ & 0,03 & $-0,13$ & 0,14 & 0,00 & $-0,17$ & $-0,16$ & 0,31 & 1,00 \\
\hline
\end{tabular}

Table 6

Final model

Variable understudy - Share of university extrabudgetary funds

\begin{tabular}{|l|c|}
\hline \multicolumn{1}{|c|}{ Variable } & $\begin{array}{c}\text { Coefficient (standard errors are } \\
\text { shown in parentheses) }\end{array}$ \\
\hline Exam point, Unified state exam & $0,1986(0,1332)$ \\
\hline Web of Science citations at 100 STS & $0,0014(0,001)$ \\
\hline RISC publications on 100 STS & $0,0094^{*}(0,0045)$ \\
\hline The share of defended STS for the reporting year & $-1,755^{* *}(0,6257)$ \\
\hline Number of scientific journals & $0,3655^{*}(0,1777)$ \\
\hline Share of foreign students (except CIS) & $0,3991(0,5225)$ \\
\hline Share of Foreign STS & $-0,7631(0,4658)$ \\
\hline The ratio of the average salary of STS to the average salary of the region & $0,0481^{*}(0,021)$ \\
\hline Graduated STS & $0,0397(0,1702)$ \\
\hline The percentage of full-time faculty & $-0,094(0,1562)$ \\
\hline Constant & $18,8797(18,5439)$ \\
\hline
\end{tabular}

Panel Regression with Fixed Effects:

* Significant by $5 \%$.

** Significantly $1 \%$.

Four variables turned out to be significant at a 5\% significance level: RSCI publications per 100 STS (direct correlation), the proportion of STS defenders for the reporting year (inverse correlation), the number of scientific journals (direct correlation) and the ratio of the average STS salary to the average salary in the region (direct correlation). 
The proven relationship between the share of extra-budgetary revenues and the number of publications of the RSCI per 100 STS may be related to the positive impact of scientific productivity on the share of extra-budgetary income. At the same time, it was somewhat unexpected that the indicator of the number of publications of the RSCl turned out to be significant, and not the indicator of the number of publications or the number of citations in the international database WoS. Recall that due to the multicollinearity problem, only the index of the number of citations in WoS was included in the final model. This process can be explained by the fact that the number of publications of the RSCI is better associated with the university's ability to generate its income. In particular, authors from those subject areas that are associated with obtaining the largest extrabudgetary income may be more likely to publish in the RSCI. For example, universities specializing in economics and management have higher contractual acceptance. It is also worth noting that, although the number of citations in WoS was not statistically significant, the coefficient is positive and quite close to significance ( $p$-value $=0.147$ ). This fact may serve, albeit not very reliable, but as an argument in favour of a positive relationship between the share of extra-budgetary revenues and the number of citations.

The proven negative correlation between the share of extra-budgetary revenues and the share of the defenses of STS dissertations in the current year is curious. Moreover, this indicator has the highest statistical significance. The efforts that the university directs to the successful defenses of its employees have a certain negative impact on the university's ability to receive extrabudgetary income. This conclusion is combined with the ideas that, with active development, it is more profitable and faster to attract outside staff than to grow own. At the same time, this result should not be taken as evidence that universities with high protection rates always have a low share of extrabudgetary funds - especiallly since the correlation coefficient between these indicators is almost zero (Table 5). A negative relationship is observed, taking into account the panel data structure with fixed values of all other variables of the model.

The number of scientific journals is directly related to the share of extra-budgetary revenues. An increase in publishing activity may be evidence of aspirations to concentrate on regional or national scientific activity, which may positively affect R\&D income and grants. However, it is also possible because a large number of journals, so far at Russian universities, are related to the social and humanitarian sphere and management sciences, which are characterized by a high share of extra-budgetary income in educational activities.

The share of foreign STS is quite close to significance at the $10 \%$ level ( $p$-value $=0.104$ ). Even though this result is not highly reliable, a negative relationship with the share of extrabudgetary revenues is curious. This circumstance is probably because foreign STSs are one of the factors for increasing budget financing (it is fair to say that they are also its consequence).

Finally, the ratio of STS average wages to region average wages is also directly related. If we do not consider the possible difficulties of cause-and-effect relationships, then we can assume that high wages attract qualified and motivated employees, more inclined to scientific work, R\&D and patent activity. 
At the same time, many variables are very far from statistical significance; these are the share of international students, the share of STS with a scientific degree, and the share of fulltime faculty members.

\section{CONCLUSION}

The study showed that all Russian universities are aimed at increasing the share of extra-budgetary revenues, and most of them successfully implement this goal. At the same time, the main successes of universities in improving this indicator in recent years are associated with the "low base effect", which may indicate that further growth will be more difficult. In this regard, the question arises of mechanisms that can directly or indirectly lead to an increase in the financial independence of universities.

This study is aimed not at studying the direct components of extrabudgetary income. The leading issue of this paper is studying the relationship between the main characteristics of the scientific and educational activities of the university and its share of extrabudgetary income. In our opinion, from a practical point of view, these relationships should be taken into account in the strategic and long-term planning of the development of the university.

The regression analysis revealed the university's indicators, the impact on which can be combined, and in the long run, directly or indirectly affect the share of its extrabudgetary incomes. When planning a university's scientific activity, firstly, the number and quality of publications, including not only international but also Russian ones, should be increased, this can go well with the increase in the share of extrabudgetary funds. Secondly, it should be borne in mind that the focus on high rates of defenses of dissertations can adversely affect the share of extra-budgetary income of the university, at least in the medium term. A rather interesting further direction of the study is to study the same relationship in the long run - there the result may be the opposite. Thirdly, it makes sense to pay attention to the activity models of universities with a large number of journals; they have a high share of extrabudgetary revenues. Fourth, a high salary should be planned for STS, which can positively affect the appearance of qualified and motivated employees with the skills and willingness to engage in research and development and patent activity.

In our opinion, these findings can be used by the university regulator, the Ministry of Science and Higher Education, in the preparation of tender documentation for the right to receive support for university development programs.

This analysis can be expanded by adding variables from sources other than Monitoring the effectiveness of universities. Presumably, the mechanisms that affect the amount of extrabudgetary revenues differ in different regions and different subject areas. Thus, a promising direction in the development of research is to take into account regional characteristics and various subject areas in which universities specialize. 


\section{REFERENCES}

1. Azoulay P., Ding W., \& Stuart T. (2007). The determinants of faculty patenting behavior: Demographics or opportunities? Journal of economic behavior \& organization, 63 (4), 599-623.

2. Breschi S., Lissoni F., \& Montobbio F. (2005). From publishing to patenting: Do productive scientists turn into academi inventors? Revue d'ŭconomie industrielle, 110 (1), 75-102.

3. Calderini M., \& Franzoni C. (2004). Is academic patenting detrimental to high quality research. An empirical analysis of the relationship between scientific careers and patent applications. Bocconi University: Cespri Working Paper, 162.

4. Czarnitzki D., Glanzel W., \& Hussinger, K. (2007). Patent and publication activities of German professors: an empirical assessment of their co-activity. Research Evaluation, 16 (4), 311-319.

5. Farsi J., Modarresi M., Motavaseli M., \& Salamzadeh A. (2014). Institutional factors affecting academic entrepreneurship: The case of university of Tehran. Economic Analysis, 47 (1-2), 139-159.

6. Kirby D. A. (2006). Creating entrepreneurial universities in the UK: Applying entrepreneurship theory to practice. The Journal of Technology Transfer, 31 (5), 599-603.

7. Meyer M. (2006). Are patenting scientists the better scholars? An exploratory comparison of inventor-authors with their non-inventing peers in nano-science and technology. Research Policy, 35 (10), 1646-1662.

8. Riviezzo A., Santos S. C., Licбn F., Napolitano M. R., \& Fusco, F. (2019). European universities seeking entrepreneurial paths: the moderating effect of contextual variables on the entrepreneurial orientation-performance relationship. Technological Forecasting and Social Change, 141, 232-248.

9. Sandler D. G., Evsykova I. A., Bogantseva S. S., Melnik D. A., Sterkhov A. V., \& Bondarchuk D. V. (2019). Usage of integrated indicators in the implementation of programs to improve competitiveness in the context of developing cooperation with the industry and improving the economic sustainability of universities. Russian Journal of Industrial Economics, p. 341-355. (In Russ.)

10. Shane S. A. (2004). Academic entrepreneurship: University spinoffs and wealth creation. Edward Elgar Publishing, UK/Northampton, MA, USA.

11. Stephan P. E., Gurmu S., Sumell A. J., \& Black G. (2007). Who's patenting in the university? Evidence from the survey of doctorate recipients. Econ. Innov. New Techn., $16(2), 71-99$.

12. Tanha D., Salamzadeh A., Allahian Z., \& Salamzadeh Y. (2011). Commercialization of university research and innovations in Iran: obstacles and solutions. Journal of Knowledge Management, Economics and Information Technology, 1 (7), 126-146.

13. Van Looy B., Callaert J., \& Debackere K. (2006). Publication and patent behavior of 
academic researchers: Conflicting, reinforcing or merely co-existing? Research policy, 35 (4), 596-608.

14. Van Looy B., Landoni P., Callaert J., Van Pottelsberghe B., Sapsalis E., \& Debackere K. (2011). Entrepreneurial effectiveness of European universities: An empirical assessment of antecedents and trade-offs. Research Policy, 40 (4), 553-564.

15. Wright M., Clarysse B., Mustar P. and Lockett A. (2007) Academic Entrepreneurship in Europe. Edward Elgar Publishing, Massachusetts, USA.

\section{INFORMATION ABOUT THE AUTHORS}

1. Daniil G. Sandler (Russia, Ekaterinburg) - PhD in Economic Sciences, Associate Professor of the Department of Financial Management, Leading Researcher, Research Laboratory for University Development Issues, Vice-Rector (Economics and Strategy). Ural Federal University named after the First President of Russia B. N. Yeltsin. E-mail: d.g.sandler@urfu.ru. Scopus ID: 56581474400

2. Dmitry A. Gladyrev (Russia, Ekaterinburg) - Senior Lecturer at Department of Economics. Ural Federal University named after the First President of Russia B. N. Yeltsin. E-mail: d.a.gladyrev@urfu.ru. Scopus ID: 57208191401 
N. B. Kirillova, O. N. Tomyuk, M. A. Dyachkova

\section{Educational segment of modern media market: features and trends in digitalization}

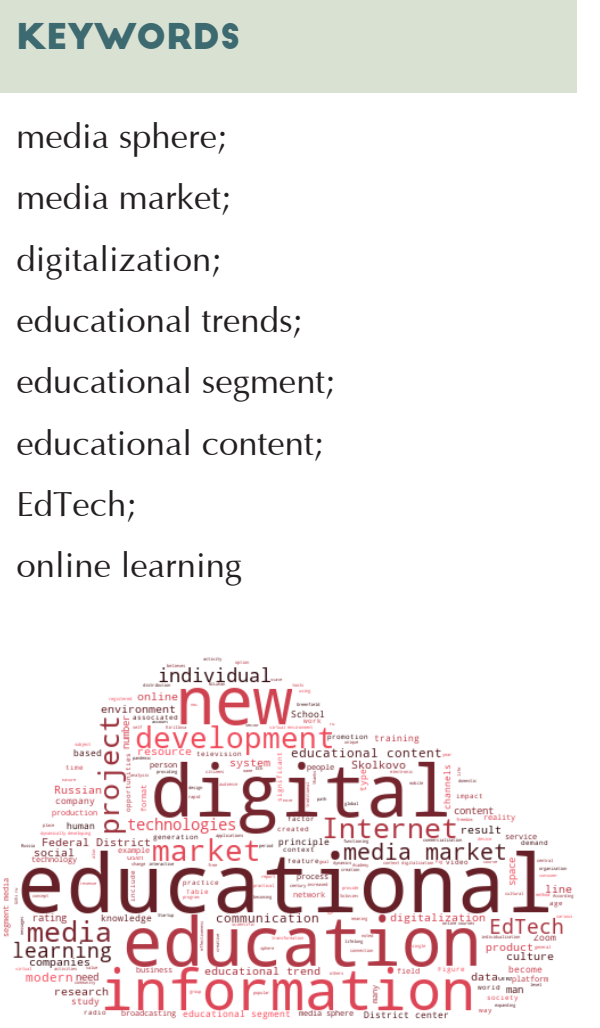

Word Cloud Generated by:

https://wordscloud.pythonanywhere.com/

\section{ABSTRACT}

Introduction. The relevance of the study is due to increased efficiency and accessibility of education in the context of digitalization.

Materials and methods. In the research process, general and special methods of scientific knowledge were used: systemic, structural and functional analysis, expert assessments, analysis and comparison of statistical data obtained as a result of studying the media market.

Results and discussion. The main feature of the media market is that the actors in the media market are firms, individuals involved in the production and promotion of media content, i.e. text messages, audio, video messages, infographics and other types of content. The emphasis in the study is on the modern media market, changing under the influence of a new generation of digital technologies. It is proved that the value of digital transformation for consumers of educational content is associated with the ability to meet individual educational needs, build individual educational trajectories. Analyzed are data on monitoring the effectiveness of economic activity of EdTech companies offering educational content and working in the field of its promotion. The educational trends in the educational segment of the media market and the factors affecting their promotion are identified.

Conclusions. The study allowed concluding that there is a high demand among users of digital, accessible and high-quality educational content for all levels of education from different fields of knowledge

Kirillova, N. B., Tomyuk, O. N., \& Dyachkova, M. A. (2020). Educational segment of modern media market: features and trends in digitalization. Economic consultant, 30 (2), 48-61. doi: 10.46224/ ecoc.2020.2.5 


\section{INTRODUCTION}

$\mathrm{T}$ he modern world, becoming a digital civilization, is "a type of development of society, in which the analogue and linear formats of communication and the functioning of systems are replaced by digital, electronic, which determine not only the nature and direction of human and social activities but become the main ones, determining goals and the meanings of human life and activity" [2, p. 519].

Society integrates a variety of socio-cultural phenomena with an angle of refraction through the prism of digitalization [24]. The figure as a key, universal position, in the context of globalization, is put on a par with other "cultural fields" - the alphabet, account, print, Internet. In this regard, the new - the digital equivalent, like the others, is a way that allows fixing the world of culture [1].

Understanding of digitalization in conjunction with new educational practices in all spheres of human being that arose in connection with dynamically developing information technologies is typical for many researchers [25]. Digitalization is woven into the being of man, constructing a new, virtual environment, exerting a transformative effect on the vital activity of modern man.

O. S. Dovbysh defines the media market as "the totality of actors (firms or individuals) involved in the production, packaging or distribution of media content" [7]. O. S. Drobysh calls content as a distinctive feature of the media market in comparison with other business markets. Media, depending on the context, includes various types of data, not only text messages, but also audio and video messages, infographics.

Features of the media product affect the organization of the production process and the configuration of the media market. So, if a single product is based on unique individual content, for the creation of which a specific team is created, then the same type of content requires an organized process, which, as a result, involves different business strategies.

The media market has changed in the context of digitalization. The digital transformation of the market is stated in the report of the SKOLKOVO Business School Research Institute for Emerging Markets (2017): "a new generation of digital technologies creates a new level of consumer value by a previously unattainable combination of accessibility and customization, with the delivery of analytically customized goods and services on demand and often at a much more attractive price compared to the traditional offer" [11]. The report noted the features of the "digitized" consumers: awareness, knowledge of the tools of "cost-free switching between suppliers" of goods and services. The report notes that "the key value of digital transformation is for consumers: cheaper goods and services, offered taking into account individual needs and tasks and delivered where they are needed, and at that moment in time when they are needed [11]. These features give consumers "market power", transforming "market competition", SKOLKOVO analysts consider. 


\section{MATERIALS AND RESEARCH METHODS}

In the research process, general and special methods of scientific knowledge are used: system, structural and functional analysis, expert assessments, analysis and comparison of statistical data obtained as a result of studying the media market and its educational segment.

\section{ANALYSIS OF THE LITERATURE}

Modern scientific research touches on many problems associated with the digital age. The emergence of the Internet, virtual reality technologies, the prediction of their development and their place in the life of people back in the 60s of the 20th century was described in the works of M. McLuhan, S. Lem, M. Castells and other scientists. M. McLuhan from the first thesis "after watching television, a little mouse attacks an adult cat" (previously it was the other way around) and to the last proves that the world is changing [19]. If for three thousand years based on mechanical technologies the world underwent only fragmentary changes, then now, M. McLuhan wrote in the book "Understanding Media: External Extensions of Man" (1964), the outlines of a new era with expanding opportunities for humans are visible [19]. S. Lem, in his Sum of Technology (1963) writes about a virtualized society [18]. F. Hammit believes that the future lies with virtual reality [10, p. 112]. Moreover, M. Castells, exploring the network space, expressed the idea that "the Internet was created as a means of free global communication" [4, p. 5].

The Internet, as a new substance created by man, represents unlimited educational opportunities for the man himself.

The rapid change of information educational technologies, one technological solution to another, increasing information flows, erasing time and space boundaries, the emergence of new educational trends are becoming a significant research problem in foreign and domestic science. G. Jenkins (Massachusetts Institute of Technology) as applied to the community, communicating in a virtual environment, introduces the term "culture of participation", the essence of which consists of a combination of four components - expression (new ways of expressing emotions), collaboration (teamwork), translation (information flow), affiliation (communication in the community) [12, p. 3].

In the works of N. B. Kirillova, the information age is considered in conjunction with the global media environment, when the established "information industry" has an impact on all spheres of life [15]. The current level of cultural development is determined by how electronic they operate with the concepts of "electronic culture" (M. Schwarz [23], K. Weltmann [30] and others), "virtual reality" (J. Lanier [17] and others), talk about the impact of digitalization on the meanings of being [3].

Digitalization is woven into education, constructing a new, virtual environment, having a transformative effect on the way education is received. Information technology is becoming 
the backbone of On-line education. New digital ways of transmitting information not only provided people with interactive communications but also created a virtual environment for satisfying educational needs.

N. B. Kirillova, justifying the creative nature of the media sphere in the context of the formation of "Homo medium", identifies many essential aspects: the "subject-object" nature of the relationship in the system of "man-media reality-society" through the concepts of "influence", "impact"; the media environment is a resource of directed socialization and, at the same time, free self-determination with learning opportunities, the satisfaction of leisure needs.

V. S. Stepin, L. F. Kuznetsova, comparing the value systems of traditional and technogenic cultures, revealed the dominants of modern culture - freedom of choice, variability, individualization, expanding opportunities for the development of individual creative principles in a person [26]. Researchers emphasize that the digital environment is a factor in the development of the individuality of modern man.

Anthropocultural practice, meaning individualization, is defined through the concepts of "individual trajectory", "individual route". The Internet-space in this context acts as a unique environment with the potential to design an individual strategy for transforming being as a whole and being of a person. T. M. Kovaleva names three interconnected action vectors that provide an individual strategy in the context of individualization: vector $X$ - social (using the resources of society), $Y$ - subject (immersion in the field of knowledge of interest), $Z$ anthropological (improving oneself) [16]. In the digital environment, the education process is personality-oriented, has an impact on human behaviour, the formation of its "I" concept, and is a motivational space, an environment of great opportunities and self-realization.

Information technologies rapidly bursting into life have updated new vectors in the study of education, namely, the study of transformations in education, new educational practices that have become a reality in the context of digitalization. Digitalization has enriched education with new phenomena: "Digital Humanities" as a field of humanitarian knowledge using IT (for example, digital humanities, computer linguistics); "Art \& Science" as an "interactive semantic space" with network communications in scientific and educational environments, for example, On-line. Digitalization with new educational practices and educational environments necessarily requires a person to own a dynamically developing new ICT toolkit, to be included in the process of continuing education.

D. Tapscott calls the generation of people born in the period from the 90s. XX century and later, "Net Generation" [27]. L. Rosen, based on a study of the features of the new generation, suggests using the term "iGeneration" to designate a modern person, wherein "i" is the type of digital technology popular with a modern person (iPhone, iPod, iTunes) and individualized types of activities that become possible thanks to these technologies [22]. An illustration is the data of the All-Russian representative poll of the All-Russian Public Opinion Research Center "People in Digital: The Age of Post-Truth" (information as of November 24-25, 2018): 84\% of Russians are Internet users, $66 \%$ of them use the Internet daily, $62 \%$ - users of social networks, $95 \%$ of the entire young population aged 18 to 24 years - users of social networks, access to 
which $88 \%$ of young people through a mobile phone/smartphone. According to the results of the VTsIOM study, the conclusions were drawn: "The Internet is increasingly having a real and quite tangible impact on everyday life." Thus, the Internet, digital technologies and devices have become new cultural and historical tools that mediate the activities and communications of modern man. For a person of "i" generation, everyday life is connected with a number, now, L. Rosen believes, one must "take advantage" of their love for technology and reorient education, coordinating it with individual human needs [22].

The Internet, as a phenomenon of digital culture, is multifunctional. N. B. Kirillova singles out as one of the essential functions singles out the economic function associated with commercialization, the effectiveness of information technologies and products [13, p. 219-220].

\section{RESEARCH RESULTS AND DISCUSSION}

The media market is quite impressive. As far back as the 1990s, radical structural and functional changes took place in the domestic television and radio broadcasting, associated with the commercialization of the media sphere, which becomes an element of the market system, subject to the laws of its functioning [13]. The logic of the process of commercialization of the media sphere is as follows: the accumulation of functioning media structures, the buildup of material, financial, intellectual resources necessary for the production and distribution of content. So, at the beginning of the XXI century, such media holdings as VGTRK (channels "Russia", "Culture", central radio stations "Radio of Russia", "Mayak", "Youth", "Orpheus", international broadcasting and 92 regional state television and radio companies were formed), Gazprommedia group (NTV, NTV + channels and other channels). If we characterize the modern media market, we can note its dynamics, caused in particular by the rapid development of the Internet, the advent of digital broadcasting channels, electronic publications (Table 1, Fig. 1).

Table 1

Public register of the broadcasting infrastructure of the Russian Federation (sample based on data from the central cities of the Federal Districts as of June 2020) [29]

\begin{tabular}{|l|c|c|c|c|c|}
\hline \multirow{2}{*}{ Name of the Federal District (FD) } & \multicolumn{2}{|c|}{ Radio broadcasting } & \multicolumn{2}{|c|}{ Television broadcasting } & $\begin{array}{c}\text { Broadcast } \\
\text { Cable }\end{array}$ \\
\cline { 2 - 5 } & $\begin{array}{c}\text { number of } \\
\text { DCh* }\end{array}$ & $\begin{array}{c}\text { number of } \\
\text { ACh** }\end{array}$ & $\begin{array}{c}\text { number of } \\
\text { DCh* }\end{array}$ & $\begin{array}{c}\text { number of } \\
\text { ACh** }\end{array}$ & $\begin{array}{c}\text { CTV*** } \\
\text { number of } \\
\text { channels }\end{array}$ \\
\hline $\begin{array}{l}\text { Central Federal District (center - } \\
\text { Moscow) }\end{array}$ & 63 & 79 & 672 & 10 & 6697 \\
\hline $\begin{array}{l}\text { North-West Federal District (center }- \\
\text { St. Petersburg) }\end{array}$ & 3 & 69 & 680 & 13 & 4350 \\
\hline $\begin{array}{l}\text { Southern Federal District (center }- \\
\text { Rostov-on-Don) }\end{array}$ & 3 & 20 & 20 & 16 & 845 \\
\hline
\end{tabular}




\begin{tabular}{|l|c|c|c|c|c|}
\hline $\begin{array}{l}\text { North Caucasian Federal District } \\
\text { (center - Pyatigorsk) }\end{array}$ & 3 & 21 & 20 & 15 & 493 \\
\hline $\begin{array}{l}\text { Volga Federal District (center - Nizhny } \\
\text { Novgorod) }\end{array}$ & 3 & 33 & 20 & 11 & 1314 \\
\hline $\begin{array}{l}\text { Ural Federal District (center - } \\
\text { Ekaterinburg) }\end{array}$ & 3 & 40 & 20 & 8 & 2354 \\
\hline $\begin{array}{l}\text { Siberian Federal District (center - } \\
\text { Novosibirsk) }\end{array}$ & 3 & 29 & 20 & 13 & 637 \\
\hline $\begin{array}{l}\text { Far Eastern Federal District (center - } \\
\text { Vladivostok) }\end{array}$ & 3 & 14 & 1132 & 6 & 973 \\
\hline
\end{tabular}

* DCh - digital channels.

** ACh - analog channels.

*** CTV - cable television.

Figure 1 shows the distribution of registered media by type based on data from the Federal Service for Supervision of Communications, Information Technologies and Mass Communications, which, in accordance with the Federal Law "On Mass Media" [28], maintains a unified all-Russian register of registered media [6].

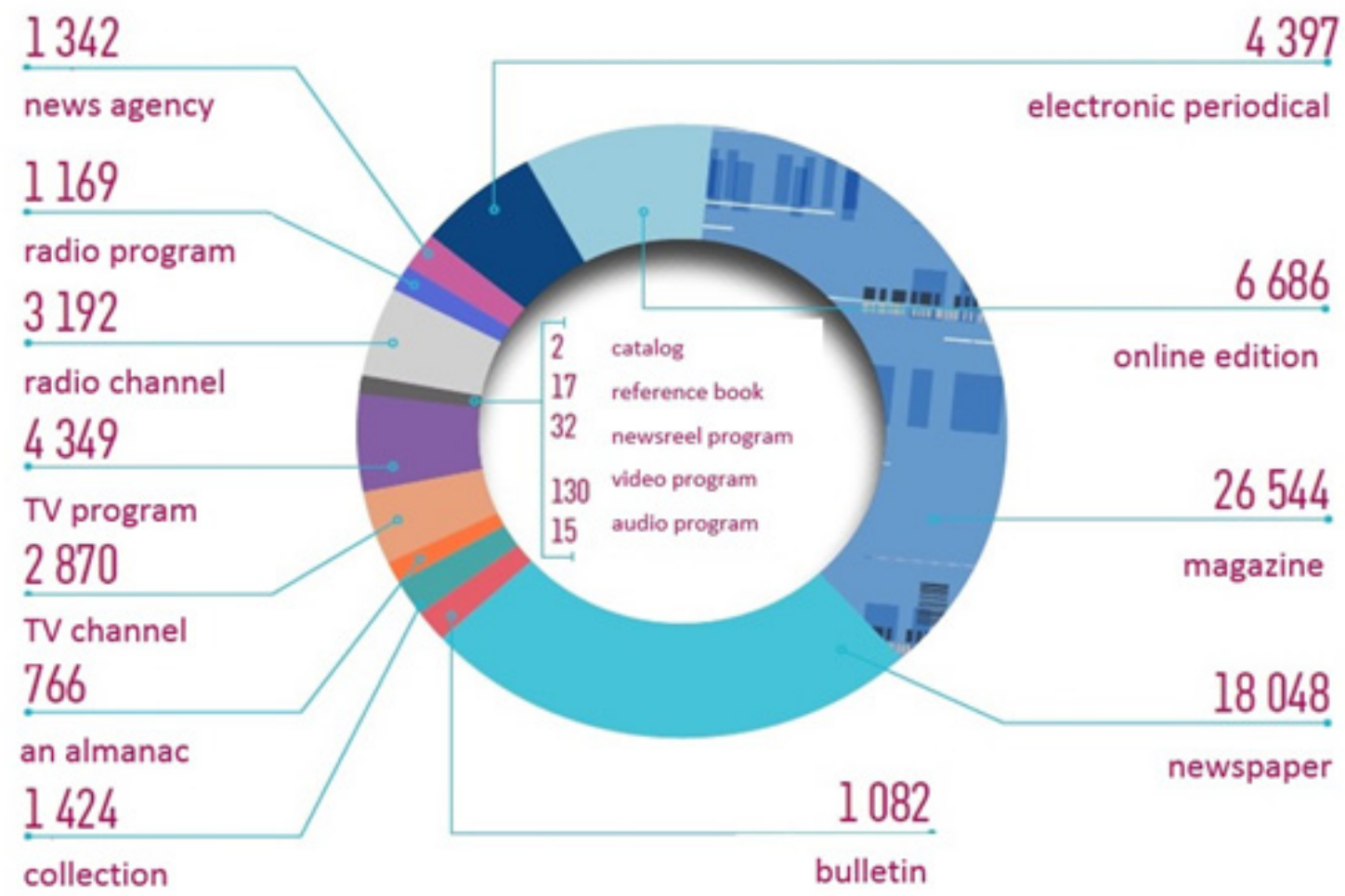

Figure 1 Distribution of registered media by type (2018)

Educational content is being promoted in all media, new media. In the field of education, due to the wave of technological innovations, a new space of new educational initiatives and educational projects (educational startups) that are created from scratch is being formed. Such educational projects were called "Greenfield", which refers to the meaning of the English word "greenfield" - a project that does not have any restrictions imposed by the previous work. "Greenfield" in education is not a mastered space where it is entirely comfortable, without adjusting to the existing contours, projects that have received the unique name "EdTech" are being mastered. 
In the educational services market, both state and private companies act as subjects. Many rating agencies monitor and analyze the effectiveness of the economic activities of companies offering educational content. Let us analyze the results of the rating of private Russian EdTech companies according to the results of 2018, presented by the media holding RosBusinessConsulting (after this - RBC) [31]. The rating was prepared by A. Basov (RBC), D. Karakash (IIDF), A. Soloviev (Skolkovo Digital), D. Starikov (cluster of the Skolkovo IT Foundation), N. Tsarevskaya-Dyakina (EdTech-accelerator Ed2).

The largest Russian companies EdTech (companies of technological educational projects) were included in the rating. In contrast, the position in the rating was determined by the size of revenue for the year. It should be noted that the rating did not include international projects, projects of state organizations and universities for which EdTech is an applied activity (for example, the Open Education platform).

Table 2

The largest EdTech companies in Russia: RBC rating (company data, Contour Focus systems, open sources, 2018) [31]

\begin{tabular}{|c|l|l|}
\hline No & \multicolumn{1}{|c|}{ Name of company } & \\
\hline 1 & Skyeng & P 1100 million \\
\hline 2 & «Netologiya-group» & P 780 million \\
\hline 3 & iSpring & P627 million \\
\hline 4 & MAXIMUM Edukation & P600 million \\
\hline 5 & «Umney» ("Smarter") & P560 million \\
\hline 6 & SkillBox & P540 million \\
\hline 7 & «UCHi.RU» & P500 million \\
\hline 8 & «Dnevnic.ru» & P500 million \\
\hline 9 & GeekBrains & P480 million \\
\hline 10 & «GetCourse» & P420 million \\
\hline 11 & «Mirapolis» & P368 million \\
\hline 12 & «Your tutor» & P300 million \\
\hline 13 & «Info-lesson» & P246 million \\
\hline 14 & City Business School & P207 million \\
\hline 15 & Lingualeo & P200 million \\
\hline 16 & InternetUrok & P175 million \\
\hline 17 & Company group Puzlle Englich & P170 million \\
\hline 18 & Easy Ten & P150 million \\
\hline 19 & Sikorsky Academy & P145 million \\
\hline 20 & «Algoritmica» & P143 million \\
\hline 21 & «Vikium» & P135 million \\
\hline 22 & eQueo & P130 million \\
\hline 23 & «Universarium» & P120 million \\
\hline 24 & EnglishDom & P110 million \\
\hline 25 & HTML Academy & P101 million \\
\hline 26 & YaClass & P100 million \\
\hline & & \\
\hline
\end{tabular}




\begin{tabular}{|l|l|l|}
\hline 27 & Inlearno & P95 million \\
\hline 28 & Teachbase & P95 million \\
\hline 29 & Skill Cup & P94 million \\
\hline 30 & «Netrica» & P89 million \\
\hline 31 & Otus & P80 million \\
\hline 32 & FROO & P74 million \\
\hline 33 & Uniweb JetSkills JetSpeak LiveCV JetTrack & P70 million \\
\hline 34 & SkillFactory & P61 million \\
\hline 35 & Eduson & P60 million \\
\hline
\end{tabular}

EdTech consists of many segments; namely, the system projects Uchi.ru, Diary.ru, Infourok, YaClass and others; P2P training, online lessons, applications, training content that attracts and holds the audience in the face of intense competition. Many Russian companies in the EdTech sector are successfully operating on the Russian market (Table 2). Based on the rating data, it can be concluded that users of educational media products need affordable and high-quality educational content for all levels of education and in different fields of knowledge, and the EdTech market, in turn, is an actively developing segment of the media market.

It should be noted that the Moscow School of Management SKOLKOVO is a serious participant in the educational services market, actively working to promote the range of educational programs (for example, Executive coaching; LIVE Startup Academy; School of Rectors; School development step; Startup Academy Junior; Career navigator Junior LIVE and other programs) taking into account existing needs and built on the principle of "learning through action" [8]. According to analysts, educational projects are promising, since most of them are financed from the proceeds from sales.

The educational segment of the media market in the context of digitalization is a dynamically developing market with pronounced educational trends. Consider the fundamental educational trends of the modern media market N. Tsarevskaya-Dyakina believes that digitalization has served as an important factor in the development of educational trends such as online learning, individualization, tutoring, mentoring, "lifelong learning" [31]. D. Karakash (IIDF) identifies commercial lines that are more promising on the EdTech market, such as the development of system projects (Uchi.ru, Diary.ru and other projects), online courses in creative specialities, gamification and neuro device applications, in which reflects the global educational trend, manifested in the dominance of entertainment educational content - "entertainment", which attracts and retains an audience in a competitive environment in the educational segment of the media market [31]. A. Basov (RBC) speaks of digitalization as a factor in increasing the effectiveness and accessibility of education, including "the creation of educational content, services for selecting educational programs, educational aggregator platforms, solutions for managing personal, educational paths and knowledge verification technologies" [31]. D. Starikov (Skolkovo) provides the following data: thanks to EdTech Skolkovo projects, the target audience increased by 50\% over the year; EdTech Skolkovo projects in 2021 can close $80 \%$ of the domestic online education market; such large companies as Sberbank and Yandex are unfolding in the educational segment of the media market, which is projected to capture 
a significant market share; the appearance of popular startups in preschool, general and additional education of children and adults; the need for personalized content and technological solutions for its selection [31]. A. Soloviev (Skolkovo Digital venture partner) emphasizes the rapid growth of EdTech: 2017 - EdTech is not in the top ten investment segments, 2018 - the educational segment entered the TOP-5 segments for investment, since there are business models in this segment, for example, an online school [31]. Online education, and, along with it, adaptive blended learning, says A. Soloviev.

Table 3

Educational trends in online learning and factors influencing their promotion

\begin{tabular}{|c|c|}
\hline Educational trend & Factors Affecting Educational Trends \\
\hline Individual learning path & $\begin{array}{l}\text { A request for an individual educational trajectory, a flexible educational } \\
\text { route, an individual educational program. } \\
\text { The development of EdMarket. } \\
\text { The modular structure of the educational product line. }\end{array}$ \\
\hline Lifelong learning & $\begin{array}{l}\text { Production and consumption of educational content for all ages. } \\
\text { Labour market transformation }\end{array}$ \\
\hline Mobile learning & $\begin{array}{l}\text { Development of applications for mobile devices that provide the } \\
\text { opportunity to consume educational products in a convenient place for } \\
\text { the user. }\end{array}$ \\
\hline Online Learning & $\begin{array}{l}\text { Design and promotion of online courses. } \\
\text { A variety of additional options (feedback, course mastery control, } \\
\text { course mastery diagnostics and other options). }\end{array}$ \\
\hline Practical orientation of training & An educational product, such as online case-based courses. \\
\hline Internships and employment & $\begin{array}{l}\text { An educational product, including an internship (practical) module. } \\
\text { Proposals related to the possibility of the practical development of } \\
\text { knowledge and the guarantee of subsequent employment. }\end{array}$ \\
\hline Blended learning & Educational courses that include online and offline training. \\
\hline Multiformat training & $\begin{array}{l}\text { Online courses are offering educational content in the video, audio, test } \\
\text { format and other formats. }\end{array}$ \\
\hline Gamification & Online courses with gaming technology. \\
\hline $\begin{array}{l}\text { The trend towards the creation of } \\
\text { community and networking }\end{array}$ & $\begin{array}{l}\text { An educational product with resources for networking, building } \\
\text { relationships with people to solve various kinds of tasks (social, } \\
\text { professional), and providing mutual assistance. }\end{array}$ \\
\hline
\end{tabular}

D. Evstafiev, L. Tsyganova note that the sociocultural multi-vector becomes a reality of the virtual world [9]. Moreover, it is in education that, first of all, in new and understandable formats, the consequences caused by the pandemic crisis are manifested. In connection with the transition of educational organizations in conditions of social isolation to the distance learning format, all areas of activity are implemented through Internet information resources. The need for the development of digital tools and digital services has grown; practices such as Zoom conferences on-line (remote presence) have gained importance.

McKinsey \& Company has the goal to assist universities in preparing for various work scenarios during the primary campaign. McKinsey \& Company conducted a study of the moods of graduates. As a result, it was found that graduates of schools, despite the expanding On-line 
education, still have higher education in priority [5]. At the same time, the question arises: will classical education continue as a social institution with sustainable social communications? We see a connection between the processes occurring in education in a pandemic and the further development of lifelong education, digital didactics, information educational technologies, the expansion of mixed and distance learning formats at all levels of education.

It is evident that in the context of digitalization, the pandemic as a milestone event not only led to the promotion of educational content thanks to the Internet, On-line digital resources (on-line training, on-line conferences), platforms made it possible to design individual educational strategies, but also increased the demand for EdTech-projects, educational content, as a result, the number of users of the product of the company "Uchi.ru" increased by 50\%, "Pearson" - by 400\% [31].

Here are the results of the research - TOP-5 platforms for video conferencing, conducted by Medialogia, a developer of an automatic system for monitoring and analyzing media and social media in real-time from April 1, 2020, to May 11, 2020 (Fig. 2). The research methodology includes: posting messages on Twitter, VKontakte, Odnoklassniki, Facebook, Instagram, YouTube, Telegram, TikTok, forums and blogs; ranking on the SM Index (in thousand) [20].

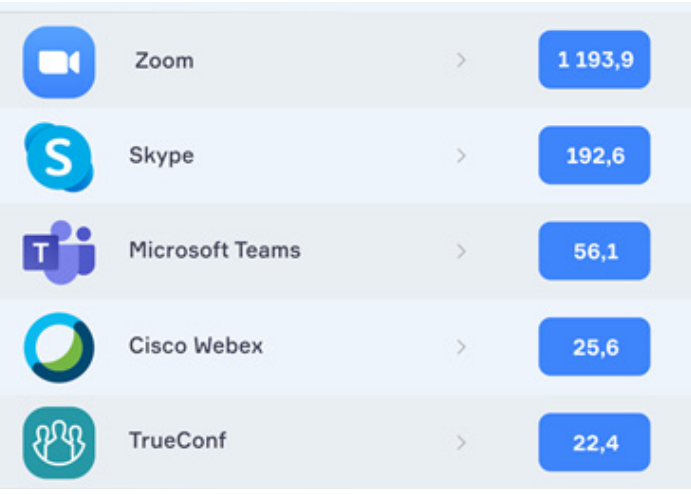

Figure 2 TOP-5 platforms for video conferencing

During the spread of COVID-19 and in connection with the transition of educational organizations to the remote interactive learning mode, digital educational content became more popular, the promotion of which was facilitated by the latest technological solutions, for example, Zoom Video Communications. Zoom turned out to be the most popular and affordable option, as evidenced by the dynamics of Zoom revenue (Fig. 3).

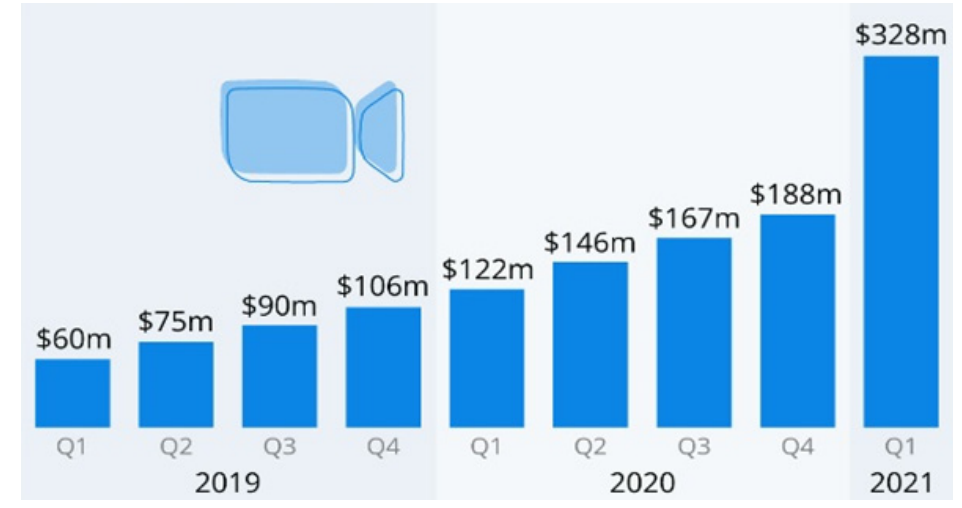

Figure 3 Zoom revenue dynamics for the period from 01.01.2019 to the present (with a forecast for 3-4 Q 2020, 1 Q 2021) 
The dynamics of demand testifies to the high demand for this method of communication, transmission and exchange of information, about the integration of Zoom in to study, work, everyday life. Zoom was especially in demand in the educational segment of the media market. The company's revenue in the indicated period (Fig. 3) will increase by $169 \%$ and amount to $\$ 328 \mathrm{~m}$.

It should be noted that under the current conditions, the experiment on providing data transfer services to citizens and providing access to the Internet information and telecommunication network in the Russian Federation for the use of socially significant information resources in the Internet information and telecommunication network is socially significant. One of the goals of the pilot project for citizens in self-isolation is to ensure comfortable citizens receive free of charge the necessary information. The list of Internet resources includes information resources from the field of "Education and Training" [21].

\section{CONCLUSION}

The active introduction of digital technologies in the media sphere determines its development, which has become an integral part of the media market. The digital development of the media sphere must comply with the principles of digital freedom: the principle of freedom for citizens, the principle of freedom for business, the principle of responsibility, the principle of responding to challenges in the digital sphere. In general, the media market associated with the production and promotion of media content is actively developing, with the educational segment playing a significant role in it. The educational content market covers all traditional media and new media and it is actively developing on all platforms.

The educational segment of the media market in the context of digitalization is a dynamically developing market with pronounced educational trends, one of which is lifelong learning, associated with the production and consumption of educational content for all ages, individual educational paths.

\section{ACKNOWLEDGMENTS}

The reported study was funded by RFBR, project number 20-013-00813 "Educational potential of the media sphere as a space for the development of legal culture and human rights culture in modern Russia". 


\section{REFERENCES}

1. Antipov, A. A. (2018). Cultural and philosophical foundations of digital culture. Man. Society. Inclusion, 2 (34), 37-44 (in Russian).

2. Astafyeva, O. N., Nikonorova, E. V., \& Shlykova, O. V. (2018). Culture in digital civilization: a new stage in understanding the strategy of the future for sustainable development. Observatory of Culture, 5 (15), 519 (in Russian).

3. Astafyeva, O. N., Nikonorova, E. V., \& Shlykova, O. V. (2019). Digital culture: a new stage in the transformation and understanding of the smart future strategy. Information era: new paradigms of culture and education: monograph / N. B. Kirillova (Ed.). Ekaterinburg, Publishing House Ural. University, 2019, 46-68 (in Russian).

4. Castells, M. Galaxy Internet: Reflections on the Internet, business and society / A. Matveeva (Trans.; V. Kharitonova (Ed.). Ekaterinburg, U-Factoria Publ., 2004, 5 (in Russian).

5. Charag, Krishnan, Jonathan, K. Law. COVID-19 and US higher education enrollment: Praparing leaders for fall [Electronic resource]. Retrieved from: https://www. mckinsey.com/industries/social-sector/our-insights/covid-19-and-us-higher-educationenrollment-preparing-leaders-for-fall (Access mode: 21.05.2020).

6. Distribution of registered media by type / Public report of the Federal Service for Supervision of Communications, Information Technologies and Mass Communications. The 2018 year. Moscow, 2019, p. 48 [Electronic resource]. Retrieved from: https://rkn. gov.ru/docs/doc_2406.pdf (Access mode: 06.16 2020) (in Russian).

7. Dovbysh, O. (2015). Media Markets in the Focus of Social Network Analysis. Journal of Economic Sociology = Ekonomicheskaya sotsiologiya, 4 (16), 85-107. Retrieved from: http://ecsoc.hse.ru/2015-16-4.html (in Russian).

8. Educational programs [Electronic resource]. Retrieved from: https://common.skolkovo. ru/ru/educational-programmes/ (Access mode: 15.05.2020) (in Russian).

9. Evstafiev, D., Tsyganova, L. Transformations of social space as a premonition of a new world [Electronic resource]. Retrieved from: https://www.hse.ru/news/community/362878514. html (Access mode: 07.05.2020) (in Russian).

10. Hammet, F. (1993). Virtual Reality. New York, Straus Ed. Publ., 112.

11. How to understand digital transformation? Working paper by the Institute for Emerging Market Research, SKOLKOVO Business School (IEMS). 2017, 34. [Electronic resource]. Retrieved from: https://iems.skolkovo.ru/downloads/documents/SKOLKOVO_IEMS/ Research_Reports/SKOLKOVO_IEMS_Research_2017-05-18_en.pdf (Access mode: 04.04.2020) (in Russian).

12. Jenkins, H., Clinton, K., \& Purushotma, R. etc. (2006). Confronting the Challenges of Participatory Culture: Media Education for the 21st Century, 3.

13. Kirillova, N. B. (2008). Media management as an integrating system. Moscow, Academic project Publ., 412.

14. Kirillova, N. B. (2008). The diversity of cultures in the global media space and the search for a new identity. Media management as an integrating system. Moscow, Academic Project Publ., 51-66 (in Russian). 
15. Kirillova, N. B. (2017). The global media environment as the evolution of media culture. The Paradoxes of Media Civilization: selected articles, Ekaterinburg, Publishing House Ural. Univ., 7-19 (in Russian).

16. Kovaleva, T. M. (2010). Organization of tutoring in a modern school. Problems of modern education, 4, 19-23 (in Russian).

17. Lanier, J. (2012). You Are Not a Gadget. London, Penguin Books, 240.

18. Lem, S. (1964). Summa Technologiae. Krakw, Wydawnictwo Literackie, 501.

19. McLuhan, M. (2003). Understanding Media: External Extensions of Man / V. G. Nikolaev (Trans.). Moscow, Hyperborea; Kuchkovo Field Publ., 464. (in Russian).

20.Medialogy [Electronic resource]. Retrieved from: https://www.mlg.ru/products/smm/ (Access mode: 21.06.2020) (in Russian).

21. Order of the Ministry of Telecom and Mass Communications of Russia No. 148 of 03/31/2020, "On an experiment on providing citizens with free of charge communication services for data transfer and providing access to the information and telecommunication network "Internet" in the Russian Federation to use socially significant information resources in information and telecommunication network "Internet" [Electronic resource]. Access mode: https://digital.gov.ru/ru/documents/7146/ (Access mode: 01.06.2020) (in Russian).

22. Rosen, L. (2007). Teaching the iGeneration. Educational Leadership, 68 (5), 10-15.

23. Schwarz, M. E-Culture: Crossovers and Challenges [Electronic resource]. Retrieved from: http://eculturefactory.de/download/schwarz.pdf (Access mode: 01.04.2020).

24. Smetankina, L. V., \& Shabanov, L. V. (2018). Culture of creativity in the globalization project (socio-philosophical analysis / Creativity as a national element: media and social activity: a collection of articles. St. Petersburg, Publishing House of St. Petersburg State University of Economics, 414-421 (in Russian).

25. Soldatova, G. U., Rasskazova, E. I., Chigarkova, S. V., \& Lvova, E. N. (2018). Digital culture: rules, responsibility and regulation / Digital society as a cultural-historical context of human development: a collection of scientific articles. Kolomna, State Social and Humanitarian University Publ., 374-379 (in Russian).

26. Stepin, V. S., \& Kuznetsova, L. F. (1994). Scientific picture of the world in the culture of technogenic civilization. Moscow, IFRAN Publ., 274 p. (in Russian).

27. Tapscott, D. Growing up digital: The rise of the Net Generation. New York, McGrawHill Publ., 1999.

28. The law of the Russian Federation dated 12.27.1991 No. 2124-1 (as amended on 01.03.2020) "On the media" [Electronic resource]. Retrieved from: http://docs.cntd.ru/ document/9003299 (accessed date: 12.06 2020) (in Russian).

29. The public register of the communications and broadcasting infrastructure of the Russian Federation [Electronic resource]. Retrieved from: http://reestr-svyaz.rkn.gov.ru/ (Access mode: 12.06.2020) (in Russian).

30. Veltmann, K. (2002). Electronic culture: achievements and prospects. Information Society, 1, 24-30 (in Russian).

31. Largest EdTech companies in Russia: $R B C$ rating [Electronic resource]. Retrieved from: https://trends.rbc.ru/trends/education/5d68e8fb9a7947360f1e2e52 (Access mode: 03.05.2020) (in Russian). 


\section{INFORMATION ABOUT THE AUTHORS}

1. Natalia B. Kirillova (Russia, Ekaterinburg) - Professor, Doctor of Culturology, Head of the Department of Culturology and socio-cultural activities, Department of Art, Culturology and Design . Ural Federal University named after the first President of Russia B. N. Yeltsin. E-mail: n.b.kirillova@urfu.ru. Scopus ID: 57215900537

2. Olga N. Tomyuk (Russia, Ekaterinburg) - Senior Lecturer, Department of Ontology and Theory of Knowledge, Department of Philosophy. Ural Federal University named after the first President of Russia B.N. Yeltsin. E-mail: olga.tomyuk@urfu.ru. Scopus ID: 57211983935

3. Margarita A. Dyachkova (Russia, Ekaterinburg) - Associate Professor, PhD in Pedagogical Sciences, Associate Professor of the Department of Art Education. Ural State Pedagogical University. E-mail: dyachkova.margarita@yandex.ru. Scopus ID: 57211982998 


\section{A. Kravchenko, N. R. Pashuk, A. A. Vertinova, I. A. Bedrachuk \\ Trends and priority areas of state policy development in higher education for the period of 2000-2020}

\section{KEYWORDS}

education;

higher education;

state policy;

coordination of priority areas and results;

federal targeted programs for education development;

priority areas;

regulatory legal acts

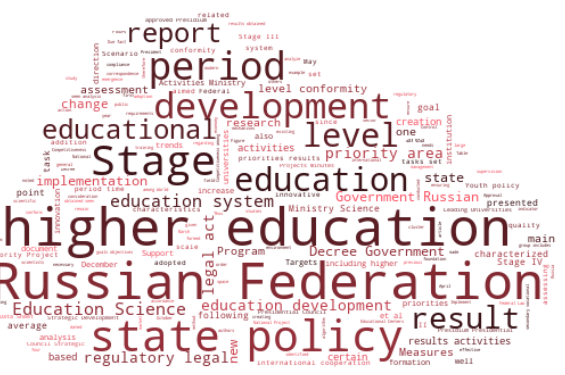

Word Cloud Generated by:

https://wordscloud.pythonanywhere.com/

\section{ABSTRACT}

The purpose of this article is to compare the results of the implementation of regulatory legal acts related to state policy in higher education, adopted for the period of 2000-2020, with the developed priority areas in education. According to the reports on the results of the activities of the Ministry of Science and Higher Education of the Russian Federation for the same period, the priority areas in higher education and the results of legislative framework functioning for the period under study were analyzed. As a result, four stages of state policy in higher education were identified (such grouping is determined by the periods of validity of the considered regulatory legal acts), including documents that regulate the education system as a whole and are narrowly focused on higher education. It should be noted that the implementation of the fourth stage has not yet been completed due to the fact that the period of validity of regulatory legal acts ends in 2020; therefore, several scenarios of the course of events were made up. Based on this study, an approach was formed to assess the conformity of priority areas and the results of state policy in the field of higher education, which helped to identify "bottlenecks" in the control over the implementation of the defined priorities.

Kravchenko, L. A., Pashuk, N. R., Vertinova, A. A., \& Bedrachuk, I. A. (2020). Trends and priority areas of state policy development in higher education for the period of 2000-2020. Economic consultant, 30 (2), 6275. doi: $10.46224 /$ ecoc.2020.2.6 


\section{INTRODUCTION}

A $s$ a result of the changes in world trends, including mass education, the implementation of the "third mission" by universities [1], the growth in the number of specialties, the market orientation of educational institutions, over the past decades the large-scale changes have taken place in higher education, which are characterized by a change in the paradigm of education, the restructuring of the education management system, the creation of new tools, methods, and sets of measures for the effective functioning and development of universities in Russia and at the international level. These actions were the result of the fact that the education system, formed over a long period of time, being conservative [2], is changing under the influence of modern social relations, requiring from the education sector the constant and dynamic development, meeting new quality requirements made by all interested parties.

Today, the education system in the Russian Federation is being reformed. The reform process has affected and given the new meaning to the goals, tasks, and functions implemented by universities in their activities. Many of them were reorganized, others received new statuses, reflecting their special significance both at the regional and national levels. Thus, the changes and modernization of higher education are accompanied by the formation, testing and adaptation of completely new institutions and mechanisms that are based on the principles of the new public management. For example, the shift to managerial skills and competencies, the transition to the activities based on effective contracts, the consideration of the result of activities as an object of managerial activity [3]. To a greater or lesser extent, these principles are reviewed throughout the entire period of reforming the higher education system and are institutionalized in regulatory legal acts that regulate all processes occurring in the higher education system.

Any change in the reform process is fixed at the legislative level; therefore, the issue of the state policy evolution in higher education and evaluation of its implementation remains relevant. Consequently, in the context of ongoing state organizational and institutional changes in the higher education system, the research objective is to review the approved regulatory legal acts and to identify the correspondence between the goals, objectives, and the results of the activities of state authorities in higher education. The consideration of the period from 2000 to 2020 is the most relevant, since during this period, the large-scale changes in higher education took place.

\section{MATERIALS AND METHODS}

Based on the literature review in the field of state policy, including in higher education, four research groups can be identified.

The first and largest is the group, which includes the studies aimed at analyzing the main characteristics of the country's state policy in education, including higher education at a certain point in time. 
An example is the scientific results reflected in the article by Kotenev and Kuzmin, where the authors analyze the main documents that determine the priorities for education development in Russia as of 2015. Similar results were achieved in the studies conducted by Ivanova [4], Rostova [5], Chernykh [6], where the main vector of state policy in education in Russia is considered and the authors' assessment of its effectiveness is given. This group also includes the reports of UNESCO [7] and the OECD Centre for Educational Research and Innovation (CERI) [8], as well as the ones made by scientists such as Madani [9], Magnbsson et al. [10] and others.

It is worth noting that in the study of state policy in education, the main role is given to the Federal Law "On Education in the Russian Federation", the analysis of versions of which is reflected in research papers by Agarkova [11], Chekmarev and Matershev [12], and Poskonina [13]. Grinevich et al. [14] pay special attention to the priorities of state policy in international education, which is aimed at creating and supporting the country's image and its cultural attractiveness. In addition, such economists as Korotkova [15], Andryushina and Lutsenko [16], Bespalov et al. [17], Alexandrov et al. [18], Tokarskaya and Zhukova [19], Nosov [20], Pankova [21], Lapenkova [22] and many other scientists studied the state of Russian state policy and legal regulation in education and in the field of educational services.

The second group includes scientific papers that examine the main trends in reforming the educational system, including the higher education system, over a certain period of time.

For example, Komkov in his article analyzed the reforms of the education system in Russia, carried out in the period of 1990-2013 [23]. Characteristics of the state strategy for primary and secondary vocational education development for the period of 2001-2011 are found in the works by Skovorodneva [24]. Trends in setting goals of state policy in education for the period of 2000-2013 are presented in the work by Magalnik [25], while Nasutseva analyzes the effectiveness of the state policy for the period of 2000-2010 [26]. The analysis of documents regulating the education sector of Pakistan from 1947 to 2017 was conducted by the scientists Khushik and Dimer [27]. Eviss et al. [28] examined the state policy of one of the education levels in Egypt for the period of 1990-2017.

The third group includes the studies where the main method is a comparative analysis of the guidelines and priorities of state policy in education, including higher education, between different countries or cities, conducted by Bayramov [29], Yashchuk [30],Nosov [20], Edwards et al. [31], lyengar and Surianarain [32] and others.

The study presented in this article relies on the consideration of state policy in a certain period of time, since in this way it is possible to analyze the changes that have occurred in dynamics over a given period of time. Federal Law "On Education in the Russian Federation" No. 273-FZ dated December 29, 2012 combines the general provisions and rules governing the activities at certain educational levels, including in higher education. This document is also the basis for the creation of other regulatory legal acts in education, and its implementation sets the main trends in education development in general, including higher education. 


\section{RESULTS}

To consider the trends in state policy in the field of higher education over a 20-year period, it was divided into 4 stages: from 2000 to 2005, from 2006 to 2010, from 2011 to 2015, and from 2016 to 2020, in accordance with the terms of validity of the adopted Federal Targeted Education Development Programs (FTEDPs) (Figure 1). It should be noted that at each of the stages, in addition to the documents related to all educational levels, the regulatory legal acts focused on the higher education system were also adopted.

The choice of priority areas is based on the reports of the Ministry of Science and Higher Education of the Russian Federation, while the analysis is carried out only in those areas, the mention of which can be traced both in FTEDPs and in the reports of the Ministry of Science and Higher Education of the Russian Federation.

To analyze the results of a certain stage, the reports of the activities of the Ministry of Science and Higher Education of the Russian Federation for the final year of the stage were studied, since these reports summarized all the activities aimed at higher education development, regarding the achievement of the tasks at a certain stage.

Stage I (2000-2005) was related to the adoption of Federal Law of April 10, 2000 No. 51-FZ "On the Approval of the Federal Education Development Program", which included the following extended tasks: improving the regulatory framework in accordance with existing regulatory documents regulating the activities of the educational system, creating a unified educational space throughout the Russian Federation, the expansion of international cooperation, the development of scientific activity and the unity of education and science. This program contained the goals, content and procedures for the development of the entire education system from 2000 to 2005. This stage is also characterized by the adoption of documents aimed directly at higher education development, the adoption of a model regulation on a higher education institution of the Russian Federation (Decree of the Government of the Russian Federation of September 17, 2001 No. 676) and such concept as a university complex (Decree of the Government of the Russian Federation of April 5, 2001 No. 264). In general, this stage can be characterized as a stage that sets the direction and general goals of future reforms in higher education of the Russian Federation. The conformity of the tasks set and the results obtained can be seen in the analysis of the "Report on the Results of the Activities of the Ministry of Education and Science of the Russian Federation in 2005 and Targets for 2006".

Stage II (2006-2010) was related to the adjustment of existing regulatory legal acts. Thus, according to the amendments made on March 11, 2011 to Decree of the Government of the Russian Federation of December 23, 2005 No. 803 “On the Federal Education Development Program for the Period of 2006-2010", the following targets were formed and enshrined at the statutory level: the formation of a lifelong education system, the improvement of education quality and technology, the development of the practical orientation of educational programs correlating with the needs of citizens, society, and the labor market. 


\begin{tabular}{|l|l|l|l|l|}
\hline \multicolumn{1}{|c|}{ Higher education documents } \\
I. Federal Law of April 10,2000 No. 51-FZ "On the Approval of \\
the Federal Education Development Program"
\end{tabular}

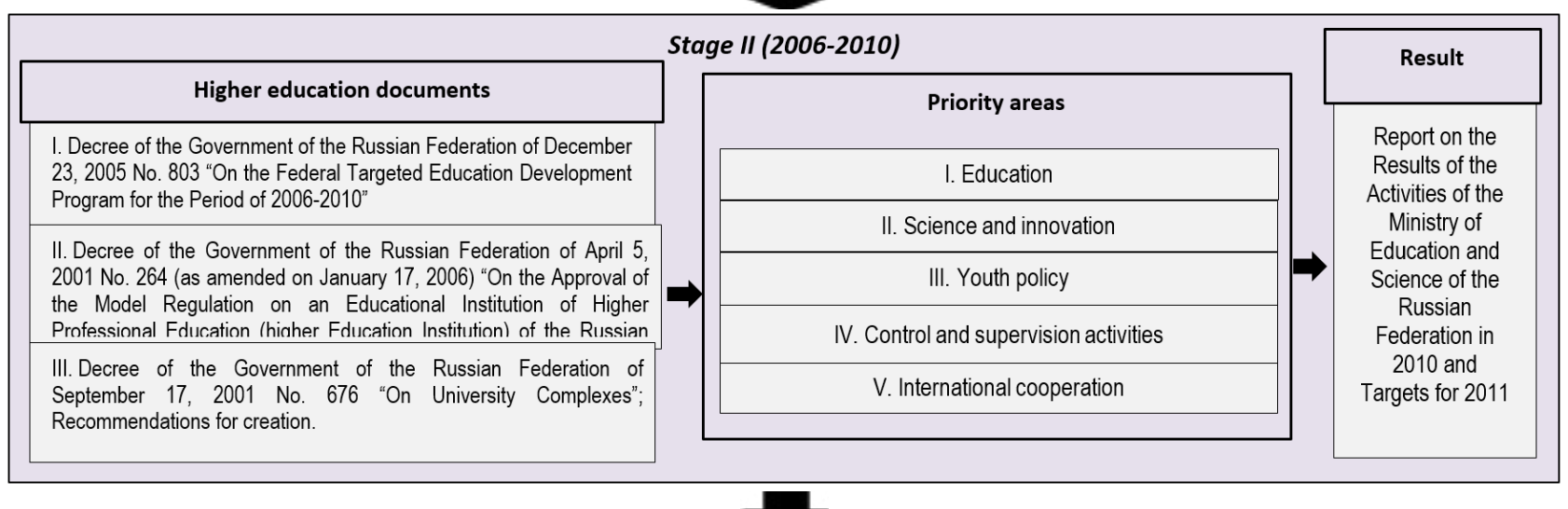

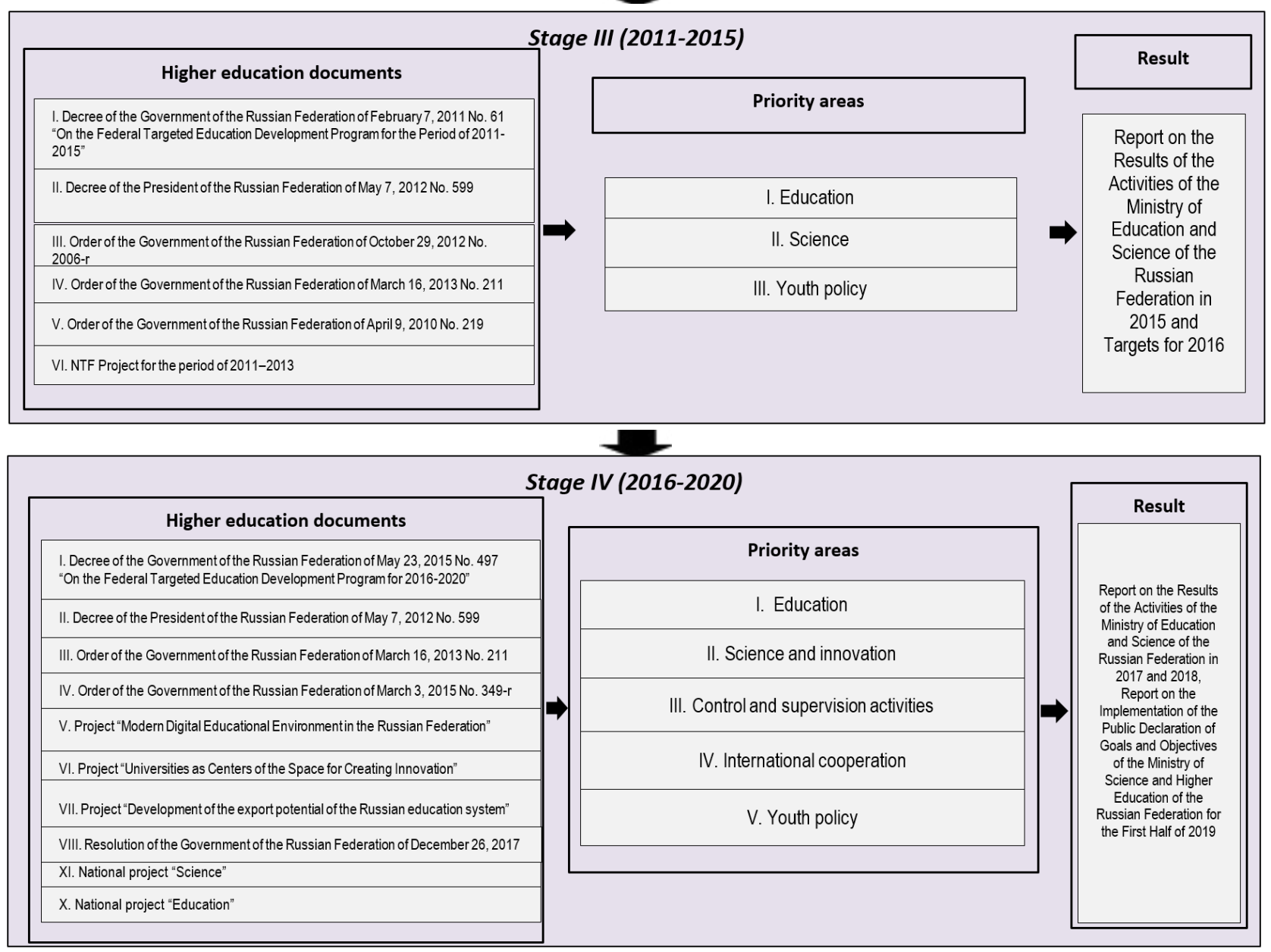

Figure 1 Stages of state policy in higher education 
In the same period of time, Decree of the Government of the Russian Federation of September 17, 2001 No. 676 (as amended on February 14, 2008) "On University Complexes" (Recommendations for Creation) ceased to be effective. It should be noted that during this period, the priority areas for higher education development were adjusted for education, science and innovation, youth policy, international cooperation, as well as the monitoring and supervision direction. The conformity of the tasks set and the results obtained can be seen in the analysis of the "Report on the Results of the Activities of the Ministry of Education and Science of the Russian Federation in 2010 and Targets for 2011".

Stage III (2011-2015) involved further adjustments to the existing education development program, as well as the appearance of the first May decrees of the President of the Russian Federation regarding education, the emergence of such concept as the educational cluster and the creation of additional regulatory legal acts related to higher education. Due to the fact that another goal of FTEDPs for the period of 2011-2015 (Decree of the Government of the Russian Federation of February 7, 2011 No. 61 (as amended on December 25, 2015)) was to ensure the availability of quality education that meets the requirements of innovative socially oriented development of the Russian Federation, the following regulatory legal acts were adopted:

- Decree of the Government of the Russian Federation of April 9, 2010 "On State Support for the Development of Innovative Infrastructure in Federal Educational Institutions of Higher Professional Education", the basis of which is the formation of an innovative environment, the development of interaction between educational institutions and industrial enterprises, support for the creation of business entities;

- Decree of the President of the Russian Federation of May 5, 2012 No. 599 "On Measures to Implement the State Policy in Education and Science", which improves the state policy in education and science and the training of qualified specialists, taking into account the requirements of the innovative economy and develops research and development activities by increasing the volumes of financing of state scientific foundations and foundations of leading universities.

In addition, within FTEDPs for the period of 2011-2015, tasks were identified for the development of the education quality assessment system and the demand for educational services. Following this, Decree of the Government of the Russian Federation dated October 29, 2012 No. 2006-r "On the Approval of the Action Plan for the Development and Improvement of Competitiveness of Russian Leading Universities among the World's Research and Educational Centers" and Decree of the Government of the Russian Federation dated March 16, 2013 No. 211 "On Measures of State Support for Leading Universities of the Russian Federation in order to Increase Their Competitiveness among the World's Leading Research and Educational Centers" were adopted, which provide organizational-economic and regulatory development of leading universities of the Russian Federation to increase their competitiveness among the world's leading research and educational centers. Separately, it is necessary to consider the project of the National Training Foundation (NTF) "The Study of Prerequisites and the Formation of Basic Tools for the Development of Educational Clusters Based on the Network 
Interaction of Leading Engineering Universities with Enterprises and Vocational Education Institutions of Other Levels in the Interests of Developing Priority Sectors of the Economy in the Constituent Entities of the Russian Federation", since it is one of the largest steps taken by the state in ensuring compliance with the needs of the labor market and the region, through the development of mechanisms for the creation and development of multi-level interregional cluster-type systems. Regarding the development priorities, one could say that they have been enlarged to three priorities (education, science, and youth policy), but the remaining tasks, for example, in the direction of international cooperation, were distributed in all directions (the task of "developing bilateral and multilateral international relations in education" in the direction of "science").

This stage is characterized by the emergence of new regulatory legal acts that support the implementation of previous goals and objectives and set the new ones, in particular, with regard to creating the innovative environment of the Russian Federation and the competitiveness of Russian universities. The conformity of the tasks set and the results obtained can be seen in the analysis of the "Report on the Results of the Activities of the Ministry of Education and Science of the Russian Federation in 2015 and Targets for 2016".

Stage IV (2016-2020) entails assistance in the implementation of previous goals and objectives. Thus, in Decree of the Government of the Russian Federation of May 23, 2015 No. 497 "On the Federal Targeted Education Development Program for the Period of 2016-2020", one of the new tasks is the creation and dissemination of structural and technological innovations in secondary vocational and higher education, as well as the creation of infrastructure ensuring the conditions for training staff for the modern economy. In addition, Order of the Government of the Russian Federation of March 3, 2015 No. 349-r "On the Approval of a Set of Measures Aimed at Improving the Secondary Vocational Education System for the Period of 2015-2020" establishes measures to ensure that graduates' qualifications meet the requirements of the modern economy, approves monitoring of the quality of training. During this period, Decree of the President of the Russian Federation of May 5, 2012 No. 599 "On Measures to Implement the State Policy in Education and Science" and Decree of the Government of the Russian Federation of March 16, 2013 No. 211 “On Measures of State Support for Leading Universities of the Russian Federation in order to Increase their Competitiveness among the World's Leading Research and Educational Centers" were adopted. Decree of the Government of the Russian Federation of December 26, 2017 No. 1642 "On the Approval of the State Program of the Russian Federation "Education Development" implements state policy directions in education through measures to ensure global competitiveness of Russian education, increase the proportion of graduates, increase the number of students involved in the activities of public associations.

This stage is characterized by the formation of many projects related to higher education and science: "Data Sheet of the Priority Project "Modern Digital Educational Environment in the Russian Federation" (approved by the Presidium of the Presidential Council for Strategic Development and Priority Projects, Minutes No. 9 of October 25, 2016), "Data Sheet of the 
Priority Project "Universities as Centers of the Space for Creating Innovation" (approved by the Presidium of the Presidential Council for Strategic Development and Priority Projects, Minutes No. 9 of October 25, 2016), "Data Sheet of the Priority Project "Development of the Export Potential of the Russian Education System" (approved by the Presidium of the Presidential Council for Strategic Development and Priority Projects, Minutes No. 6 of May 30, 2017), "Data Sheet of the National Project "Science" (approved by the Presidium of the Presidential Council for Strategic Development and National Projects, Minutes No. 16 of December 24, 2018), "Data Sheet of the National Project "Education" (approved by the Presidium of the Presidential Council for Strategic Development and National Projects, Minutes No. 16 of December 24, 2018). Priority areas of activities are expanding again and becoming narrowly focused; thus, in this period there are 5 priority areas.

Due to the fact that this period is not over yet, one can talk about the conformity of the tasks set and the results obtained when analyzing the "Report on the Results of the Activities of the Ministry of Education and Science of the Russian Federation in 2015 and Targets for 2016", as well as the "Report on the Implementation of the Public Declaration of Goals and Objectives of the Ministry of Science and Higher Education of the Russian Federation for the First Half of 2019".

To assess the identified stages, the authors proposed an approach to assessing the conformity of priority areas and the results of state policy in higher education, based on the methods of qualitative assessments and quantitative interpretation. To carry out a quantitative interpretation of qualitative indicators, a scale was introduced for assessing the level of compliance of priorities and goals identified in regulatory legal acts with the main state policy results presented in progress reports of the Ministry of Science and Higher Education of the Russian Federation. The main characteristics of each area of state policy in points are presented in Table 1.

Table 1

Scale for assessing the level of conformity of priorities and results of state policy in higher education by points

\begin{tabular}{|l|c|l|}
\hline \multicolumn{1}{|c|}{ Level of conformity } & Point & \multicolumn{1}{c|}{ Characteristics } \\
\hline Low level & 1 & Do not conform at all \\
\hline Average level & 2 & Conform with large differences \\
\hline Above-average level & 3 & Conform with slight differences \\
\hline High level & 4 & Fully conform \\
\hline
\end{tabular}

To assign a certain level of conformity, the following assessment algorithm was formed.

This algorithm is based on determining the area of higher education development, then on a comparison between the chosen priority area and the result of the activities of the Ministry of Science and Higher Education of the Russian Federation. 


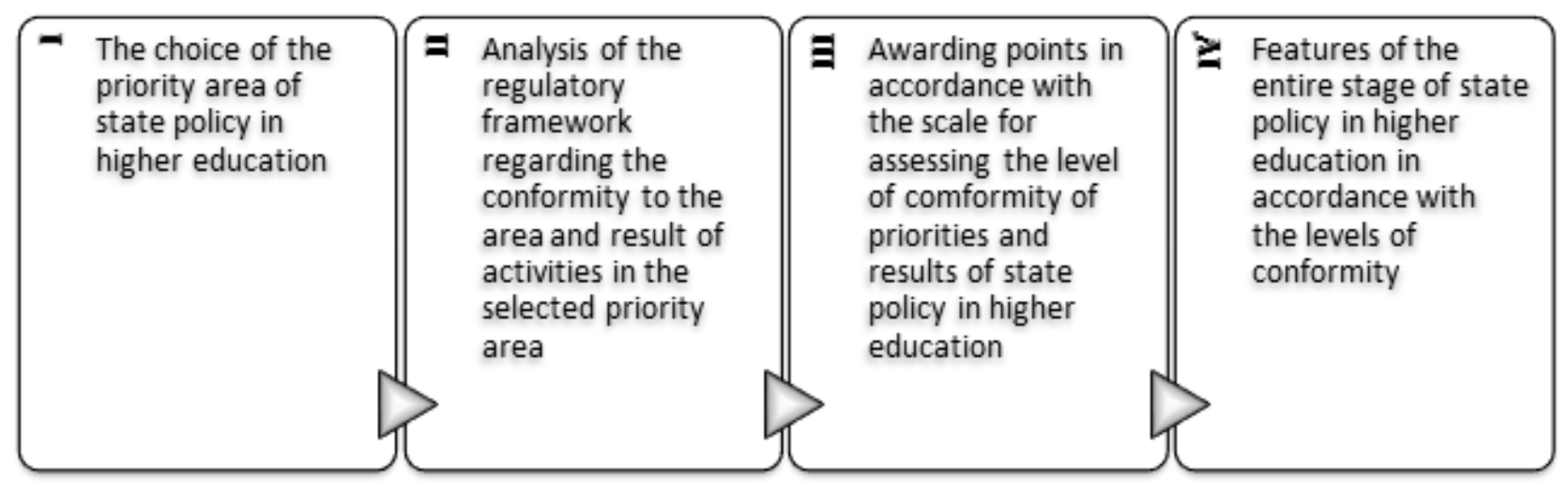

Figure 2 Algorithm for assessing the level of conformity of priority areas and results of state policy in higher education

\section{DISCUSSION}

According to the results of the analysis of the legal framework in education and reports of the Ministry of Science and Higher Education of the Russian Federation, the following points were assigned in each area of state policy, presented in Table 2.

Table 2

Assessment of the level of conformity of priorities and results of state policy in higher education

\begin{tabular}{|c|c|}
\hline Area & Point \\
\hline \multicolumn{2}{|l|}{ Stage I (2000-2005) } \\
\hline Ensuring the unity of the educational space of the Russian Federation & 2 \\
\hline Regulatory support & 2 \\
\hline Development of national cultures, regional cultural traditions and characteristics & 2 \\
\hline Development and maintenance of democratic, state-public management of the education system & 3 \\
\hline Economic mechanisms of the functioning and development of the education system & 2 \\
\hline $\begin{array}{l}\text { Development of international cooperation and international activities of the Russian Federation in } \\
\text { education }\end{array}$ & 2 \\
\hline The average of Stage I & 2.2 \\
\hline \multicolumn{2}{|l|}{ Stage II (2006-2010) } \\
\hline Education & 3 \\
\hline Science and innovation & 3 \\
\hline Youth policy & 2 \\
\hline Control and supervision activities & 2 \\
\hline International cooperation & 2 \\
\hline The average of Stage II & 2.4 \\
\hline \multicolumn{2}{|l|}{ Stage III (2011-2015) } \\
\hline Education & 3 \\
\hline
\end{tabular}




\begin{tabular}{|c|c|c|}
\hline Science & & 3 \\
\hline Youth policy & & 3 \\
\hline & The average of Stage III & 3 \\
\hline \multicolumn{3}{|c|}{ Stage IV (2016-2020) } \\
\hline Education & & 3 \\
\hline Science and innovation & & 3 \\
\hline Youth policy & & 3 \\
\hline International cooperation & & 2 \\
\hline Control and supervision activities & & 3 \\
\hline & The average of Stage IV & 2.8 \\
\hline
\end{tabular}

Therefore, to sum up, it can be concluded that in accordance with the rating scale presented above, Stages I and II are currently assessed at 2.2 and 2.4 points, respectively, which indicates a correspondence between the areas and results with a high degree of deviations, Stage III is above average, unlike the two previous ones, and is characterized by only slight deviations between the priority areas presented in the report results. It should be noted that Stage IV is assessed preliminarily since it ends only in 2020. Based on the foregoing, a schedule of changes in the correspondence between priorities and results of activities can be made up over four stages for the period of 2000-2020.

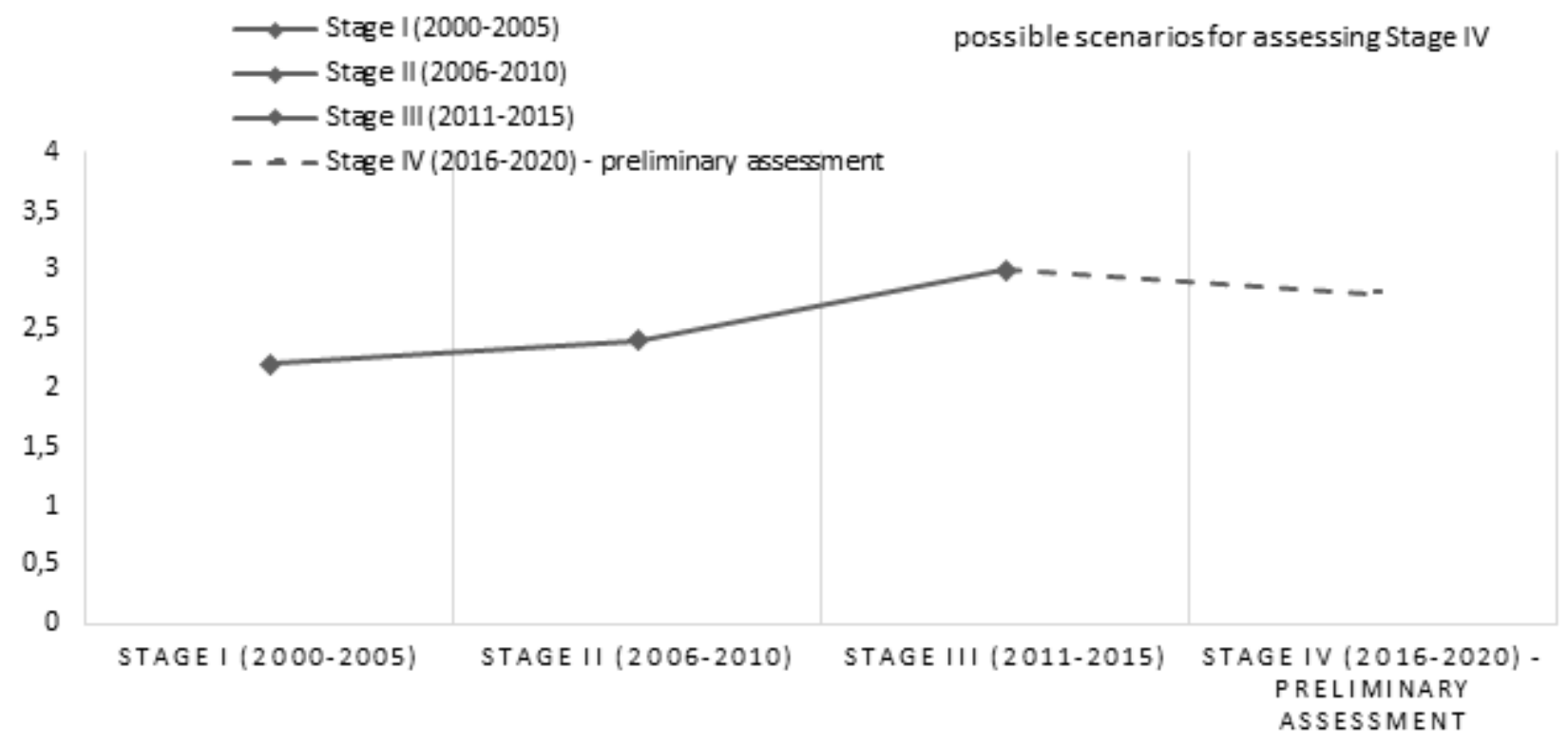

Figure 3 Changes in the correspondence between priorities and results of activities during four stages for the period of 2000-2020

In the graph, the transition from Stage III to Stage IV is indicated by a dashed line due to the fact that there is no final data on the results of this stage; therefore, one can talk about possible scenarios for assessing Stage IV:

- Scenario 1 involves increasing the level of conformity of priority areas and results up to the high level;

- Scenario 2 assumes that the level of conformity will remain at the same level as in the previous period; 
- Scenario 3 involves a decrease in the level of conformity;

- Scenario 4 (preliminary assessment) assumes that the level of conformity will remain at the same level as in the preliminary assessment.

\section{CONCLUSION}

The analysis and assessment of regulatory legal acts in state policy in the field of higher education in priority areas showed that in the 20-year period, the implementation of state policy in higher education can be divided into 4 periods (Stage I - 2000-2005, Stage II - 20062010, Stage III - 2011-2015, Stage IV - 2016-2020). These periods are characterized by the alternation of the stages initiating the new goals and supporting them, as well as the emergence of new regulatory legal acts in each of the stages. However, the assessment confirmed the existence of discrepancies between the results of the implementation of these acts and priority areas; from stage to stage, there is an expansion, then a narrowing of the priority areas, and, consequently, their targets, which confirms the lack of continuity.

There is also a lack of openness in the results of the implementation of a regulatory legal act. This can be proved by the following facts: if there are planned indicators for a specific project, certain time limits, there is no link in the report on the implementation or non-fulfillment of the program. It is also not indicated in which report this indicator can be found. These actions do not allow stakeholders to study and trace the line of state policy in higher education, moreover, it casts doubt on the significance of the tasks set earlier.

Nevertheless, the formation of an effective state policy in higher education requires absolute coherence and transparency in the implementation of regulatory legal acts. For this purpose, it is necessary to constantly monitor the level of conformity of the priorities and results of activities of state authorities in higher education in order to reduce risks and negative trends arising from inconsistencies between the central authority and its subordinate bodies. In addition, it is necessary to strengthen control over observing the consistency between the priorities and the results described in the reports. Certainly, an issue on necessary measures to increase the level of compliance between priority areas and results needs to be addressed separately.

\section{REFERENCES}

1. Santos, G., Marques, C.S., Justino, E., \& Mendes, L. Understanding Social Responsibility's Influence on Service Quality and Student Satisfaction in Higher Education. Journal of Cleaner Production, 256. Retrieved July 15, 2020, from https://www.sciencedirect.com/ science/article/pii/S0959652620306442

2. Dzhavadova, O.M. (2019). Priorities of Government Policy in Education. Law: History and Modernity, 2. Retrieved July 15, 2020, from https://cyberleninka.ru/article/n/ 
prioritety-gosudarstvennoy-politiki-v-sfere-obrazovaniya

3. Maskaev, A.I., \& Savko, P.O. (2019). The Role of Institutional Changes in Higher Education in the Socio-Economic Development of the Region (on the Example of the Rostov Region). Topical Issues of Economics and Law, 4. Retrieved July 15, 2020, from https://cyberleninka.ru/article/n/rol-institutsionalnyh-izmeneniy-v-sfere-vysshegoobrazovaniya-v-sotsialno-ekonomicheskom-razvitii-regiona-na-primere-rostovskoyoblasti

4. Ivanova, V.I. (2012). State Policy in Education as an Indicator of the Effectiveness for Political Modernization in Modern Russia. TuISU Bulletin. Humanitarian Sciences, 2.

5. Rostova, O.S. (2012). Modern Approaches to the Integration of Scientific Knowledge into the Educational Process. Leningrad Law Journal, 4.

6. Chernykh, N.A. (2008). On the Relevance of Modernization of State Policy in Higher Professional Education. ChelSU Herald, 10.

7. UNESCO. (2013). UNESCO Handbook on Education Policy Analysis and Programming. Vol. 1: Education Policy Analysis. Retrieved July 15, 2020, from https://unesdoc.unesco. org/ark:/48223/pf0000221189.

8. Centre for Educational Research and Innovation - CERI. (n.d.). Retrieved July 15, 2020, from http://www.oecd.org/education/ceri/

9. Madani, R.A. (2019). Analysis of Educational Quality, a Goal of Education for All Policy. Higher Education Studies, 9(1). Retrieved July 15, 2020, from https://files.eric.ed.gov/ fulltext/EJ1203706.pdf

10. Magnısson, G., Guransson, K., \& Lindqvist, G. (2019). Contextualizing Inclusive Education in Educational Policy: The Case of Sweden. Nordic Journal of Studies in Educational Policy, 5(2), 67-77. Retrieved July 15, 2020, from https://www.tandfonline. com/doi/full/10.1080/20020317.2019.1586512.

11. Agarkova, D.A. (2013). Principles for the Implementation of State Policy in Education in the Framework of the new Federal Law "On Education in the Russian Federation". State and Municipal Administration Bulletin, 2.

12.Chekmarev, V.V., \& Mathershev, V.V. (2014). Institutionalization of the Russian Education Sector. Economics of Education, 4.

13. Poskonina, O.V. (2015). State Policy of Modern Russia in Higher Education. Udmurt University Bulletin. Series "Economics and Law", 2.

14. Grinevich, Yu.A., Kemaev, K.V., \& Kemaeva, M.V. (2011). The State Policy of Russia in International Education as a Mechanism for the Development of the Real Sector of Economy. NNSU Herald, 5-2.

15. Korotkova, M.V. (2013). Implementation of State Policy in Education. Scientific Notes of the Tambov Branch of RUYS, 1.

16. Andryushina, E.V., \& Lutsenko, N.O. (2014). State Policy of the Russian Federation in Education. Power, 7.

17. Bespalov, M.V., Kotenev, V.A., Kuzmin, A.V., \& Ryakhovskaya, T.V. (2014). State Policy 
and Legal Regulation in Education and the System of Educational Services in Modern Russia. TSU Bulletin, 12(140).

18. Alexandrov, A.Yu., Vereshchak, S.B., \& Ivanova, O.A. (2015). Legal Problems of Correlation of State and Public Control in Higher Education. Topical Issues of Economics and Law, 2(34).

19. Tokarskaya, L.V., \& Zhukova, I.V. (2015). Implementation of the State Policy of the Russian Federation in the Field of Inclusive Education. Society and Power, 5(55).

20. Nosov, A.G. (2016). State Policy in Education - Reforms, Results, Expectations. Saratov University News. New Series. Acmeology of Education. Developmental psychology, 1.

21. Pankova, N.V. (2008). The Influence of Globalization Factors on the State Policy in Higher Education. Scientific and Technical Journal of St. Petersburg State Polytechnic University. Economic Sciences, 3-1(58).

22. Lapenkova, L.A. (2015). General Guidelines of State Policy in Higher Education in Terms of Academic Mobility. Bulletin of the Perm State Pedagogical University. Series No. 1. Psychological and Pedagogical Sciences, 2.

23. Komkov, S.K. (2013). State Policy and Management of Modern Russia in Education. Outlines of Global Transformations: Politics, Economics, Law, 27.

24. Skovorodneva, O.I. (2012). Implementation of State Policy in Vocational Education in Russia (2001-2011): Based on Materials from the South of Russia. VSPU News, 3.

25. Magalnik, L.A. (2013). Trends in Goal-Setting for Top-Level Education in Modern Russia. ISLU Bulletin, 3(24).

26. Nasutseva, F.A. (2012). State Policy in General Education of the Russian Federation for the Period of 2000-2010: The Results of Modernization. VSPU News, 3.

27. Khushik, F., \& Diemer, A. (2018). Critical Analysis of Education Policies in Pakistan: A Sustainable Development Perspective. Social Science Learning Education Journal, 3(09), 01-6. Retrieved July 15, 2020, from http://innovativejournal.in/index.php/sslej/article/ view/2282

28. Ewiss Z.M.A., Abdelgawad F., \& Elgendy, A. (2019). School Educational Policy in Egypt: Societal Assessment Perspective. Journal of Humanities and Applied Social Sciences, 1(1), 55-68. Retrieved July 15, 2020, from https://www.emerald.com/insight/content/ doi/10.1108/JHASS-05-2019-004/full/html

29. Bayramov, V.D. (2012). Educational Policy in Relation to Persons with Disabilities as a Kind of Social Policy of the State: Essence and Principles. Central Russian Bulletin of Social Sciences, 2.

30. Yashchuk, T.F. (2013). State Policy of the Russian Federation and the Republic of Kazakhstan in Higher Education: Comparative Legal Analysis. Omsk State University Bulletin. Series: Law, 2(35).

31. Edwards Jr., D.B., Morrison, J., \& Hall, S. (2019). The Suspect Statistics of Best Practices: A Triple Critique of Knowledge Production and Mobilisation in the Global Education Policy Field. Globalization, Societies and Education, 18(2). Retrieved July 15, 2020, 
from https://www.tandfonline.com/doi/abs/10.1080/14767724.2019.1689489?journal Code $=$ cgse 20

32. Iyengar, R., \& Surianarain, S. (2010). A Comparative Analysis of Education Policy and Practice: The Case of Institutions in Mumbai and Delhi. Perspectives on Urban Education, 19-28. Retrieved July 15, 2020, from https://files.eric.ed.gov/fulltext/EJ912058.pdf.

\section{INFORMATION ABOUT THE AUTHORS}

Lyudmila A. Kravchenko (Russia, Vladivostok) - Director of the Department of Monitoring and Forecasting. Vladivostok State University of Economics and Service. E-mail: Iyudmila. kravchenko@vvsu.ru

Natalia R. Pashuk (Russia, Vladivostok) - Assistant of the Department of Economics and Management. Vladivostok State University of Economics and Service. E-mail: nataliakravchenko@inbox.ru

Anna A. Vertinova (Russia, Vladivostok) - Assistant of the Department of Economics and Management. Vladivostok State University of Economics and Service. E-mail: vertinova. anna@mail.ru

Ilya A. Bedrachuk (Russia, Vladivostok) - Associate Professor, PhD in Economic Sciences. Director of the Department of Economics and Finance. Vladivostok State University of Economics and Service. E-mail: ilya.bedrachuk24@vvsu.ru 


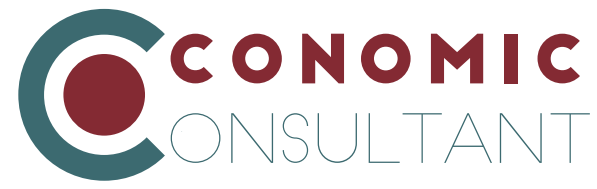

\section{K. Egorov}

\section{Human capital and effective development}

\section{KEYWORDS}

human capital;

quality of human capital;

effective economic development;

competitiveness;

elites;

labour resources;

levels of human capital management

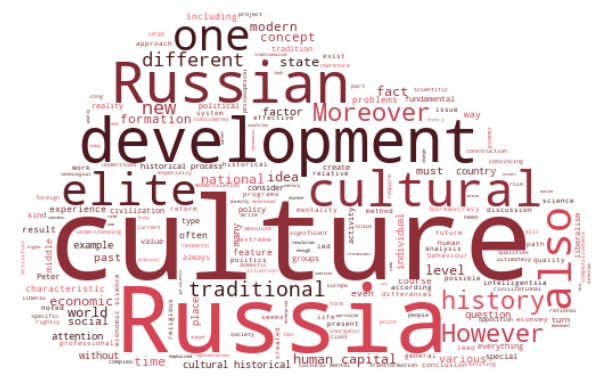

Word Cloud Generated by:

https://wordscloud.pythonanywhere.com/

\section{ABSTRACT}

Introduction. The relevance of the study is associated with the emerging tendency to overcome the purely "cost" approaches in economic science. Specialists raise the question of revising the existing methods for assessing human capital, the need to reckon with the capital of culture, cultural and moral capital.

Methods. The research methodology was a set of approaches and methods for studying human capital: a historical approach, factor and comparative analysis.

Results and discussion. The article examines the quality of human capital at two levels of its management and development, i.e. the "highest" and "grassroots": at the level of ordinary workers and entrepreneurs, firms and enterprises, and at the level that defines for them the "rules of the game", i.e. the elite. Attention is drawn to the cultural and historical specifics of the study of the phenomenon, affecting current activities. The author traces the tendency to overcome purely "cost" approaches in economic science, as part of the "trend", raises the question of revising existing methods for assessing human capital, the need to reckon with cultural capital, cultural and moral capital.

Conclusions. The transition to an innovative development path is impossible without the involvement of human capital, the development of which will enhance the country's competitiveness and ensure economic development

Egorov, V. K. (2020). Human capital and effective development. Economic consultant, 30 (2), 76-88. doi: 10.46224/ecoc.2020.2.7 


\section{INTRODUCTION}

$\mathrm{T}$ he formation, qualities of human capital, is one of the most popular and significant scientific and practical problems, the development of which directly depends on effective development. In economic science, it seems, a turn has begun towards what seems obvious: an institutional approach is not enough, no matter how broad it is, a so-called "cultural-mental" approach is also needed. This theme is convincingly written, for example, by representatives of the Dutch School of Economics S. Begelsdeyk and R. Maseland [3].

For Russia, this result of decades of searching and discussion is also significant because the change of development paradigm at the end of the 20th century was mostly under the pressure of ideas according to which the Russian mentality and values of a market economy are poorly compatible, so the mentality must be changed. It has been argued that there is a fundamental and only Western economic model that has justified itself. Moreover, cultural and country differences in ensuring effective economic development are fading into the background in the context of globalization, informatization and other features of our time. However, the changes taking place in science today cannot but lead to the same thing in politics, in its intellectual and personnel support, including in matters of the formation of human capital.

\section{MATERIALS AND RESEARCH METHODS}

The historical approach allows considering the genesis of the studied process or phenomenon in the historical aspect. Factor analysis makes it possible to closely address such factors of the historical process as demographic, technological and geographical.

A comparative analysis made it possible to compare the studied processes and phenomena, which expanded the possibilities of understanding and describing human capital in accordance with the existing reality, concepts and goals of effective development.

\section{RESULTS AND DISCUSSION}

Understanding of many contemporary problems is often promoted by their kind of "historical examination". At the same time, the vast majority of what was said about what happened and is happening "with us" and "they" have, in my opinion, a remarkable: in the methodology of the classic - M. Weber was underestimated, oddly enough, the fact that, in addition to everything. He essentially proposed to consider the motives and quality of actions at two levels of management and development of human capital - "higher" and "grassroots". At the level of ordinary workers and entrepreneurs, firms and enterprises, and at the level that defines for them the "rules of the game" - the elite, floors of power. It will be permissible 
to recall that an outstanding scientist proceeded from the fact that a person, as a child of a particular culture, "considers universal historical problems from a completely certain point of view". He emphasized the importance of upbringing, "which was determined by the religious atmosphere of the homeland and family", for "choosing a profession and further direction of professional activity"; He wrote about the "sustainable internal identity of every religion" and the opposition to the "spirit" of Protestant traditionalism. Moreover, in the end, with the statement "The capitalist economy no longer needs the sanction of one or another religious doctrine...", and the "World View" is now, as a rule, determined by the interests of trade or social policy." There is a "Transformation of politics into an" enterprise ", which requires skills in the struggle for power" [21].

Each country (to a greater or lesser extent) has its own cultural and historical specifics that affect current activities. Of particular importance in the formation of this specificity are the key turns of history, their consequences. We can distinguish two turning points - the Peter's reforms and the October Revolution of 1917. There are judgments according to which these were breaks in history, and they were led to a tendency to extremes, dominant in Russian culture, and our lack of a middle culture. Among these conclusions, there are allegations that in the Petrine era "Russia had to abandon the sensual Russian-Orthodox worldview and take the path of rational perception of the world" [20, p. 255]. The external habit of this thesis is more, however, unobvious. It draws much of their traditional interpretation of Weber's views on the role of Protestant ethics in establishing the market. However, if we turn to history, we must bear in mind that the reformation, anti-Catholic movements and other movements took place in different countries in Europe, and Protestant ethics took different shades. There is only the "apparent unity of Protestantism" associated with the "uncritical use" of the term itself [14].

Moreover, modern science states that "so far there is no convincing empirical evidence for the thesis that entrepreneurial culture explains national or regional differences in the level of entrepreneurial activity"; "There is also no convincing evidence of a fundamental empirical connection between entrepreneurial culture and economic growth" [3, p. 215]. However, in this context, one should consider not only the usual opposition "Russia - the West", but also the "double standards" of a different kind that are poorly covered in the literature (at least, in the domestic one). The mentioned Dutch researchers of actual problems of economic science note, for example, that "it may be useful to consider the literature on law and finance as a product of a specific culture: attacks on France have long become a characteristic feature of British and American culture (and vice versa). As a result of this, any typology that places France and the USA at the same end of the scale, contrasting them with Great Britain, will be rejected as unconvincing" [3, p. 343]. Of course, the level of tension in the noted oppositions is different; however, not to see their presence, especially it would be wrong.

From the standpoint of philosophy, the philosophy of culture, it is essential that "every concept is based on historical and cultural soil, which belongs not only to it but also to many other concepts... Separate rationalities do not exist as monads... they are characterized by a multitude of interweaving with other rationalities. This fact means that there are not only many 
types of rationality, but also a wide range of transitions between them, which, in turn, has a high degree of differentiation" [7, p. 414]. Without such a vision, various politicians that have taken shape in history appear at best as sketches for writing history and describing modernity.

Therefore, it should be assumed that, firstly, there is a non-vanishing cultural-country specificity of the application to the realities of even the basic tenets of unshakable theories. Secondly, domestic and foreign policy, economy and culture, interethnic, interreligious relations, i.e., different areas of the national state and public life permeate different types of rational and irrational.

Different types exist in different countries, especially in a country like Russia. Moreover, they exist in various combinations. Finally, globalization and information technologies "blur the boundaries" between local civilizations. However, they do not negate the fact that various cultural-mental, national subjects of history implement in their way the general civilization field of modernity.

In the cultural-historical context, the faults of Russian history should also be considered. In assessments of Peter's reforms, in exaggerating the significance of the poetic formula of genius about a "hacked window to Europe", the sources of concepts about the cultural isolation of Russia-Russia, the lack of unity of our history. Moreover, the department of progress prescribes any increase in attention to foreign experience in them, and the appeal to traditions is called a reversal. The fact, however, is that Russia has never been a culturally autonomous country, being a part of the Christian world. Europe and Russia inherited antiquity through different parts of the great Roman Empire. Of course, the differences in church-religious dogma that deepened after the split of Christianity influenced both politics and culture. The well-known separation of Russia from the European world was aggravated in the XIII-XV centuries. Horde conquest and even led to isolation. The reforms of Peter I gave a new impetus to relations between Russia and Europe; however, they were mainly a continuation of the policies of his predecessors. It is a continuation, but with a larger-scale than ever, appeal to the European experience. There was a deliberate borrowing of political and economic ideas, traditions in the organization of education and science, stylistics and new trends in art and other processes. There was a complex process of combining traditions and innovations in culture, which often had a contradictory character with the rise of either influences or traditional and even archaic principles, which resulted in the formation of a huge empire with a distinctive culture. P. N. Milyukov in the unsurpassed and still multivolume work "Essays on the History of Russian Culture", created a picture of the natural centuries-old cultural and historical path of Russia-Russia, as the history of the development of culture in the broad sense and all its clusters.

Moreover, he focused not only on the most famous, better visible but also on the internal laws of existence inherent in the culture. Moreover, V. O. Klyuchevsky characterized the radical Peter's transformations, wrote follows: this is a reform that "was not a revolution in its goals and results, but only in its methods and impression, which made on the minds and nerves of contemporaries" [13, p. 202]. 
The revolution of the 17 th year is the only conscious attempt in the history of Russia to "break off" the course of historical and cultural development, to create something unprecedentedly new. It was in its pure form a social experiment with attempts to abandon traditions, national experience. While the Peter's era was created by individuals who acted in full accordance with the general historical and sociological regularity deduced by P. A. Sorokin: "Many forms of human behaviour in by their very nature they exclude intentional motivation in the face of the future and suggest motivation coming from past experience" [19, p. 198]. The Soviet project was implemented based on the primacy of utopian ideas about the future. It was motivated by the future, although, faced with insurmountable problems, politicians tried to land him, referring to both the experience of the past and the realities of the present. What ultimately happened is known. The present of Russia testifies: the cultural and mental foundations of national development turned out to be more stable than the Bolsheviks had expected and were not unsuccessful in overcoming the difficulties accompanying the current fundamental reforms. It can be argued: in a sense, the construction of the building of the new Russia is in many ways a restoration of the pre-revolutionary. Of course, given the fact that the time is different and the experience behind is extraordinary. This construction is not akin to new construction in its purest form but to reconstruction. This process is precisely the name of the construction of the "new" Cathedral of Christ the Savior - it is recreated.

In addition to questions about the isolation of Russia, the exaggeration of its features, the discontinuity of the domestic cultural and historical process, statements about the absence of a middle ground in Russian culture, and therefore rationalism, deserve special attention. Perhaps N. A. Berdyaev formulated the first and most vividly this idea. He argued that Russia differs from the West in that "it does not have the gift of creating a secondary culture... The Russians are characterized by some kind of powerlessness, some mediocrity in everything relative and average. However, the history of culture and the public is all, in fact, average and relative; she is not absolute. Since the kingdom of God is the kingdom of the absolute and the finite, the Russian people easily give up everything relative and average to the power of the kingdom of the devil", "the Russian spirit longs for absolute Divine freedom. Therefore... it is difficult for the Russians to create a relative culture, which is always the last but one thing, not the last. Russians are always in slavery in the middle and relative and justify this by the fact that in the final and absolute, they are free" [4, p. 25-26]. However, these conclusions become part of Berdyaev's holistic conception only when they are considered in unity with his ideas about the role of religion and culture in the cultural and historical process: "Culture is always proud of the antiquity of its origin, inextricable connection with the great past. Moreover, the culture honours a special kind of grace of the priesthood. Culture, like the Church, cherishes its continuity more than anything else ... In culture, there is an eternal struggle of eternity with time ... a culture in which there is religious depth always strives for resurrection" [5, p. 249]. At the same time, the "successors" of the line of the outstanding philosopher, depriving it of spiritual, religious foundations, ultimately cultural ties, come to the utmost sociological, to the schematic. One can even meet the assertion that Russia is an 
"inorganic civilizational type", and the inability to get out of contradictions under, for example, the baselessness of the intelligentsia, lame decisions, leads to "disorganization of reproductive activity, growth of social entropy". Moreover, the conclusion: "In fact, there is a sociocultural pathology that requires a diagnosis and treatment" [1, p. 772, 781]. However, it seems logical, does not answer fundamental questions. For example, such: how could such a culture, "sociocultural pathology" create and develop civilization, being inorganic, even anomalous, for many centuries, preserve vast spaces and wealth, successfully resist organic civilizations, including frequent and large-scale military clashes? Is it possible to consider - despite all our troubles, falls and other calamities, that by global standards Russia has developed poorly, unsuccessfully? Moreover, what are the limits of the subjectivity of the elites, if we focus on the characteristics of our intelligentsia? The search for answers should be sought not in the usual patterns and ideologies that have long been unable to escape from the vicious circle of questions, do not lead to convincing conclusions, but in other, not traditional philosophical proposals. So, Yu. M. Lotman, comprehending the depths of classical Russian literature (and not only Russian), wrote, "Russian culture is characteristic and understood not only by its binary but also by its ternary." In his opinion, what is needed is not the search for a third special way, but the imposition on the Christian binary of "popular representations of the pagan type, justifying, accepting the world." This world is the "world of good, the world of evil and the world of ordinary life." As S. P. Zalygin precisely formulated politics: any ideas must be "pacified" by the experience and culture of the people, "brought to a common denominator" of national life [6, p. 405-422]. Attention should be paid to the fact that our elites (different, changing each other) are often really marked by one common quality - they create, in the words of O. Mandelstam, "without feeling the country". One must understand by "not feeling", "not knowing" adherence to theories and ideas without their conjugation with realities, with reality. At the same time, it is more accurate to write about creativity (reformatory or revolutionary), the transformative activity of not the intelligentsia, but the elites. The latter also have, and sometimes, perhaps, intelligentsia predominates. However, the ruling elites do not include all intelligentsia and not all its groups, movements, directions suffer from the same groundlessness or administrative futility.

A factorial analysis of history seems to be promising with a careful and balanced appeal to what concerns our peculiar European character, to the peculiarities of Russian Orthodox culture in the bosom of Christianity, to the historically developed multinational and multiconfessional of Russia. S. A. Nefedov, for example, successively following this method, attaches particular importance to such factors of the historical process as demographic, technological and geographical. According to him, in the course of modernization, westernization (especially after Peter) in Russia it was not "just the adoption of individual Western institutional and technical innovations; in the process of this adoption, a synthesis of introduced and traditional elements took place" [15, p. 28]. However, referring to the issues under discussion, one should finally decide on "what is traditional?". It seems that V. B. Zemskov is right: "Culture, mentality, consciousness at every moment of their historical being keep all layers of the original and later created "ready" for action: archaic, traditional, modern. Moreover, all three components 
appear in multilateral and diverse cross-relations, depending on development options. This relationship is not only opposition but also cooperation. The middle member of the triad - the traditional - is once modern, arising from archaic in interaction with innovations and becoming the middle normativity, "holding" the system" [22, p. 223-224]. I must emphasize, I believe that the mid-normative traditional is a conditional cultural, value "median"; this is what exists as a dominant, "holding" the system, representing a certain "core" of the cultural-value system, which has established itself in this capacity at this stage of the cultural-historical process. The median is not in the "balance" in content but the place of position in the triad. This image is a well-established, acquired the status of the traditional, understood as a cultural-value image, a characteristic of society, civilization in its present. That is, the traditional is not the past, but the present with projections into history and the future, it is a balance that "does not accept" and archaize, immutability, ossification, and instability created by "artificial" aspirations for modernization for the sake of modernization, for changes under inorganic foreign cultural pressure. The traditional is being, but traditionalism and anti-traditionalism are ideological.

The contrast between traditional and liberal values that is widespread among us does not include life. It is vital that following the historian of Russian liberalism V. V. Leontovich, A. I. Solzhenitsyn rightly emphasized: "liberalism is alive only as long as it adheres to the evolutionary transformation of existing structures." It is extremely dangerous both when radicalism is mistaken for liberalism and when "other possible breakdowns of liberalism are triggered: towards democratic absolutism and imperialist democracy" [18]. In Russia, various groups of elites, lining up according to tradition "under the banners" of the indicated trends, create a confrontation between two large political camps. In one, elites infected with both real and imposed Europeanism, Westernized inferiority, in the other - pro-Russian, pro-Russian insufficiency, again, both real and artificially cultivated to gain "their place in the sun".

Russia has its predetermined path, but it is impossible, on the one hand, to absolutize its originality, and on the other, to privatize its special development. A unique way is not only with us. Also, this is not the third vector, the path of development between the West and the East" (you can put - North and South). The world of our time pushes more convincing into the background habitual and seemingly eternal schemes and argues that in history and the future, every somehow significant state-country, cultural-civilizational formation is individual. It/they are on a unique path because they are strong enough to face others in a different capacity. There is an inorganic, unnatural, destructive desire for civilizational and cultural uniformity. The fate of the communist project and modern programs of «democratic» dominance prove this fact.

Ultimately, all the issues raised and related issues address the topic of competitiveness. There are the competitiveness of states, national-state entities and, to a large extent, of nations (no matter how sensitive this issue maybe), the competitiveness of elites (political, economic and other types of elites) and labour resources. Moreover, here such circumstance draws attention. There is dominant research and, later, administrative and managerial approaches that are deprived of self-criticism. They led to the formation of a "separation" of methodologies, 
and then, of course, of analysis methods and interpretations of what managers and executors are in the national system of functioning of the economy, politics, and other spheres of public and state life. The elites, mainly on their tops, are "guided by the telescope" of humanitarian knowledge, most often purely political science, and labour resources, groups that provide professional and production activities and management at the middle and lower levels, are "examined under the microscope" of vocational and other social statistical and sociological meters. The second layer, level, as a rule, also falls under the concept of "human capital", assessed according to "technological", "instrumental" criteria and checked against them for effectiveness. However, with one fundamental caveat: when "contingencies" arise when it is not easy to explain why the quality of human capital does not lead to the efficiency set by the "researchers", "correction factors" are often included, which are often "explanations" of the whole mentality. In our case, this is a discussion about the eternal Russian, Russian inability to rationally think and act, about the notorious "shovels" when referring to the Soviet, and even the current periods of development. It should be noted that the concept of "homo soveticus" became most widespread after the publication of the novel of the same name by A. A. Zinoviev, who, we must not forget, belongs to the hard and precise aphorism formulated later: "They aimed at communism, but ended up in Russia". It will also be worthwhile to recall that a close, similar concept was introduced back in 1918 by the remarkable philosopher and theologian S. N. Bulgakov, speaking of attempts to create a "homo socialisticus".

It is gratifying that both the methodological "absurdity" and the politicization, ideologization of professional issues, apparently, nevertheless begin to be overcome, the corresponding conceptual scientific proposals appear. In the discussion materials of one of the International Scientific Conferences, for example, questions were raised about what national elites are, what is their essence, how do they influence the state's domestic and foreign policy, including the problems of forming approaches to macro- and microeconomics, education policy, health care. Moreover, this directly affects the quality and development of human capital in a narrow, familiar sense. Noting these points, Yu. M. Osipov rightly emphasizes: "In the modern complex and hierarchically structured civilizational society, which consists of many diverse societies (sub- or subsociums), there is also an equally complex and hierarchically structured elitist structure - the social system of various elites: from local and special (specialized) to general and complex (integral), and most importantly, from power, central and higher to subservient, local and lower... If we choose something specific as an assessment of the elite from the past, then we are guided by the fact is not that we are talking about the past, but that we consider some elements to be the best, wise, effective. Hence the orientation toward those historical eras and those representatives of the elite whose activities in the past ultimately brought positive results for the country, the people... Even despite various kinds of "deviations" - cruelty, rudeness, Machiavellianism... However, fuss There is a situation when the "innovators" turn out to be conservatives, because, contrary to evidence, they become the creators of a new utopia... Morality, reason, dedication and love for the homeland have always been and remain the criterion for entering the power elite... However, due to the increasing financial factor in 
modern "Economic civilization".., the criterion for selecting the elite is money. They began to replace everything... In this regard, a new approach to joining the elite is approved, without any traditions and prejudices" [17, p. 11, 24-25].

The criteria are "listed" correctly. At the same time, firstly, we must insist that when considering history not as a political or some other "private", but as a cultural-historical process, the risk of subjectivization and modernization of some aspects of the past is significantly reduced. Secondly, there is no reason to idealize both antiquity and the recent past. A "business" approach has always been present. Another thing is that today in the "business", apparently, the very content of the latter is changing. Finances, perhaps, are becoming more significant than, for example, nepotism, although they got it first of all, and now everything is there.

In this regard, criticism of the state and bureaucracy from various positions deserves attention, including, concentrating on the fact that the free market in the classical liberal sense does not exist (at least not today). So, professor of the London School of Economics D. Graber, noting this, writes mainly about the replacement of elites in their general understanding by bureaucracy. He argues: the liberal policy of "reducing the role of government" in the economy "did not work," "English liberalism, for example, did not lead to a decrease in the share of the state bureaucracy, but exactly the opposite result," to "increase the total amount of regulation, the total amount of paperwork the total number of bureaucrats". Contrary to the dreams of liberals, literally "a real cultural transformation" has taken place, a particular "culture of complicity" is being created, encompassing education, science, the media, corporate and family ties, ensuring the existence of bureaucracy and career growth. "When historians begin to compose the epitaph of neoliberalism, they will have to write that it was a form of capitalism that systematically gave priority to political imperatives over economic ones" [8]. This kind, at some points approaching imperative judgments, must be comprehended, without forgetting about the problematic history of liberalism in Russia, the features of our statehood, including the peculiarities of the Russian bureaucracy.

Moreover, some proposals, ideas that require differently posed questions are not only theoretical but also quite practical. W. Beck precedes his famous work, "The Society of Art Nouveau: On the Road to Another Art Nouveau," meaningfully. He writes that in modern conditions a new, different "social reality" has formed, and "It is more reminiscent of the fate of the estates in the Middle Ages than the class situations of the 19th century. In any case, it no longer recognizes class inequality (as it does not recognize border groups, differences between a city and a village, national or ethnic affiliation). Unlike class and class situations, it develops not under the sign of poverty, but under the sign of fear and is not a "traditional relic", but a product of Art Nouveau at the highest stage of its development... (All this) carries threats that transform what is brought in the modern world to the extreme, individualism in its extreme opposite" [2, p. 1-2]. Of course, one should not "shy from one extreme to the other", oblivion or underestimate traditional social differences, factors. At the same time, one should take seriously the idea of an emerging or already existing new social reality. Moreover, to speak, however, it is nevertheless necessary, not about the disappearance of sociality, but the acquisition by it of new qualities. 
Without attention to the features of the new reality, and, therefore, to the distinguishing features of modern generations, to build and implement projects, programs for the formation of the personnel of organizations, enterprises, and collectives is not reasonable, not productive. Moreover, this is of particular importance when addressing in theory and practice to the problems of the development of human capital in special, including close to extreme conditions - the same Far North. Experts rightly pay attention to this [16, p. 8-13]. These plots acquire an individual sound and significance during the current stage of Arctic exploration with expanding and incomparable international participation and cooperation, which is incomparable with previous times. Both on international cooperative principles, and in strengthening the inevitable interstate interaction in the implementation of national Arctic programs.

Moreover, this is associated with the need to increase attention to the national, ethnic, socio-psychological characteristics of various social, socio-professional groups. Furthermore, determining the Arctic programs of the elites, and those from whose environment "labour collectives" are formed, and, naturally, their leaders. Inattention to the quality of the representatives of the first managerial level, that is, the elites, looks at least short-sighted. What has already been said in principle, especially when it comes to developing policies and implementing large-scale programs related to the participation of particularly vulnerable groups of the population? In this case, the small peoples of the North. These are delicate questions in their way when implementing projects that involve often "non-traditional" cultural and historical neighbours participating in joint work in particular conditions. Joint activity is inevitable, and it concerns both state collectives (the same military and border formations) and private ones.

Nevertheless, be that as it may, the new twists and turns noted cannot but be based on the fundamental classical ideas that have been tested by the time about the necessary "minimum" of data for understanding the situation and possible directions, the results of its development. "Without knowledge of the society and culture in which a given individual is born and grows, no personal traits of his - beliefs, ideas, beliefs, tastes, addictions, and that which causes hostility - cannot be understood; all his mentality, manners and customs, his style of behaviour and lifestyle are completely incomprehensible. Not only the psychosocial personality as a whole but also many of its biological qualities are moulded and determined by the space in which it grows" [19, p. 185-186]. Such ideas require constant philosophical, sociophilosophical and cultural-philosophical reflection in both scientific and practical activities. The question should be raised about the urgent need to derive a humanitarian examination of various modern practices "from captivity" of individual "monoscientific" preferences. Modernity, reality compels us to think and act differently, including by returning culture to its proper place: "... at the beginning of the twentieth century, the evolution of the concept of "culture" led to its splitting into two different meanings: "cultural" and "cultivated", and the established boundaries between economic science, sociology, history and anthropology led to the disappearance of culture from economic thought. Culture began to be understood as 
something opposite to the object of economic research. While economic science began to study everything universal, normal and rational, "culture" developed into a concept denoting specific varieties, irrational deviations from the standard economic model. To the extent that culture continued to be found in economic thought, it was usually on the periphery of analysis. They resorted to culture to study the marginal features of human behaviour, which could not be explained in any way within the framework of the (limited) rational behaviour of actors, or to study behaviour in general in marginal countries that are lagging in development" [3, p. 76]. Once the "rationalists" won. Now we have to unqualify, interpreting in a new way, this is an innocent, obviously overly overloaded concept.

\section{CONCLUSION}

Recently, there has been a tendency to overcome purely "cost" approaches in economic science, as part of the just noted "trend". So, in the Report of the Higher School of Economics, in the chapter on the leading role of culture in the formation of human capital, it is stated that "indicators of the cultural sphere are not directly included in the calculation of indices of both human development and human capital and human potential" [9, p. 62, 68]. Specialists persistently raise the question of revising the existing methods for assessing human capital, the need to reckon with the capital of Culture, Cultural and moral capital. The presence of thin "emotional-mental layers" in the "building material of human activity" is rightly noted. It is proposed at all levels at which factors of competitiveness of human capital are considered to highlight cultural factors. Not excluding, without going around the mega-level at which the objects of research "are economic unions of states, individual continents and regions of the world", which also work "values, moral qualities, linguistic and cultural competence of a person, cultural and ethnic characteristics, psychological characteristics" $[10 ; 11 ; 12]$. However, all this essential humanitarian, cultural and mental set must be considered concerning individual states, to their interaction. Moreover, it should be emphasized once again: it is necessary to measure, check for professional suitability and those who at the "highest level" determine the policy of formation, reproduction, development of human capital, both the most important factor in effective development and those who "realize the lowest level" in human capital potential.

\section{REFERENCES}

1. Akhiezer, A. S. (1998). Russia: criticism of historical experience. (Sociocultural dynamics of Russia). Vol. I, 2nd ed. Novosibirsk, Siberian Chronograph Publ., 772-781.

2. Beck, W. (2000). Risk Society: on the way to another Art Nouveau. Moscow, ProgressTradition Publ., 1-2.

3. Begelsdijk, S., \& Maseland, R. (2016). Culture in economic science: history, 
methodological considerations and areas of practical application in modern times. Moscow; St. Petersburg, Publishing house of the Gaidar Institute; Publishing House "International Relations; Faculty of Liberal Arts and Sciences of St. Petersburg State University".

4. Berdyaev, N. A. (1990). The fate of Russia. Moscow, Publishing House of Moscow State University, 25-26.

5. Berdyaev, N. A. (1990). The philosophy of inequality. Moscow, Thought, 249.

6. House of the Russian Academy of Civil Aviation, 2006, 405-422.

7. Gorbunova, L. S. (2012). Post-non-classical practices in the context of "fluid modernity". Post-non-classical practices: experience of conceptualization. St. Petersburg, Mir Publ., 414.

8. Greber, D. (2016). Utopia rules: about technology, stupidity and the secret charm of the bureaucracy. Moscow, Ad Marginem Press, 11-13, 22, 25-31, 119.

9. Human capital as a factor in socio-economic development. The short version of the report: the XVII April International Scientific conference "On the problems of the development of the economy and society". Moscow, April 19-22, 2016. Moscow, Publishing House: House of the Higher School of Economics, 62, 68.

10. Ilyinsky, I. V. (2014). Assessment of human capital: the transformation of methodology. Design. Materials Technology, 4 (34), p. 102.

11. Ilyinsky, I. V. (2011). Competitiveness of human capital: the methodology of knowledge Design. Materials Technology, 5 (20), p. 115.

12. Ilyinsky, I. V. (1996). Investments in the future: education in innovative production. St. Petersburg, SPbUEU Publ., 30.

13. Klyuchevsky, V. O. (1989). Works. In 9 vol. The course of Russian history. Part 4. Moscow, Thought Publ., 202.

14. Magnum ignotum: A history of concepts. (2016). On the 10th anniversary of the death of Reinhart Kozellek. Moscow, Capital, 20-24, 28-29 (in Russian).

15. Nefedov, S. A. (2011). History of Russia: a factor analysis. From the end of the Time of Troubles to the February Revolution. Vol. I. Moscow, Publishing. House "Territory of the Future", 28.

16. Okunev, Yu. P. (2004). Culture of the Russian North in the globalization system. Arkhangelsk, University of Primorsky Publ., 8-13.

17. Osipov, Yu. M. (2009). The national elite is the fate of Russia (theses). The national elite is the fate of Russia. Moscow; Volgograd: Volgograd Scientific Publishing House, 11, 24-25.

18. Solzhenitsyn, A. (1995). On the Russian edition of the book of V. V. Leontovich, "The History of Liberalism in Russia" // Leontovich V. V. The History of Liberalism in Russia (1762-1914) / I. Ilovaiskoy (Trans.). Moscow, Russian Way Publ., IV, III.

19. Sorokin, P. A. (1992). Man. Civilization. Society. Moscow, Politizdat Publ.

20. Viktorov, V. V. (2007). Culturology: Textbook. Moscow, High school textbook 
Publ., 255.

21. Weber, M. (1990). Selected Works. Moscow, Progress Publ., 1990, 44, 64-65, 80, 91, $660,706$.

22.Zemskov, V. B. (2001). The imbalance in the system of interaction archaic - traditionalmodern as a factor in cultural dynamics. Culture in the era of civilizational demolition: Materials of the International Scientific Conference. Moscow, Scientific Council on the History of World Culture at the Presidium of the Russian Academy of Sciences, $223-224$.

\section{INFORMATION ABOUT THE AUTHOR}

Vladimir K. Egorov (Russia, Moscow) - Doctor of Philosophy, Professor and Head of the UNESCO's Chair of the Institute of State Service and Management. Russian Presidential Academy of National Economy and Public Administration of the Russian Federation. E-mail: vk_egorov@mail.ru 